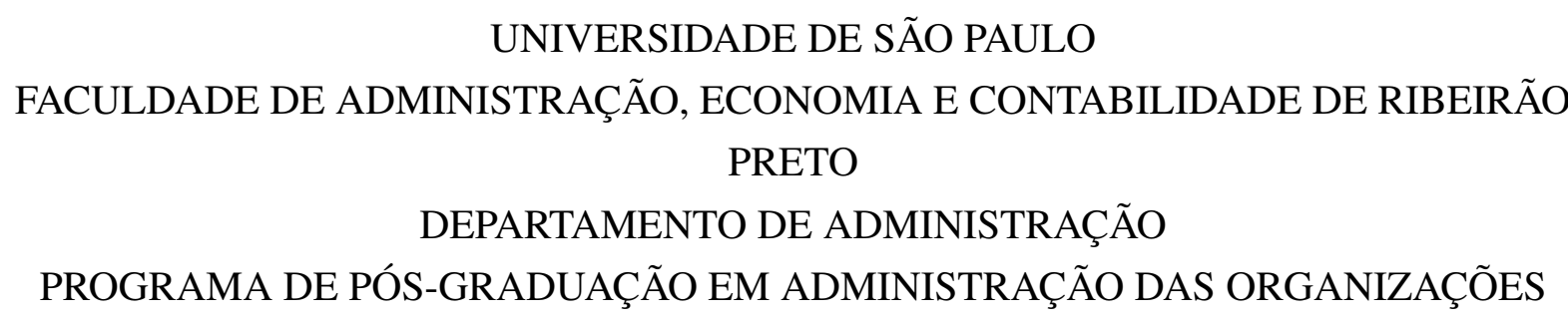

JOSÉ AUGUSTO MORAIS DE ANDRADE JÚNIOR

\begin{abstract}
Análise dinâmica estrutural de uma cadeia global de geração de valor modelada por hipergrafos: estudo de caso da cadeia global do ferro e aço de 1996 até 2016
\end{abstract}

ORIENTADOR: PROF. DR. MARCIO MATTOS BORGES DE OLIVEIRA

RIBEIRÃO PRETO 


\author{
Prof. Dr. Vahan Agopian \\ Reitor da Universidade de São Paulo \\ Prof. Dr. André Lucirton Costa
}

Diretor da Faculdade de Economia, Administração e Contabilidade de Ribeirão Preto

Prof. Dr. João Luiz Passador

Chefe do Departamento de Administração

Prof. Dr. Alexandre Pereira Salgado Junior

Coordenador do Programa de Pós-Graduação em Administração de Organizações 
José Augusto Morais de Andrade Júnior

\section{Análise dinâmica estrutural de uma cadeia global de geração de valor modelada por hipergrafos: estudo de caso da cadeia global do ferro e aço de 1996 até 2016}

Tese apresentada ao Programa de PósGraduação em Administração de Organizações da Faculdade de Economia, Administração e Contabilidade de Ribeirão Preto da Universidade de São Paulo, para obtenção do título de Doutor em Ciências.

Versão Corrigida. A original encontra-se disponível na FEA-RP/USP.

UNIVERSIDADE DE SÃO PAULO

FACULDADE DE ADMINISTRAÇÃO, ECONOMIA E CONTABILIDADE DE RIBEIRÃO PRETO DEPARTAMENTO DE ADMINISTRAÇÃO

PROGRAMA DE PÓS-GRADUAÇÃO EM ADMINISTRAÇÃO DAS ORGANIZAÇÕES

Orientador: Prof. Dr. Marcio Mattos Borges de Oliveira

Ribeirão Preto

2019 
Autorizo a reprodução e divulgação total ou parcial deste trabalho, por qualquer meio convencional ou eletrônico, para fins de estudo e pesquisa, desde que citada a fonte.

FICHA CATALOGRÁFICA

Andrade Júnior, José Augusto Morais de

Análise dinâmica estrutural de uma cadeia global de geração de valor modelada por hipergrafos: estudo de caso da cadeia global do ferro e aço de 1996 até 2016. Ribeirão Preto, 2019.

127 p. : il. (algumas color.) ; $30 \mathrm{~cm}$.

Tese de Doutorado, apresentada à Faculdade de Administração, Economia e Contabilidade de Ribeirão Preto/USP. Área de concentração: Administração.

Orientador: Prof. Dr. Marcio Mattos Borges de Oliveira.

1. Ferro e Aço. 2. Análise estrutural. 3. Cadeia global. 4. Análise dinâmica. 5. Insumo-produto. 
- Como tudo que faço, Ad maiorem Dei gloriam. Que seja tudo para maior glória de Deus.

- Aos meus antepassados, pois a minha existência nesse universo físico é decorrência da existência prévia deles.

- Para minha esposa Jussara Passos e meus filhos Messias Neto, Pedro Henrique e Gabriela, pelo tempo que dediquei a esta tese.

- Este trabalho é dedicado às crianças adultas que, quando pequenas, sonharam em se tornar cientistas.

"Não vos amoldeis às estruturas deste mundo, mas transformai-vos pela renovação da mente,

a fim de distinguir qual é a vontade de Deus: o que é bom, o que Lhe é agradável, o que é perfeito. "

(Bíblia Sagrada, Romanos 12, 2) 


\section{AGRADECIMENTOS}

- Ao Criador do Universo, pela possibilidade de minha existência.

- Agradeço ao meu orientador, Prof. Dr. Marcio Mattos Borges de Oliveira, pela paciência e orientação nesta caminhada.

- Agradeço à Profa. Dra. Sonia Valle Borges de Oliveira, pela gentileza em ajudar com a metodologia e a revisão desse trabalho.

- Agradeço ao todos os meus mestres na Universidade de São Paulo - USP, em especial na Faculdade de Economia, Administração e Contabilidade de Ribeirão Preto - FEARP, que me propiciaram um ambiente acadêmico instigante. Não os nomearei para não correr o risco de esquecer de mencionar algum.

- Agradeço também a todo o seu corpo administrativo e diretivo pelo tratamento carinhoso e gentil.

- Agradeço também ao Programa de Pós-Graduação em Administração das Organizações da FEARP, nas pessoas dos seus professores, funcionários e colegas, pela oportunidade e enorme paciência.

- Agradeço a todos os que, direta ou indiretamente, permitiram a realização dessa pesquisa.

"Tudo vale a pena, se a alma não é pequena." 
"A VIDA É SONHO

É certo; então reprimamos esta fera condição, esta fúria, esta ambição, pois pode ser que sonhemos; e o faremos, pois estamos em mundo tão singular que o viver é só sonhar e a vida ao fim nos imponha que o homem que vive, sonha o que é, até despertar.

(...)

Que é a vida? Um frenesi. Que é a vida? Uma ilusão, uma sombra, uma ficção; o maior bem é tristonho, porque toda a vida é sonho e os sonhos, sonhos são." 


\section{RESUMO}

ANDRADE JR, José Augusto Morais de. Análise dinâmica estrutural de uma cadeia global de geração de valor modelada por hipergrafos: estudo de caso da cadeia global do ferro e aço de 1996 até 2016. 2019. 127 f. Tese (Doutorado) - Faculdade de Administração, Economia e Contabilidade de Ribeirão Preto, Universidade de São Paulo, Ribeirão Preto, 2019.

Embora o Brasil tenha uma das maiores reservas de minério de ferro do mundo, estimada em 170 bilhões de toneladas, e também possua siderúrgicas próximas às minas de ferro, como a Usiminas, por exemplo, o Brasil exporta minério de ferro e importa produtos semi-acabados de aço de outros países, como o Japão e a China. O objetivo desta pesquisa é modelar a cadeia de valor global de ferro e aço e analisar sua dinâmica estrutural para verificar se esse modelo é capaz de determinar os fatores que impulsionam a geração de valor e que levaram alguns países a ter maior impacto sobre seu desenvolvimento econômico do que outros. A modelagem da cadeia de valor usa a técnica padrão de análise de entrada-saída de balanço de massa (método de modelagem estrutural ampliado de Leontief), detalhado na revisão da literatura. Para obter esses resultados, foi necessário coletar e consolidar diferentes bancos de dados utilizando ferramentas capazes de conciliar, tratar e analisar o grande volume de dados presentes nesses diferentes bancos de dados, em diferentes unidades e níveis de agregação. A análise da dinâmica estrutural revelou uma série de aspectos fundamentais para entender a guerra comercial entre os EUA e a China. A China passou de $10 \%$ da produção mundial de aço bruto para $50 \%$ em 20 anos, reduzindo a relevância de outros países no contexto da cadeia de ferro e aço. Além disso, a análise revelou que o Brasil exporta quase exclusivamente minério de ferro bruto. A Austrália, por exemplo, conseguiu agregar mais valor do que o Brasil. Isso revela, portanto, que a análise da dinâmica estrutural modelada por hipergrafos pode gerar informações semânticas relevantes sobre o contexto, atores e interesses envolvidos e pode servir como um mapa para orientar decisões e políticas voltadas para uma melhor inserção e atuação de um país em uma cadeia global de produção.

Palavras-chave: Ferro e Aço. Análise estrutural. Insumo-produto. Cadeia global. Análise dinâmica. 


\begin{abstract}
ANDRADE JR, José Augusto Morais de. Dynamic structural analysis of a global value chain modelled by hypergraphs: a case study of the global iron and steel chain from 1996 to 2016. 2019. 127 p. PhD Thesis - Faculdade de Administração, Economia e Contabilidade de Ribeirão Preto, Universidade de São Paulo, Ribeirão Preto, 2019.
\end{abstract}

Although Brazil has one of the largest reserves of iron ore in the world, estimated at 170 billion tons, and also steel mills near the iron mines, such as Usiminas, e.g., Brazil exports iron ore and imports (semi-)finished steel products from other countries, such as Japan and China. The objective of this research is to model the global value chain of iron and steel and to analyse its structural dynamics to verify if this model is able to determine the factors that drive the generation of value and that have led some countries to have greater impact on their economic development than others. Value chain modelling uses the standard mass balance input-output analysis technique (Leontief's extended structural modelling method), detailed in the literature review. To obtain these results, it was necessary to collect and consolidate different databases using tools able to reconcile, treat and analyse the large volume of data present in these different databases, in different units and levels of aggregation. The analysis of the structural dynamics revealed a series of fundamental aspects to understand the commercial war between the USA and China. China has shifted from $10 \%$ of the world's crude steel production to $50 \%$ in 20 years, reducing the relevance of other countries in the context of the iron and steel chain. In addition, the analysis revealed that Brazil exports almost exclusively crude iron ore. Australia, for example, was able to add more value than Brazil. This reveals, therefore, that the analysis of the structural dynamics modelled by hyper-graphs can generate relevant semantic information about the context, actors and interests involved and can serve as a map to guide decisions and policies aimed at a better insertion and performance of a country in a global value chain.

Keywords: Global Value Chain. Iron and Steel. Dynamic Structural. Input-Output Analysis. 


\section{LISTA DE ILUSTRAÇÕES}

Figura 1 - Matrizes de insumo-produto . . . . . . . . . . . . . . . . . . . . 21

Figura 2 - Unidade acumuladora de custos levando em consideração os fatores de pruduçao capital(K), trabalho(L), materias-primas (M) e energia (E). . . . . . . 24

Figura 3 - O modelo da RAND (Leontief com balanço de massa e energia) . . . . . . 28

Figura 4 - Participação dos principais países no consumo de energia para a indústria

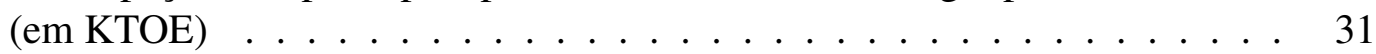

Figura 5 - Gráfico com o custo médio da energia por países . . . . . . . . . . . . 32

Figura 6 - A UAC. . . . . . . . . . . . . . . . . . . 34

Figura 7 - A UAC pode ser utilizada para evidenciar o valor adicionado por cada atividade econômica classificada pelo ISIC. . . . . . . . . . . . . . 35

Figura 8 - Diagrama da economia do ponto de vista da oferta, demanda e investimentos

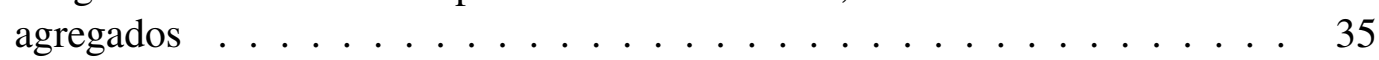

Figura 9 - Os três principais eixos que determinam os diferentes tipos de pesquisa . . . 36

Figura 10 - Os quatro paradigmas de pesquisa segundo Burrell e Morgan[(1979)] . . . . 37

Figura 11 - Fluxogramas que representam o processo de coleta e seleção das referências bibliográficas. O primeiro processo (1a...1c) representa a busca nas bases científicas pelas palavras chave. . . . . . . . . . . . . 39

Figura 12 - Um exemplo de grafo onde os nós são pessoas e as arestas são ligações entre

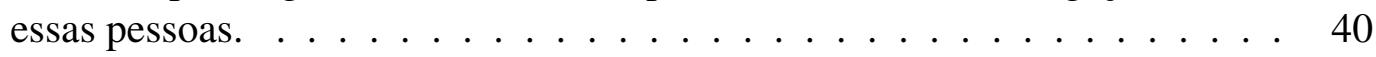

Figura 13 - A transformação de bits (pedaços de informação) em dados e depois em conhecimento. ........................ 40

Figura 14 - Valores de intermediação da centralidade do grafo usado como exemplo. . . 41

Figura 15 - Vetor de valores singulares da centralidade (eigenvector) do grafo usado como exemplo. ...................... 41

Figura 16 - Exemplo de triplas formando uma rede (grafos complexos) que permite a extração de conhecimento. . . . . . . . . . . . . . . 44 42

Figura 17 - Grafo do sistema de fluxos e estoques envolvidos na medição do produto pela ótica da produção

Figura 18 - O coeficiente de concentração de Gini. . . . . . . . . . . . . . . . . . . . . 49

Figura 19 - O processo do aço da Arcelor Mittal - Tubarão/RS . . . . . . . . . . . . . . 51

Figura 20 - Produção mundial de minério de ferro entre 1996 e 2016 (em 1000t) . . . . 53

Figura 21 - Participação na produção mundial de minério de ferro entre 1996 e 2016 . . 53

Figura 22 - Exportação mundial de minério de ferro entre 1996 e 2016 (1000t) . . . . . 54

Figura 23 - Participação na exportação mundial de minério de ferro entre 1996 e 2016 . 54

Figura 24 - Importação mundial de minério de ferro entre 1996 e 2016 (1000t) . . . . . 55

Figura 25 - Participação na importação mundial de minério de ferro entre 1996 e 2016 . 55

Figura 26 - Participação dos países, blocos e regiões na produção mundial de aço bruto

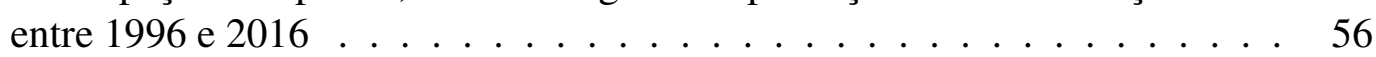

Figura 27 - Gráfico da produção mundial de aço bruto por países, blocos e regiões entre $1996 \mathrm{e} 2016 \ldots \ldots \ldots \ldots \ldots \ldots$

Figura 28 - Gráfico da produção mundial de aço bruto por países entre 1996 e 2016 (em

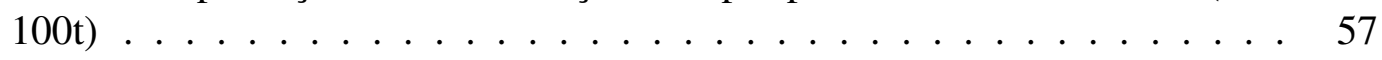

Figura 29 - Participação dos países na produção mundial de aço bruto entre 1996 e 201657

Figura 30 - Gráfico do consumo aparente de aço bruto por países entre 1996 e 2016 (em

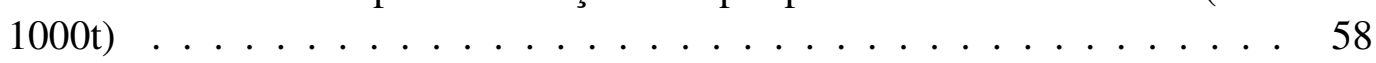

Figura 31 - Participação dos países no consumo de aço bruto entre 1996 e 2016 . . . . . 58 
Figura 32 - Gráfico da exportação de produtos (semi-)acabados de aço por países entre 1996 e 2016 (em 1000t) . . . . . . . . . . . . . . . . . . 59

Figura 33 - Gráfico da participação na exportação de produtos (semi-)acabados de aço entre 1996 e $2016 \ldots \ldots \ldots \ldots$. . . . . . . . . . . . . 59

Figura 34 - Resumo da cadeia de produção do ferro e aço . . . . . . . . . . . . . . 60

Figura 35 - Gráfico de produtividade energética da produção de aço bruto (em TJ/Mt) em relação à média mundial . . . . . . . . . . . . . . . . . . . 61

Figura 36 - Gráfico do fluxo internacional de comércio de commodities de minério de ferro 64 


\section{LISTA DE TABELAS}

Tabela 1 - Legenda das contas utilizadas no modelo RAND . . . . . . . . . . . . . . 28

Tabela 2 - Matriz insumo-produto setorial . . . . . . . . . . . . . . . . . . 29

Tabela 3 - Produção de minério de ferro entre 1997 e 2016 (1000t) . . . . . . . . . . . . 52

Tabela 4 - Tabela de consumo de energia (em TJ) por quantidade física de aço bruto

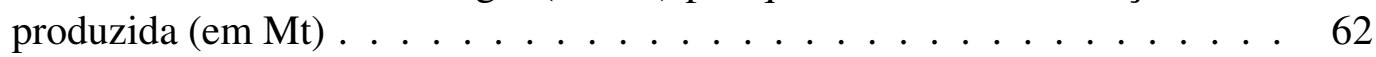

Tabela 5 - Lista de commodities HS 72XX . . . . . . . . . . . . . . . . . . 72

Tabela 6 - Lista de paises/regioes da ISO . . . . . . . . . . . . . . . . . 73

Tabela 7 - Tabela de classificação hieráquica de atividades econômicas ISIC v. 4. . . . 78

Tabela 8 - Produção de minério de ferro entre 1997 e 2007 . . . . . . . . . . . . . 82

Tabela 9 - Produção de minério de ferro entre 2008 e 2016 . . . . . . . . . . . . . . . 83

Tabela 10 - Importação mundial de minério de ferro entre 1997 e 2007 (em 1000 t) . . . 85

Tabela 11 - Importação mundial de minério de ferro entre 2007 e 2016 (em 1000 t) . . . 88

Tabela 12 - Importação mundial de minério de ferro entre 1997 e 2007 (em 1000 t) $\ldots 92$

Tabela 13 - Importação mundial de minério de ferro entre 2007 e 2016 (em 1000 t) . . . 95

Tabela 14 - Produção mundial de pelotas de aço entre 1997 e 2007 (em 1000 t) . . . . . 99

Tabela 15 - Produção mundial de pelotas de aço entre 2008 e $2016(\mathrm{em} 1000 \mathrm{t})$. . . . . 101

Tabela 16 - Produção mundial de aço bruto entre 1997 e 2006 (em 1000t) . . . . . . . . 104

Tabela 17 - Produção mundial de aço bruto entre 2007 e 2016 (em 1000t) . . . . . . . . . 105

Tabela 18 - Consumo aparente de aço (equivalente em aço bruto) entre 1996 e 2006 (em

\begin{tabular}{|c|}
\hline \multirow[t]{2}{*}{$\ldots \ldots$} \\
\hline \\
\hline \\
\hline
\end{tabular}

Tabela 19 - Consumo aparente de aço (equivalente em aço bruto) entre 2007 e 2016 (em

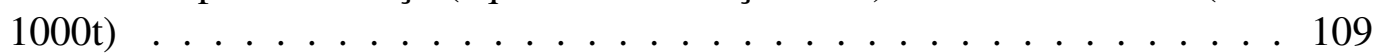

Tabela 20 - Produção mundial de aço bruto (em Mt) por país / grupo / região de 1996 a

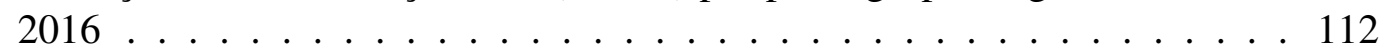

Tabela 21 - Conteúdo da tabela WBIG_tab_flow . . . . . . . . . . . . . . . 113

Tabela 22 - Conteúdo da tabela WBIG_tab_prod . . . . . . . . . . . . . . 115

Tabela 23 - BTDIXE - Tabela de atividades industriais (ISIC) . . . . . . . . . . . 123

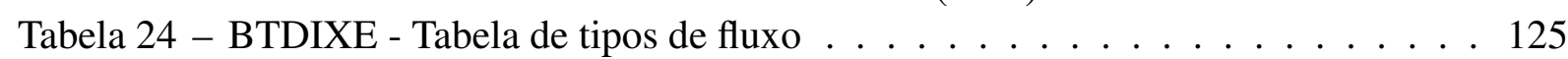

Tabela 25 - BTDIXE - Tabela de tipos de variáveis . . . . . . . . . . . . . . . . 125

Tabela 26 - BTDIXE - Tabela de categorias de uso . . . . . . . . . . . . . 126 


\section{LISTA DE ABREVIATURAS E SIGLAS}

CES Custeio-em-sequência.

CNI Confederação nacional da indústria.

FIRJAN Federação das Indústrias do Estado do Rio de Janeiro.

IEA International Energy Agency.

IPEA Instituto de Pesquisa Econômica Aplicada.

ISO International Standards organization.

OCDE Organização para a Cooperação e Desenvolvimento Econômico.

ONU Organização das Nações Unidas.

PIB Produto Interno Bruto.

UAC Unidade Acumuladora de Custos.

UNIDO United Nations Industrial Developement Organization.

USD United States dollar.

WorldSteel World Steel Association. 


\section{LISTA DE SÍMBOLOS}

J Medida de energia do sistema internacional de unidades. $\mathrm{J}=\mathrm{W} \cdot \mathrm{s}$.

KTOE Mil toneladas de petróleo equivalente (energia)..

TJ Terajoule $=10^{10} \mathrm{~J}$. Medida padrão de energia..

$\eta \quad$ Eficiência $\eta$, é a razão entre o valor do somatório das saídas e o somatório das entradas $\left(\eta=\frac{\sum \text { saídas }}{\sum \text { entradas }}\right)$.

$\mathrm{kWh} \quad \mathrm{kilowatt}-\mathrm{hora}=1000 \mathrm{~W} \cdot \mathrm{h}$. Energia de uma potência de $1 \mathrm{~kW}$ em $1 \mathrm{~h}$. . 


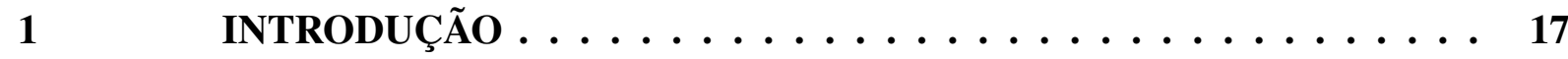

$1.1 \quad$ Introdução $\ldots \ldots \ldots \ldots \ldots \ldots \ldots \ldots$

$1.2 \quad$ Problema de pesquisa $\ldots \ldots \ldots \ldots \ldots \ldots$

$1.3 \quad$ Justificativa $\ldots \ldots \ldots \ldots \ldots \ldots \ldots \ldots$

$1.4 \quad$ Objetivos $\ldots \ldots \ldots \ldots \ldots \ldots$

$1.4 .1 \quad$ Objetivo geral $\ldots \ldots \ldots \ldots \ldots . \ldots \ldots$

$1.4 .2 \quad$ Objetivos específicos $\ldots \ldots \ldots \ldots \ldots$

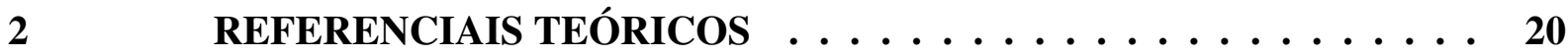

$2.1 \quad$ Input-output analysis (análise insumo-produto) $\ldots \ldots \ldots \ldots$

2.1.1 A modelagem macroeconômica através do método de Leontief para mensura-

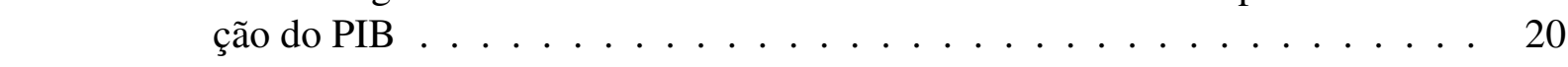

$2.1 .2 \quad$ A medição do PIB em suas diversas formas . . . . . . . . . . . . 22

$2.1 .3 \quad$ Literatura sobre a análise estrutural de entrada e saída . . . . . . . . . . . 27

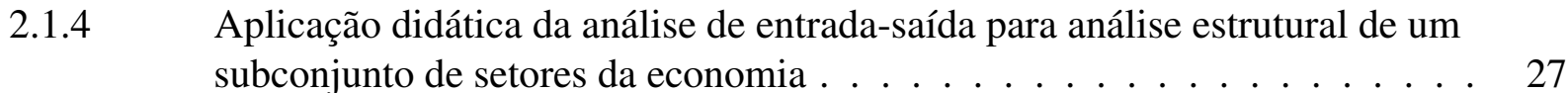

2.1.5 Produtividade e competitividade dos fatores de produção e geração de valor. 29

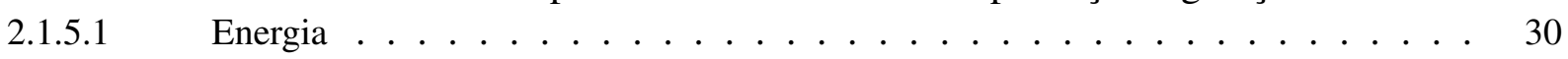

$2.1 .5 .2 \quad$ Matérias-primas - insumos $\ldots \ldots \ldots \ldots \ldots \ldots \ldots \ldots \ldots$

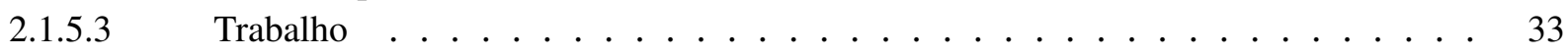

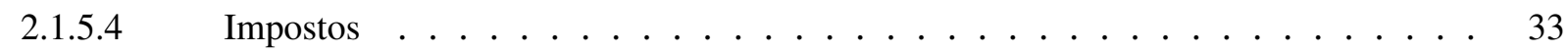

2.1.5.5 Capital, investimentos e poupança . . . . . . . . . . . . . . 33

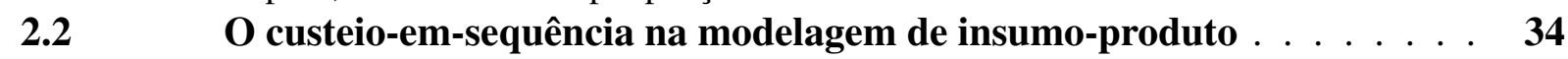

$3 \quad$ METODOLOGIA DA PESQUISA $\ldots \ldots \ldots \ldots \ldots \ldots \ldots$

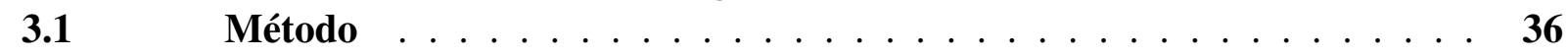

$3.1 .1 \quad$ Vertentes da pesquisa $\ldots \ldots \ldots \ldots \ldots \ldots$

$3.1 .2 \quad$ Natureza da pesquisa $\ldots \ldots \ldots \ldots \ldots \ldots$

$3.1 .3 \quad$ Técnicas de pesquisa $\ldots \ldots \ldots \ldots \ldots \ldots \ldots \ldots$

3.1.3.1 A técnica da revisão sistemática da literatura $\ldots \ldots \ldots \ldots \ldots \ldots$

3.1.3.2 Análise de hipergrafos (redes) (network statistical analysis) da cadeia global de

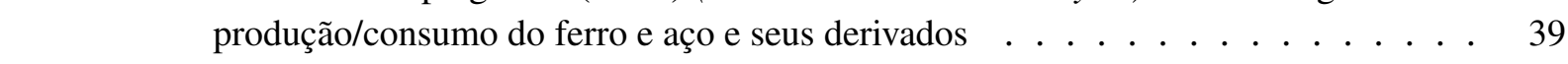

\begin{tabular}{|lll}
\hline 3.1 .3 .3 & As técnicas de análise multivariada: modelagem, calibração do modelo, simulações, \\
\hline \hline & otimizacão da calibracão do modelo $\ldots \ldots \ldots \ldots \ldots \ldots \ldots$ & $4 \ldots \ldots \ldots$
\end{tabular}

\begin{tabular}{|lll}
\hline 3.2 & Software e hardware utilizados para o processamento dos dados $\ldots$ & $\ldots 2$
\end{tabular}

3.3 Modelagem gráfica da formação do produto pela ótica da produção . . . 43

\begin{tabular}{lll}
\hline 3.4 & Formulação dos pressupostos da pesquisa $\ldots \ldots \ldots$ & $\ldots \ldots$
\end{tabular}$\ldots$

3.4.1 Desenvolvimento das proposições . . . . . . . . . . . . . . . . . . 43

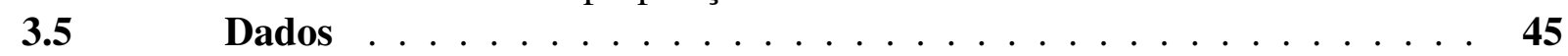

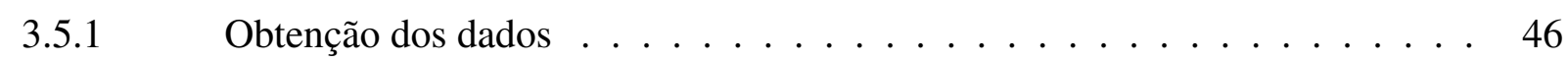

3.5.1.1 A base de dados COMTRADE . . . . . . . . . . . . . . . . . 46

3.5.1.2 A base de dados STAN da $\mathrm{OCDE} \ldots \ldots \ldots \ldots \ldots \ldots$

3.5.1.3 A base de dados BTDIXE da OCDE . . . . . . . . . . . . . . . . . 46

3.5.1.4 A base de dados WBIG do IEA . . . . . . . . . . . . . . . . . . 47

3.5.1.5 A base de dados INDSTAT . . . . . . . . . . . . . . . . . 47

3.5.1.6 A base de dados da WorldSteel . . . . . . . . . . . . . . . . . . . 47 
3.5.2 Tratamento dos dados . . . . . . . . . . . . . . . . . . . . . . . 47

3.5.2.1 Classificação e seleção dos dados. . . . . . . . . . . . . . . . . . . 48

3.5.2.2 Reconciliação dos dados . . . . . . . . . . . . . . . . . . . . . . . . 49

3.5.2.3 Cálculo das variáveis derivadas . . . . . . . . . . . . . . . . . . . . . . . . . 49

3.5.2.4 Padronização das variáveis . . . . . . . . . . . . . . . . . . . . . . . . . . 49

$\begin{array}{lll}3.5 .2 .5 & \text { Estatísticas descritivas das variáveis } \ldots \ldots \ldots & \ldots\end{array} \ldots \ldots \ldots$

3.5.2.6 Escolha da estratégia para visualização $\ldots \ldots \ldots \ldots \ldots$

$4 \quad$ RESULTADOS E DISCUSSÃO $\ldots \ldots \ldots \ldots \ldots \ldots \ldots \ldots$

$4.1 \quad$ A indústria do ferro $/ \mathbf{a c ̧ o} \ldots \ldots \ldots \ldots \ldots \ldots$

$4.1 .1 \quad$ O processo de produção do aço $\ldots \ldots \ldots \ldots \ldots \ldots \ldots \ldots$

4.1.2 Análise dinâmica da produção de minério de ferro . . . . . . . . . . . 52

$4.1 .3 \quad$ A exportação de minério de ferro $\ldots \ldots \ldots \ldots \ldots \ldots$

$4.1 .4 \quad$ A importação de minério de ferro $\ldots \ldots \ldots \ldots \ldots \ldots \ldots$

$4.1 .5 \quad$ A produção de aço bruto $\ldots \ldots \ldots \ldots \ldots \ldots \ldots$

4.1.5.1 Análise da dinâmica da produção de aço bruto por regiões, continentes, blocos, etc. $\quad 56$

4.1.5.2 Análise da dinâmica da produção de aço bruto por países $\ldots \ldots \ldots \ldots$

$4.1 .6 \quad$ A dinâmica do consumo do aço bruto $\ldots \ldots \ldots \ldots \ldots \ldots$

$4.1 .7 \quad$ A dinâmica da exportação de produtos (semi-)acabados aço bruto . . . . . . 59

$4.1 .8 \quad$ A cadeia mundial do ferro e do aço como um jogo $\ldots \ldots \ldots \ldots$. . . . . 60

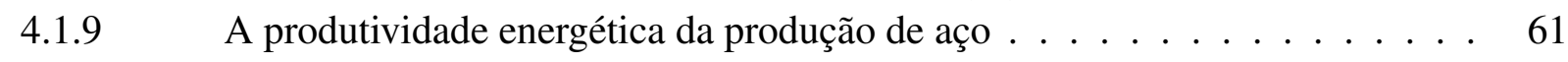

$4.1 .10 \quad$ Análise da rede internacional de comércio commodities de ferro / aço . . . . 63

5 CONCLUSÕES E LIMITAÇÕES DA PESQUISA $\ldots \ldots \ldots \ldots \ldots 65$

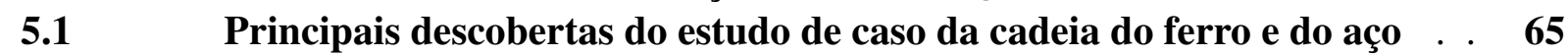

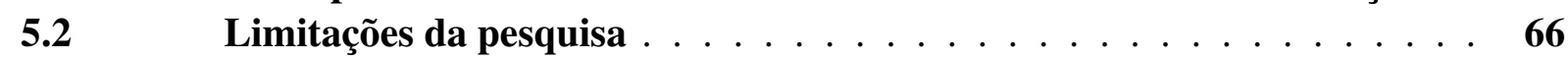

$5.3 \quad$ Considerações finais $\ldots \ldots \ldots \ldots \ldots 6$

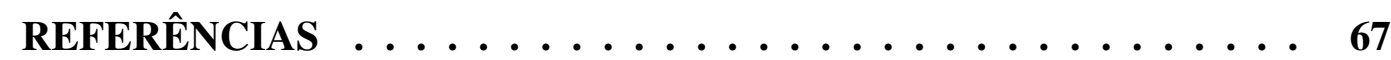

APÊNDICE A - TABELAS .............. 72

A.1 Tabelas da base de dados consolidada . . . . . . . . . . . . . . 72

A.1.1 Commodities da cadeia de ferro / aço (HS 72XX) . . . . . . . . . . . 72

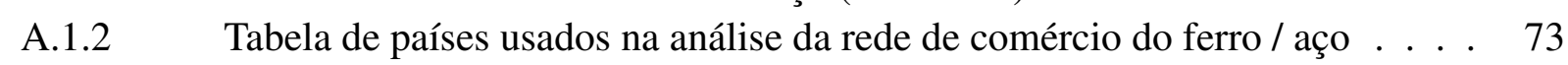

\begin{tabular}{|lll}
\hline A.1.3 Tabela de atividades econômicas ISIC $\mathrm{v} 4 \ldots \ldots \ldots \ldots$ & $\ldots \ldots \ldots$ & $\ldots \ldots$
\end{tabular}

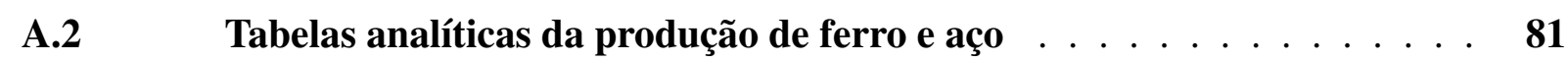

A.2.1 Produção mundial de minério de ferro . . . . . . . . . . . . . . . 81

A.2.2 Importação mundial de minério de ferro . . . . . . . . . . . . . . . 84

A.2.3 Exportação mundial de minério de ferro . . . . . . . . . . . . . . 91

A.2.4 $\quad$ Produção mundial de aço em pelotas $\ldots \ldots \ldots \ldots$

A.2.5 Produção mundial de aço bruto $\ldots \ldots \ldots \ldots$. . . . . . . . . 103

A.2.6 Consumo aparente de aço (em aço bruto equivalente) $\ldots \ldots \ldots \ldots$. . . . . 106

A.2.7 Produção mundial de aço bruto por regiões e China $\ldots \ldots \ldots \ldots$. . . . 111

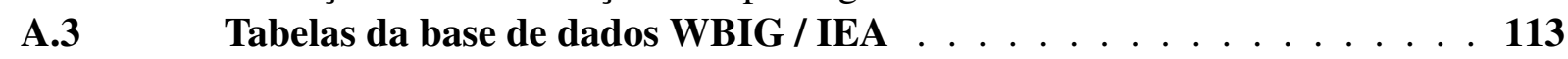

A.3.1 Tabela de variáveis de fluxo . . . . . . . . . . . . . . . . . . . 113

A.3.2 Tabela de produtos . . . . . . . . . . . . . . . . . . 115 
APÊNDICE B - PROCESSAMENTO E CONSOLIDAÇÃO DAS BASES DE DADOS $\ldots \ldots \ldots \ldots \ldots \ldots \ldots$

B.1 Base de dados WorldSteel $\ldots \ldots \ldots \ldots \ldots \ldots$

\begin{tabular}{lll}
\hline B.2 & Base de dados IEA WBIG $\ldots \ldots \ldots \ldots \ldots$
\end{tabular}

B.2.1 Scripts . . . . . . . . . . . . . . . . . . . . . . . . 118

B.2.1.1 Importação do arquivo bruto em R . . . . . . . . . . . . . . . . . 118

B.2.1.2 Tabelas auxiliares - normalização . . . . . . . . . . . . . . . . . . . . . . . 119

B.2.1.3 Filtragem e exportação . . . . . . . . . . . . . . . . . . . . 120

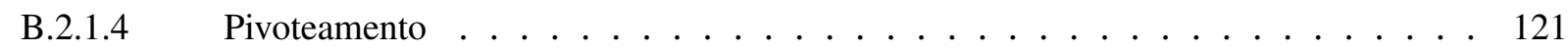

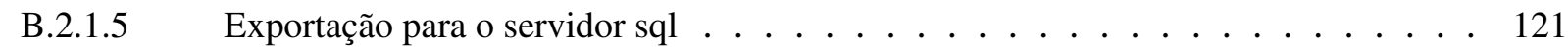

B.2.2 Tabelas auxiliares obtidas . . . . . . . . . . . . . . . . . 122

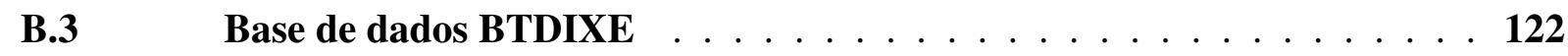

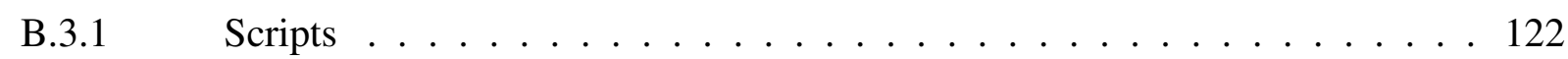

B.3.1.1 Importação do arquivo bruto em R . . . . . . . . . . . . . . . . . 122

B.3.2 Tabelas auxiliares obtidas . . . . . . . . . . . . . . . . . . . 123

B.4 Base de dados COMTRADE $\ldots \ldots \ldots \ldots \ldots \ldots \ldots$

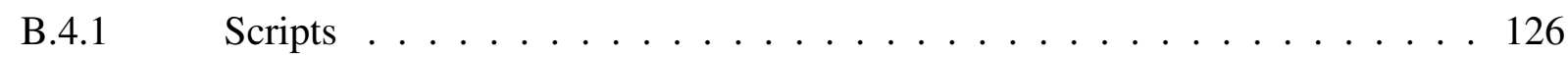

B.4.2 Tabelas auxiliares obtidas $\ldots \ldots \ldots \ldots \ldots \ldots$

B.5 Base de dados INDSTAT $\ldots \ldots \ldots \ldots \ldots \ldots \ldots \ldots$

B.5.1 Scripts . . . . . . . . . . . . . . . . . . . 126

B.5.2 Tabelas auxiliares obtidas $\ldots \ldots \ldots \ldots \ldots \ldots$

Índice . . . . . . . . . . . . . . . . 127 


\section{INTRODUÇÃO}

\subsection{Introdução}

Esse trabalho visa modelar e analisar a cadeia global de geração de valor do ferro e do aço, tanto na sua estrutura como a sua dinâmica. O tema da pesquisa é, portanto, a análise dinâmica dessa cadeia de geração de valor, o que deve permitir obter informações relevantes para a elaboração de uma política industrial que gere mais valor para um país em particular. A hipótese de trabalho é a de que possível extrair elementos relevantes (semânticos) dessa análise da dinâmica estrutural. A modelegem dessa cadeia e a análise da sua dinâmica estrutural no espaço e no tempo, podem ajudar a entender os elementos importantes para melhorar a inserção e desempenho da economia brasileira nessa cadeia de geração de valor. A despeito do Brasil possuir importantes reservas minerais, países que importam as matérias primas do Brasil e as processam geram mais valor do que o Brasil. Como exemplo, a China, país grande importador de ferro do Brasil, exporta mais valor em produtos derivados do processamento dessa matéria prima do que o Brasil. Como resultado, deve ser possível, a partir das informações extraídas, identificar os gargalos que impedem o Brasil de processar e agregar valor aos produtos que exporta, ao invés de vender commodities de baixo valor agregado.

O que faz os produtos produzidos ao lado das enormes reservas de minério de ferro, apenas como exemplo, serem menos competitivos que aqueles processados do outro lado do mundo, na China ou mesmo no Japão, como é o caso da Usiminas?

Reformulando, como um país pode exportar minério de ferro bruto e importar chapas processadas a milhares de quilômetros de distância, por serem mais competitivas que as fabricadas ao lado da mina?

Esse trabalho foi desenvolvido em três partes. Na primeira parte busca-se identificar os tópicos da literatura científica que podem ajudar a responder à questão, que tem que ver com o custo, produtividade dos fatores de produção e o nível de investimentos. Na segunda parte alguns dados preliminares são exibidos de forma a permitir a formulação das hipóteses da pesquisa e do método a ser usado para chegar-se à resposta. Por fim, são feitas algumas considerações sobre os resultados obtidos e sobre as hipóteses desenvolvidas.

\subsection{Problema de pesquisa}

Modelar e analisar a cadeia mundial de geração de valor do ferro / aço, de forma a determinar, a partir dos dados históricos, a dinâmica do aumento ou diminuição do valor gerado ao longo dessa cadeia de produção, no espaço (diversos países) e no tempo, de forma a responder à seguinte pergunta: que fatores influenciaram os resultados especialmente sobre o desempenho no valor gerado pela cadeia do ferro / aço? 


\subsection{Justificativa}

Do ponto de vista estritamente científico, que é o que interessa a essa tese, a questão se resume em identificar os mecanismos que levam alguns países a serem grandes exportadores de produtos com baixo valor agregado enquanto outros geram muito mais valor comprando esses insumos, processando-os e depois exportando produtos mais elaborados.

Neste trabalho, será feita a modelagem da cadeia de geração de valor do ferro e aço. Partindo desse modelo, busca-se determinar os fatores determinantes para que o valor gerado na cadeia de siderurgia do ferro e aço aumente ou reduza, determinando o peso de cada um desses fatores.

Trata-se, portanto, de determinar o grau de influência dos fatores de produção, no caso a energia, o capital, o trabalho e as outras matérias primas não energéticas, sobre a dinâmica da cadeia global de ferro e aço.

Essa tese se justifica, portanto, porque determinar adequadamente uma modelagem de uma cadeia de produção, que é tão básica para o crescimento do PIB porque está à montante da cadeia de geração de valor de cada país, fornecendo insumo para as outras indústrias, essa modelagem permite planejar melhor, tomar melhores decisões. E isso é particularmente importante num momento de transição para uma economia menos baseada nos combustíveis fósseis, não se poderá continuar emitindo gases de efeito estufa e outros poluentes sem pagar um preço alto por isso.

Não se pode desprezar o forte crescimento da China na cadeia mundial de geração de valor. A análise dessa cadeia, que é básica para a formação do PIB de cada país, permite perceber que o crescimento da China tomou mercado de praticamente todos os países do mundo. Em 20 anos, de 1996 até 2016, a China passou de 10\% para 50\% de toda a produção de aço do mundo. Ao mesmo tempo, a China acumulou mais de US\$ 3 trilhões em títulos do tesouro americanos (T- bonds).

A guerra comercial entre os EUA e a China na disputa pelo espaço de superpotência mundial levou à imposição de cotas para importação de aço pelos EUA e a uma guerra comercial com a China, a quem o os EUA acusam de terem "passado os EUA para trás". Olhando-se os dados, ao menos no que diz respeito o crescimento do PIB da China, da sua indústria, e, em particular, a dinâmica da cadeia de geração de valor do ferro e do aço, o que se vê é que a China teve um desempenho realmente extraordinário.

É útil perceber os EUA foram um dos países que mais sofreram com a migração dos investimentos nessa cadeia de geração de valor, o chamado "cinturão enferrujado", em alusão à região que sediava a produção de máquinas e equipamentos pesados, siderurgia, automóveis, etc.

Nesse contexto, se sabe que o Brasil tem passado por um período de "desindustrialização", com o aumento das importações até mesmo de cafés e outros derivados imediatos dos produtos agropecuários que exportamos para o mundo. Se de um lado a nossa economia tem sido sustentada pela exportação de commodities, tais como os produtos agropecuários e minerais, do outro sabe- 
se que os empregos de qualidade, que oferecem bons salários e benefícios, continuam sendo os do setor industrial. Mas, como se trata de um trabalho científico, cumpre definir exatamente o que significa o termo "desindustrialização", qual seu conceito matemático exato, de forma que se possa torná-lo operacional.

O Instituto de Pesquisa Econômica Aplicada (IPEA), publicou recentemente uma coletânea de artigos em dois volumes (Negri e Cavalcante (2014), Negri e Cavalcante (2014), Ellery Jr. (2014)) sobre a questão da competitividade do Brasil. O Brasil, reconhecem os pesquisadores desse renomado Instituto, vem perdendo competitividade industrial nos últimos anos, e, conforme mostra a história econômica, é a indústria o setor capaz de agregar mais valor, gerar empregos mais bem remunerados e com maiores benefícios, e enfim, gerar valor e riqueza. Em Negri e Cavalcante (2014), os autores mostram de forma bem elaborada a importância de políticas que tenham como o objetivo o aumento da competitividade industrial brasileira.

Poucos tem falado do pequeno vigor da nossa economia, quando comparada à de alguns nossos vizinhos tais como Chile e Colômbia, ou até mesmo a outros países comumente chamados de "emergentes", tais como China, Índia, dentre outros, e, principalmente, das razões desta baixa competitividade da nossa economia, e, em especial, a da nossa indústria.

\subsection{Objetivos}

\subsubsection{Objetivo geral}

O objetivo desta pesquisa é o de modelar a cadeia mundial de geração de valor do ferro e do aço, identificando, a partir da análise da dinâmica estrutural, os fatores que levaram determinados países a terem maior impacto no seu desenvolvimento econômico.

\subsubsection{Objetivos específicos}

Esta pesquisa tem como objetivos específicos:

- Identificar, através da revisão sistemática da literatura os diversos determinantes da formação do PIB e os diversos elementos de fluxo e estoque que interferem na sua variação ao longo do tempo.

- Modelar as atividades econômicas, que geram valor para os atores (países), de uma forma tal que seja possível consolidar o grande volume de dados (big data) provenientes de diferentes origens e em diferentes formatos e unidades, gerando uma base de dados única e consistente.

- Utilizando das ferramentas de ciência de dados (data science), analisar os dados e produzir visualizações capazes de extrair informações relevantes sobre o desempenho dos diferentes países na cadeia de valor em análise ao longo do tempo. 


\section{REFERENCIAIS TEÓRICOS}

\subsection{Input-output analysis (análise insumo-produto)}

2.1.1 A modelagem macroeconômica através do método de Leontief para mensuração do PIB

A análise de entrada e saída (ou insumo-produto) foi elaborada pelo laureado com prêmio de economia em homenagem a Alfred Nobel, o russo naturalizado norte-americano Wassily Leontief (1905 - 1999). Em Leontief (1986), o próprio autor reuniu e republicou uma coletânea com seus artigos que tratam do seu modelo de medição do produto agregado. Posteriormente, esse método foi adotado como modelo para as contas nacionais, servindo para fazer uma análise estrutural das economias dos países(e.g.Miller e Blair (2009), Kim (1973), Co-operation e Development (2015), Zamora (2015), Christ (1955), Bess e Ambargis (2023), Bullard, Penner e Pilati (1978), ten Raa e Mohnen (1994), Bhagavana e Din (1980) ).

Depois dos artigos seminais de Leontief e da adoção de sua técnica de mensuração do produto agregado (Produto Interno Bruto (PIB) e valor gerado por cada setor da economia, muitos foram os avanços incorporados, a exemplo da conservação de massas utilizada por Hare (1981) para, em conjunto com os valores em unidades monetárias, fazer o balanço de massas e calculando uma série de variáveis e indicadores úteis para sua análise.

Um outro bom exemplo da modelagem econômica utilizando a técnica da análise estrutural de entrada/saída (ou insumo/produto) está em Hudson e Jorgenson (1975). Formalmente, o modelo de análise proposto por Leontief é dado por um sistema de $\mathrm{n}$ equações com $\mathrm{n}$ incógnitas. Ele pode ser utilizado para mapear a geração de valor um determinado setor da economia, uma determinada região geograficamente definida ou até mesmo as relações comerciais do comércio internacional.

Em termos matemáticos, o método de Leontief consiste num conjunto de matrizes que são manipuladas utilizando-se da álgebra linear. Usando letras minúsculas para vetores-coluna e maiúsculas para matrizes, temos uma forma compacta para esse conjunto de equações. Sejam

$$
x=\left[\begin{array}{c}
x_{1} \\
\vdots \\
x_{n}
\end{array}\right], Z=\left[\begin{array}{c}
z_{11} \ldots z_{1 n} \\
\vdots \\
z_{n 1} \ldots z_{n n}
\end{array}\right], f=\left[\begin{array}{c}
f_{1} \\
\vdots \\
f_{n}
\end{array}\right]
$$

Tem então a equação 2.2, onde $\mathrm{x}$ representa a produção agregada de $\mathrm{n}$ produtos, a matriz $\mathrm{Z}$ representa a quantidade de insumos comprados para a produção de um dos produtos do vetor $\mathrm{x}$ e f representa a demanda final de cada produto.

$$
x=Z i+f
$$

Leontief já vislumbrava a possibilidade de fazer uma análise econômica mundial, embora a adoção da sua técnica de apuração das contas nacionais tenha demorado mais em alguns países 
que em outros. Além do que, há países onde não se pode confiar nos números apurados, seja por problemas metodológicos ou de qualquer outra natureza. No seu artigo, Leontief (1974), ele esboça esse modelo análise em nível mundial, cujos dados só recentemente começaram a ficar disponíveis, ainda que com inúmeras dificuldades que serão discutidas na parte de metodologia desse trabalho.

Esse modelo básico pode ser estendido de inúmeras formas, como mostra o livro Miller e Blair (2009). Hare (1981), por exemplo, agrega um balanço de materiais a essa equação. A correlação entre essa equação com as contas nacionais é deduzida em Miller e Blair (2009, p. 13-15). Um exemplo mais amplo, que leva em consideração o comércio internacional e as contas nacionais é mostrado na figura 1 .

Figura 1 - Matrizes de insumo-produto

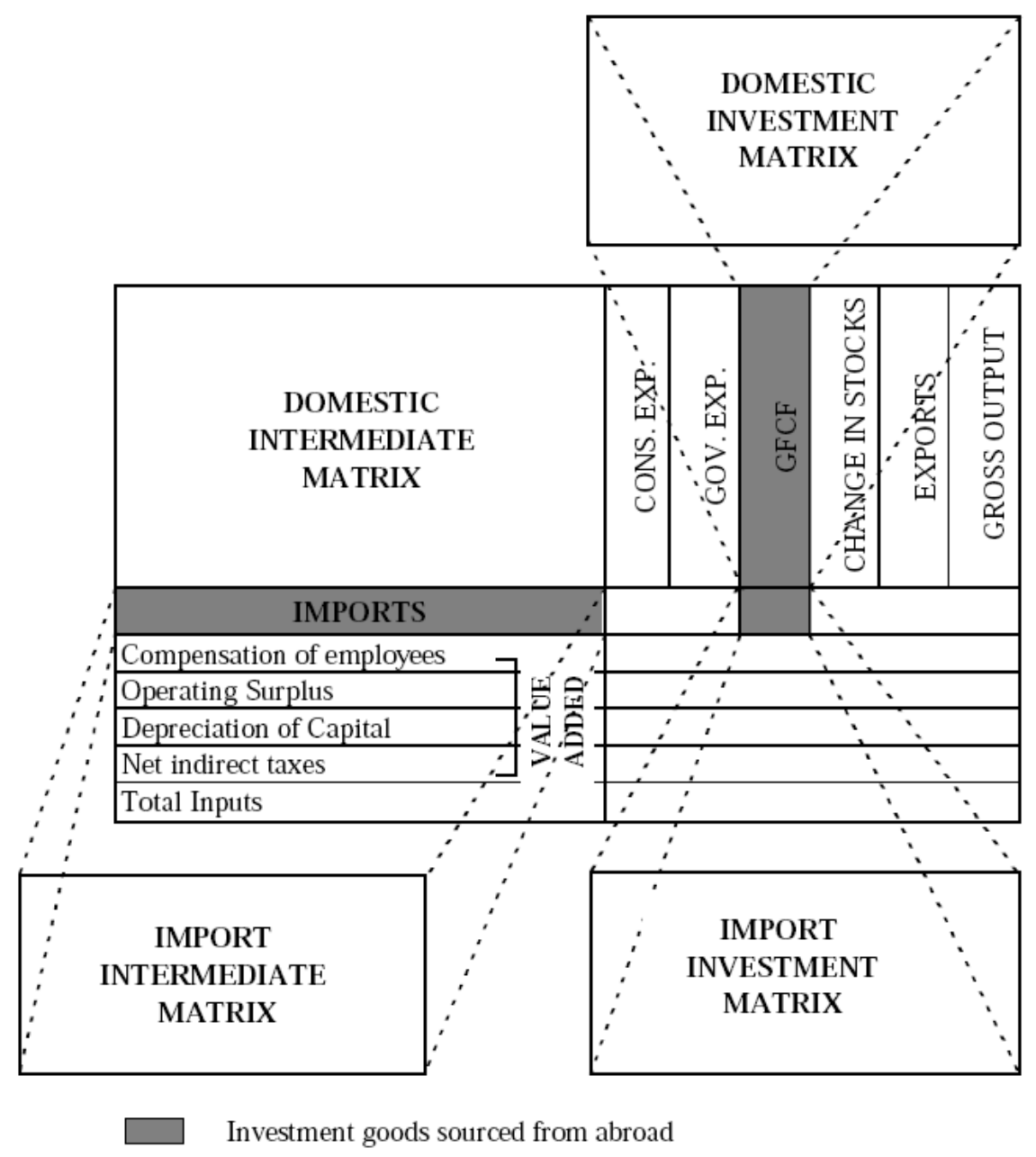

Fonte: CO-OPERATION; DEVELOPMENT, 2015, p.4).

$\operatorname{Raa}(2005)$ traz uma abordagem moderna à técnica, tratando do modelo dinâmico, do modelo estocástico, da questão da eficiência, dentre outras extensões. Ele aborda as questões mais importantes sobre o método de Leontief, seu desenvolvimento e como suas deficiências foram sanadas ou mitigadas. Em suas próprias palavras: 
The theory of input-output analysis is a major leap forward from the work of those who led up to Leontief's analysis (1966, particularly chapter 7). The advance here was formulation of the structure of the interdependencies of an economy in a way that was less abstract and far more operational than anything that had appeared before. Models are quantified with the aid of empirical data for an economy, enabling their use as a guide for concrete policy decisions as well as for pure understanding. In dealing with a substantial set of such simultaneous economic interrelationships, nothing like that had ever been done before. While some of the areas of application of the quantified input-output models are obvious - as, for example, their use as a guide to central planning - the applications go far beyond that, sometimes in totally unexpected directions. Thus, Leontief's (1970) application to environmental issues was, surely, far from obvious, though once it had been carried out, it does seem an evident and natural way to go about the analysis of its subject. Perhaps an even more striking and unexpected application was that to international trade. Leontief (1953) showed that US imports are more capital-intensive than its exports. [...] (RAA, 2005, p.11)

A teoria da análise input-output é um grande avanço a partir do trabalho daqueles que levaram adiante a análise de Leontief (1966, particularmente capítulo 7). O avanço aqui foi a formulação da estrutura das interdependências de uma economia de forma menos abstrata e muito mais operacional do que qualquer coisa que tinha aparecido antes. Os modelos são quantificados com a ajuda de dados empíricos para uma economia, permitindo seu uso como guia para decisões políticas concretas, bem como para a compreensão pura. Ao lidar com um conjunto substancial de tais inter-relações econômicas simultâneas, nada como isso já havia sido feito antes. Embora algumas das áreas de aplicação dos modelos de entrada-saída quantificados sejam óbvias - como, por exemplo, seu uso como guia para o planejamento central - as aplicações vão muito além que, por vezes, em direções totalmente inesperadas. Assim, a aplicação de Leontief (1970) para as questões ambientais eram, certamente, longe de ser óbvias, embora uma vez que tivesse sido realizada, parece uma maneira evidente e natural de analisar o assunto. Possivelmente uma aplicação ainda mais impressionante e inesperada foi a do comércio internacional. (RAA, 2005, p.11) (tradução nossa).

\subsubsection{A medição do PIB em suas diversas formas}

O modelo numérico da hipótese de pesquisa é baseado na ideia de que o $\mathrm{PIB}$ de um país (c) qualquer pode ser calculado como o somatório da oferta ou da demanda durante um ano $\mathrm{t}=\mathrm{y}$.

Assim, temos a equação 2.3, que é o PIB calculado sob a ótica do consumo. O PIB de um pais ("cou") XXX qualquer $\mathrm{PIB}_{\text {cou }=\mathrm{XXX}}^{t=y}$, durante o ano $t=\mathrm{y}$ (ear) qualquer, é igual à soma do consumo privado $\left(C_{p}\right)$ com o consumo do governo $\left(C_{g}\right)$ somado aos investimentos privados $\left(I_{p}\right)$, somado ao resultado da balança com o exterior, também chamada renda líquida do exterior $(\mathrm{RLE})$, exportações $(\mathrm{X})$ - importações $(\mathrm{I})=(X-I)$, que é o resultado da balança comercial, somado ao resultado da balança de turismo, que é a renda vinda do exterior $\left(R_{e}\right)$, gastos dos não-residentes menos a renda gasta por brasileiros no exterior $\left(C_{e}\right)$. Ou seja, o resultado com o exterior é dado por $\mathrm{RLE}=(\mathrm{X}-\mathrm{M})+\left(R_{e}-C_{e}\right)$. Os investimentos privados $\left(I_{p}\right)$ são a soma da formação bruta de capital fixo $(G F C F)$ com a variação de estoques INVNT. Ou seja, $I_{p}=(\mathrm{GFCF}+\mathrm{INVNT})$. Substituindo essas identidades na eq. 2.3, temos a eq. 2.4. 


$$
\begin{gathered}
\mathrm{PIB}_{\mathrm{cou}=\mathrm{XXX}}^{t=y}=C_{p}+C_{g}+I_{p}+R L E \\
\mathrm{PIB}_{\mathrm{cou}=\mathrm{XXX}}^{t=y}=C_{p}+C_{g}+(\mathrm{GFCF}+\mathrm{INVNT})+(\mathrm{X}-\mathrm{M})+\left(R_{e}-C_{e}\right)
\end{gathered}
$$

Analisando as variações desses diversos fatores que compõem o PIB real, em comparação aos outros países, deve ser possível identificar explicações para outras variações em outras variáveis relevantes, tais como as razões que levam determinados países a serem exportadores de commodities e não de produtos de maior valor agregado.

$$
\begin{aligned}
\mathrm{dF} & =\frac{\partial F_{x_{1}}}{\partial x_{1}} \partial x_{1}+\cdots+\frac{\partial F_{x_{n}}}{\partial x_{n}} \partial x_{n} \\
& =\sum_{i=1}^{n} \frac{\partial F_{x_{i}}}{\partial x_{i}} \partial x_{i}
\end{aligned}
$$

Da matemática sabe-se que a variação $\left(\Delta F=F_{f}-F_{i}\right)$ de uma função de $n$ variáveis $\left(x_{1} \ldots x_{n}\right)$ $\mathrm{F}$, onde $F\left(x_{1}, \ldots, x_{n}\right)$, pode ser aproximada usando a fórmula do diferencial total, que é mostrada na eq. 2.5. Como as variações $\Delta x_{i}$ são muito pequenas (se $\Delta x_{1}, \ldots, \Delta x_{n} \rightarrow 0 \Rightarrow \Delta F \rightarrow \partial F$ ), pode-se aproximar e dizer que $\partial x_{i} \approx \Delta x_{i}$. Assim, substituindo na eq. 2.5, tem-se a equação 2.7 .

$$
\begin{aligned}
\mathrm{dF} & \approx \frac{\partial F_{x_{1}}}{\partial x_{1}} \Delta x_{1}+\cdots+\frac{\partial F_{x_{n}}}{\partial x_{n}} \Delta x_{n} \\
& =\sum_{i=1}^{n} \frac{\partial F_{x_{i}}}{\partial x_{i}} \Delta x_{i} \\
& \approx \Delta F
\end{aligned}
$$

No caso do PIB, vamos calcular os pesos de cada de de cada variável, excluindo as possíveis colinearidades que poderiam distorcer os resultados. No caso presente, pretende-se estabelecer o seguinte critério: a soma de todos os pesos atribuídos a cada fator / variável deve sempre ser igual a $1=100 \%$. Ou seja, as derivadas parciais representam, nesse caso, os coeficientes que dizem quanto cada fator de produção (variável) representa para a geração de valor total.

Mas, até esse momento tem-se apenas os valores financeiros, dados em unidades monetárias. É possível fazer uma segunda transformação de modo a levar em consideração os pares da valores monetários (em u.m.'s) e quantidades físicas (tempo, massa, energia, etc), de modo a transformar a equação diferencial original para gerar outros dois pares de derivadas parciais: uma é derivada parcial da eficiência ( $\eta$, ou seja, o quanto de saídas em unidades físicas o sistema (setor econômico) consegue gerar para cada unidade física de entrada de cada fator de produção (variável) utilizado no processo de produção (ver figura 7). 
Figura 2 - Unidade acumuladora de custos levando em consideração os fatores de pruduçao capital(K), trabalho(L), materias-primas $(\mathrm{M})$ e energia $(\mathrm{E})$.

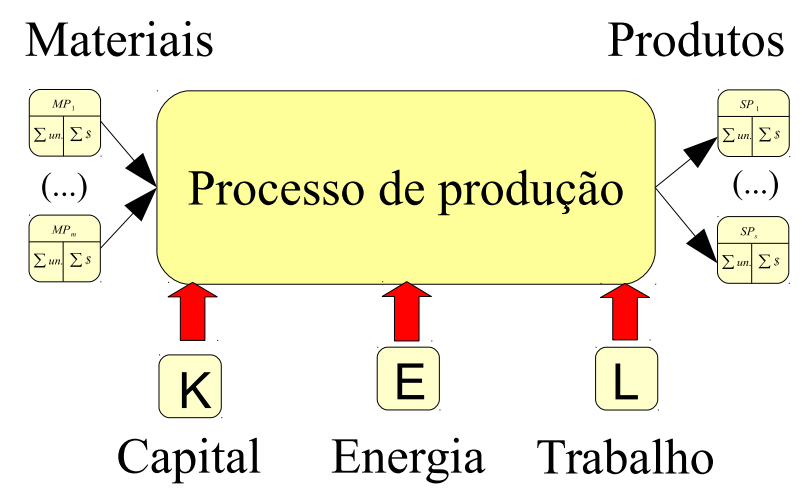

Fonte: elaborado pelo autor.

A outra derivada parcial é a do preço ( $p)$, ou seja, quanto de unidades físicas de um fator / insumo se obtém por cada unidade monetária emprega nele. Em termos matemáticos, tem-se duas variações: quantidades físicas $(\mathrm{Q})$ e quantidades monetárias $(\mathrm{M})$. A variação da quantidade física de um fator de entrada $\left(Q_{i}\right)$ e a variação do valor pago $\left(C_{i}\right)$ permitem escrever a eq. 2.11, que diz que o valor em u.m. é igual ao preço do insumo multiplicado por seu preço de mercado.

$$
\begin{gathered}
p_{\text {entrada }=i}=\frac{C_{\text {entrada }=i}}{Q_{\text {entrada }=i}} \\
C_{\text {fator }_{i}}=p_{\text {fator }_{i}} * Q_{\text {fator }_{i}} \\
\eta_{\text {física }}=\frac{Q_{\text {produtos }}^{\text {fatores }} Q_{\text {fator }}}{\sum_{i=1}} \\
\eta_{\text {valor }}=\frac{\sum_{o=1}^{\text {saídas }} C_{\text {saída }=o}}{\sum_{i=1}^{\text {entradas }} C_{\text {entrada }=i}} \\
=\frac{\sum p_{\text {saída }=o} Q_{\text {saída }=o}}{\sum p_{\text {entrada }=i} Q_{\text {entrada }=i}}
\end{gathered}
$$

A vantagem de se fazer essas transformações é que a eficiência física (eq. 2.12) não sofre mudanças de curto prazo, pois dependem da plataforma tecnológica da planta industrial do setor industrial em análise. Assim, se temos altos-fornos que trabalham à base de energia elétrica, outros que trabalham com gás natural e outros que trabalha com carvão ou coque, evidentemente que os custos de produção serão dependentes dessas escolhas, que dependem dos investimentos em capital fixo que foram feitos na construção da planta. A mudança dos insumos utilizados, bem 
como a eficiência física, são aproximadamente constantes no curto prazo, sofrendo variações no longo prazo. O preço médio de um fator, no caso de commodities, é fixado pelo mercado internacional, e, portanto, é sabido. Além disso, a comparação dos preços internacionais de cada insumo $(i)$ com o valor médio no país pode ser calculado pela eq. 2.10 .

$$
\mathrm{PIB}_{p m}=\sum_{i=1}^{\text {setores ind. }} \text { Valor agregado }_{i}+(\mathrm{T}-\mathrm{U})
$$

Sob a ótica da oferta ou da produção, temos agora que o $\mathrm{PIB}$ (a preços de mercado) é calculado segundo a equação 2.15, onde o $\mathrm{PIB}$ a preços de mercado $\left(\mathrm{PIB}_{p m}\right)$ é igual ao somatório

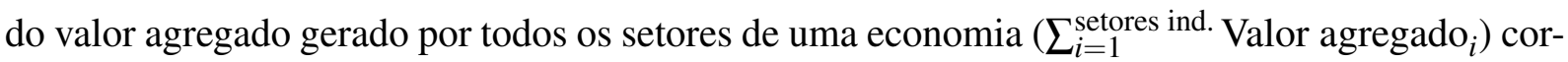
rigidos pelos impostos $(T)$ líquidos de subsídios, isenções ou renúncias fiscais $(U)$. Curiosamente, isso explica o fiasco do neo-keynesianismo, ou "nova matriz macroeconômica", implementada pelos últimos governos do Brasil. Ao contrário do que eles pensam, os subsídios e renúncias fiscais não aumentam o PIB.

$\mathrm{Na}$ análise estrutural de uma economia se busca analisar o valor gerado em relação aos custos dos fatores de produção. Essa análise precisa, portanto, levar em consideração as entradas (insumos / fatores de produção) em relação ao valor obtido pelo produto final (saídas). Considerando que essa análise se dará com commodities cujo preço é definido no mercado internacional, é preciso incorporar a essa análise a rede de comercio internacional dessas commodities e as taxas de câmbio, de modo a verificar os impactos desses preços e taxas sobre a geração de valor da cadeia produtiva em análise em cada país.

Assim, transformando o diferencial total mostrado na eq. 2.7 para que a função $F$ seja o PIB de um país (c) qualquer em um ano (y) qualquer, tem-se a equação do diferencial total do PIB na eq. 2.16, onde $f_{1}, \ldots, f_{i}$ são os diversos insumos, entradas ou fatores de produção, pois esses termos estão sendo usados indistintamente.

$$
\begin{aligned}
\Delta \mathrm{PIB} & \approx \frac{\partial \mathrm{PIB}_{f_{1}}}{\partial f_{1}} \Delta f_{1}+\cdots+\frac{\partial \mathrm{PIB}_{f_{n}}}{\partial f_{n}} \Delta f_{n} \\
& =\sum_{i=1}^{n} \frac{\partial \mathrm{PIB}_{f_{i}}}{\partial f_{i}} \Delta f_{i} \\
& \approx \partial \mathrm{PIB}
\end{aligned}
$$

Retomando a discussão sobre a necessidade de usar o valor e a quantidade física das entradas e saídas, de modo obter derivadas com variação mais lenta no tempo, tem-se que uma variação do PIB deve ser explicada pela variação em unidades monetárias do preço e pela variação da quantidade física de insumos utilizados na cadeia de produção em análise, além de outros aspectos ou variáveis não-controláveis que serão discutidos posteriormente. No momento, simplificadamente, torna-se importante verificar a adaptação do diferencial total para acomodar estas duas variáveis, o preço e a quantidade física das entradas (insumos / fatores de produção) e 
das saídas (produtos finais). Os valores dos custos dos insumos ou entradas (matérias primas ( $\left.\mathrm{MP}_{i}\right)$ trabalho $\left(\mathrm{L}_{i}\right)$, capital $\left(\mathrm{K}_{i}\right)$ e energia $\left.\left(\mathrm{E}_{i}\right)\right)$, bem como suas variações de um ano para o outro $\left(\Delta \mathrm{MP}_{i}, \Delta \mathrm{L}, \Delta \mathrm{K}, \Delta \mathrm{E}\right)$, além dos produtos finais do setor industrial $\left(\mathrm{PA}_{n}\right)$, dos custos de capital, da variação dos estoques e das variações anuais desses fatores $\left(\Delta \mathrm{PA}_{n}\right)$, são as variáveis que fazem parte do modelo inicial. Esses produtos são vendidos em três partes: consumidos internamente ou estocados ou exportados, em função de algumas outras variáveis, tal como a taxa de câmbio, que serão incluídas no modelo posteriormente.

Os valores e quantidades de insumos (entradas) e produtos (saídas) dão origem aos preços médios aparentes, permitindo que se calcule os preços médios (média aritmética) em cada ano e por cada país, dividindo os valores em unidades monetárias pelas quantidades em suas unidades físicas. A comparação a distribuição do preço médio anual de cada país com a distribuição do preço médio anual de todos os países, pode-se identificar fatores que expliquem um aumento ou redução da exportação de minério de ferro de um país para outro, ou talvez se explique a competitividade crescente ou decrescente de um país em função de um aumento acima da média geral de eficiência do conjunto de países. Essa é a hipótese nula da economia: um crescimento sustentável do PIB no tempo depende de um aumento na produtividade dos fatores (eficiência). Em termos matemáticos, tem-se na eq. 2.19

$$
\begin{aligned}
\mathrm{PIB}_{c, y, s} & =\mathrm{F}( \\
& \mathrm{MP}_{1}, \ldots, \mathrm{MP}_{i} \\
& \Delta \mathrm{MP}_{1}, \ldots, \Delta \mathrm{MP}_{i} \\
& \mathrm{~L}, \Delta \mathrm{L} \\
& \mathrm{K}, \Delta \mathrm{K} \\
& \mathrm{E}, \Delta \mathrm{E}, \\
& \mathrm{PA}_{1}, \ldots, \mathrm{PA}_{n}, \\
& \Delta \mathrm{PA}_{1}, \ldots, \Delta \mathrm{PA}_{n} \\
& ) \\
\Delta \mathrm{PIB}_{c, y, f=\mathrm{MP}} & \approx \frac{\partial \mathrm{PIB}_{f=\mathrm{MP}_{1}}}{\partial \mathrm{MP}_{1}} \\
& =\sum_{i=1}^{i} \frac{\partial \mathrm{PIB}_{c, y, f=\mathrm{MP}_{i}}+\cdots+\frac{\partial \mathrm{PIB}_{c, y, f=\mathrm{MP}_{i}}}{\partial \mathrm{MP}_{i}} \Delta \mathrm{MP}_{i}}{} \\
& \approx \partial \mathrm{PIB}_{c, y, f=\mathrm{MP}_{i}} \\
& \approx \frac{\partial \mathrm{PIB}_{c, y, f=\mathrm{PA}_{1}}}{\partial \mathrm{PA}_{1}}+\cdots+\frac{\partial \mathrm{PIB}_{c, y, f=\mathrm{PA}_{i}}}{\partial \mathrm{PA}_{i}} \\
& =\sum_{i=1}^{i} \frac{\partial \mathrm{PIB}_{c, y, f=\mathrm{PA}_{i}}}{\partial \mathrm{PA}_{i}} \Delta \mathrm{PA}_{i} \\
& \approx \partial \mathrm{PIB}_{c, y, f=\mathrm{PA}_{c}}
\end{aligned}
$$




\subsubsection{Literatura sobre a análise estrutural de entrada e saída}

A literatura sobre a influência da disponibilidade e consequentemente dos preços da energia sobre o PIB é vasta e por vezes contraditória. Por exemplo,

Korsakienè, Tvaronavic̃ienè e Smaliukienè (2014) fazem uma análise sobre o impacto do aumento de preços da energia na Lituânia - mantida a intensidade do seu uso - sobre a sua competitividade industrial no contexto dos países bálticos. Usando uma análise de correlação sobre um período compreendido entre os anos de 2000-2011, o resultado obtido é o de que um aumento nos preços da energia não tem um efeito maléfico no desenvolvimento do setor industrial ou nas exportações. Já Lim e Yoo (2013), analisando o impacto da elevação dos preços da energia sobre os preços dos produtos industriais e na inflação da Coréia do Sul, usando o método da análise de entrada-saída - ou insumo-produto -, chegaram à conclusão que $10 \%$ de aumento no preço da energia implica um impacto global sobre a economia coreana de $0,4367 \%$. Pao e Fu (2013) fizeram um estudo de causalidade entre o consumo de energia limpa e suja e o crescimento do Brasil no período compreendido entre 1980-2009. Sumariamente, eles encontraram que existe uma causalidade bidirecional entre o uso dos diversos tipos de energia (limpa ou suja, renovável ou fóssil) e o crescimento do PIB. Encontraram também o efeito substituição entre energia fóssil e energia nuclear. Segundo os autores, a metodologia por eles adotada, além da bidirecionalidade e do efeito substituição, não permite obter resultados claros acerca do relacionamento entre o uso dos diferentes tipos de energia e o crescimento econômico.

2.1.4 Aplicação didática da análise de entrada-saída para análise estrutural de um subconjunto de setores da economia

Em um trabalho para as organizações RAND, Hudson e Jorgenson (1975) propuseram o seguinte modelo macroeconômico (figura 3). A tabela 1 mostra a legenda das contas utilizadas no modelo em foco.

A tabela 2 mostra uma análise setorial de geração de valor feita por Hudson e Jorgenson (1975). Ele utilizou alguns setores (ver tabela 1) para analisar a produtividade dos fatores, isto é, a quantidade de valor gerado por cada unidade de fator utilizada. 
Figura 3 - O modelo da RAND (Leontief com balanço de massa e energia) INTERINDUSTRY TRANSACTIONS: DIAGRAMMATIC REPRESENTATION
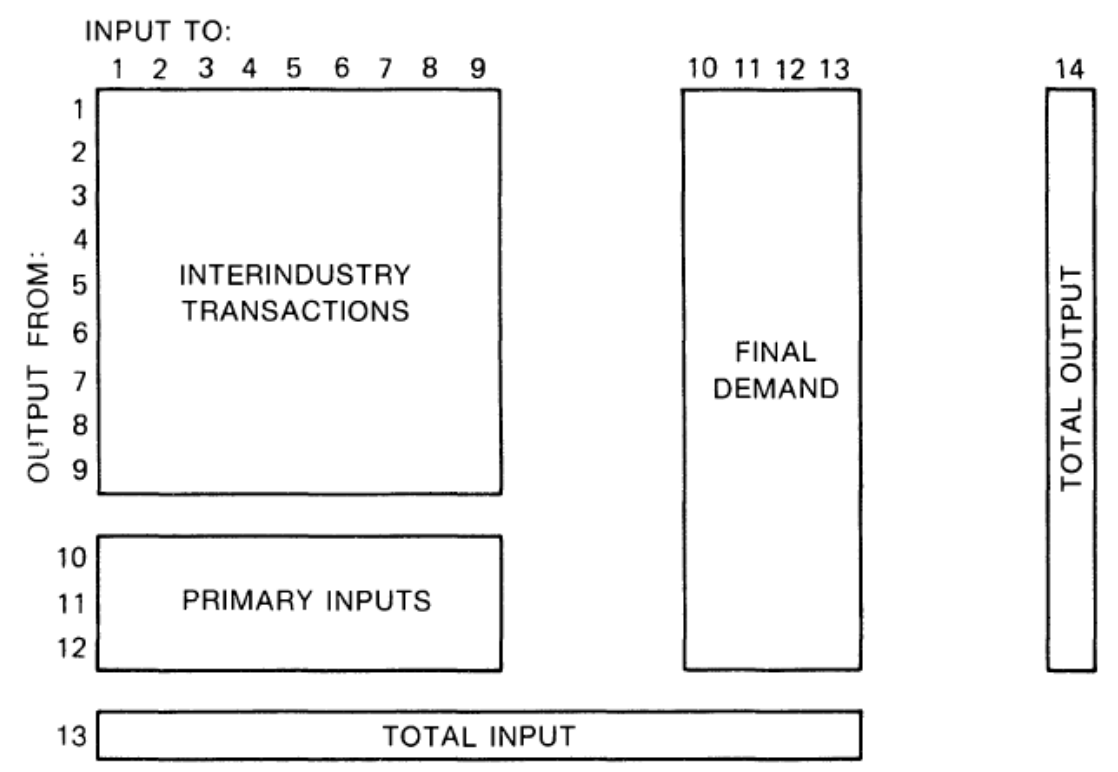

Fonte: Hudson e Jorgenson (1975).

Tabela 1 - Legenda das contas utilizadas no modelo RAND

\begin{aligned} & \hline$\# \#$ SETORES INTERMEDIÁRIOS \\ & \hline 1 AGRICULTURA, MINERAÇÃO (- ENERGIA) E CONSTRUÇÃO \\ & 2 MANUFATURA (INDÚSTRIA) (- REFINO). \\ & 3 TRANSPORTES. \\ & 4 COMUNICAÇÕES, COMÉRCIO, SERVIÇOS. \\ & 5 MINERAÇÃO DE CARVÃO. \\ & 6 PETRÓLEO CRÚ E GÁS NATURAL. \\ & 7 REFINO DE PETRÓLEO. \\ & 8 UTILIDADES ELÉTRICAS. \\ & 9 UTILIDADES DE GÁS. \\ & \hline$\# \#$ INSUMOS PRIMÁRIOS (LINHAS) \\ & \hline 10 IMPORTAÇOES (I). \\ & 11 REMUNERAÇÃO DO CAPITAL (K). \\ & 12 REMUNERAÇÃO DO TRABALHO (L). \\ & \hline \#\# DEMANDA TOTAL (COLUNAS) \\ & \hline 10 GASTOS COM CONSUMO PESSOAL. \\ & 11 INVESTIMENTO DOMÉSTICO PRIVADO BRUTO. \\ & 12 GASTOS DO GOVERNO \\ & 13 EXPORTAÇÕES \\ & \hline\end{aligned}

Fonte: adaptado a partir de Hudson e Jorgenson (1975). 
Tabela 2 - Matriz insumo-produto setorial

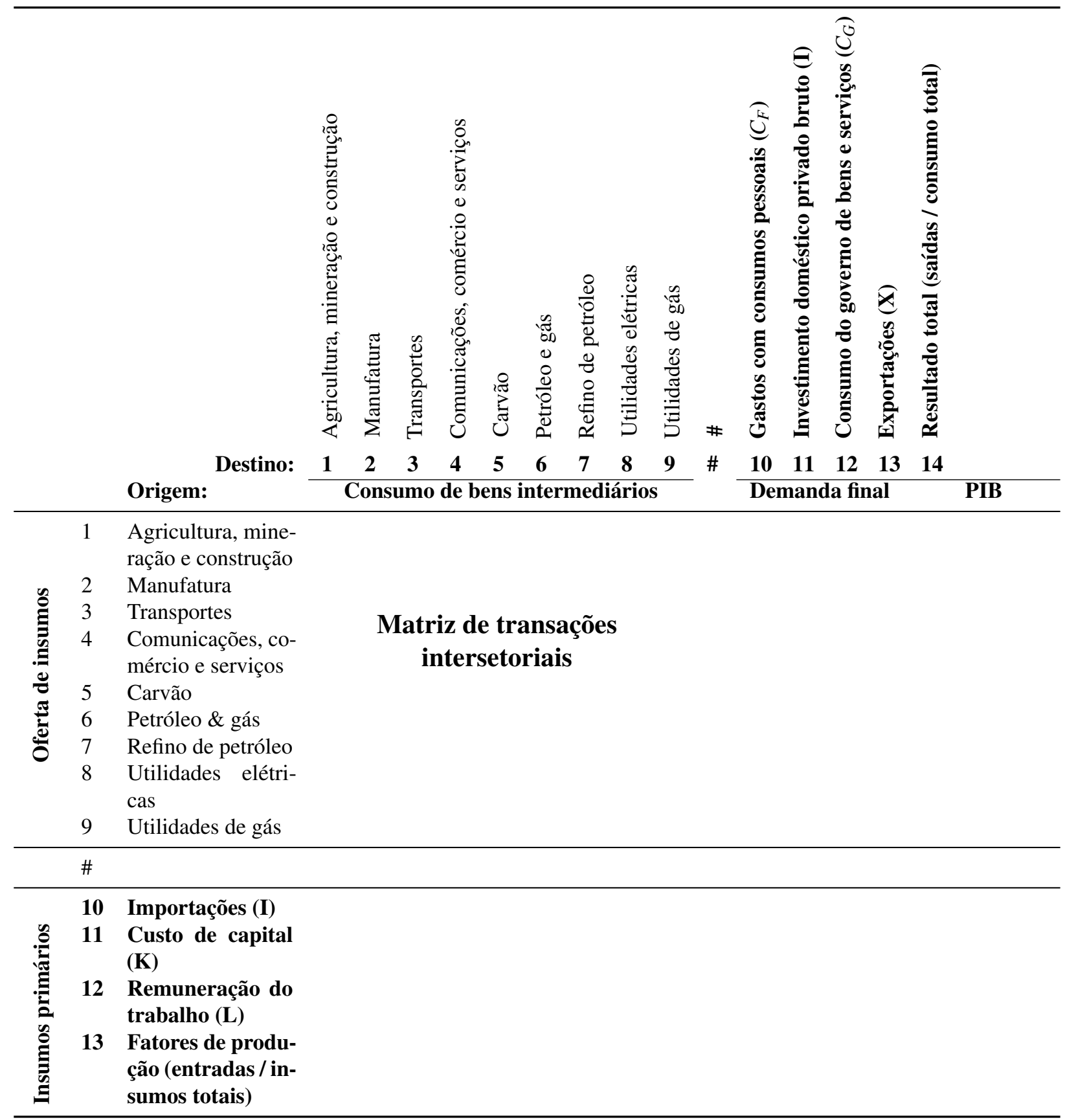

Fonte: adaptado pelo autor a partir de (HUDSON; JORGENSON, 1975)

A demanda agregada pelos produtos inclui a demanda de insumos de cada um dos nove setores incluídos no modelo (tabela 11). O resto da disponibilidade interna é alocado entre quatro categorias de demanda final: gastos pessoais de consumo, investimento privado doméstico bruto, gastos do governo e exportações.

2.1.5 Produtividade e competitividade dos fatores de produção e geração de valor

A medição dos custos e da produtividade dos fatores de produção é considerada fundamental para definir o nível de competitividade de um país no comércio internacional, especialmente 
no comércio de commodities, que, por sua natureza, excluem outros fatores tais como marca, especificações técnicas específicas, etc.

Embora crucial, a sua medição não é simples, e normalmente são utilizados artifícios tais como variáveis proxy para a sua estimação, como fica evidenciado em Messa (2014), Ellery Jr. (2014).

Os fatores de produção considerados nesse trabalho são capital (K),trabalho (L), matérias primas (M) e energia (E). A produtividade dos fatores é definida como a quantidade de produto gerada por cada fator, ambos em termos de valor monetário.

\subsubsection{Energia}

A energia é seguramente um dos principais insumos utilizados nos diferentes setores da economia. Seu preço é determinante nos custos industriais, como se demonstrará ao longo deste trabalho, afetando diretamente a competitividade da indústria de qualquer economia do mundo, como de resto atestam diversos exemplos colhidos ao longo da história econômica mundial.

Muito cedo se percebeu a importância que têm a energia dentre outros fatores por ela ser a base de funcionamento das máquinas, que permitiram a revolução industrial pioneira no Reino Unido e que continua a se renovar até os nossos dias. As antigas máquinas a vapor transformavam a energia do carvão em movimento. Este movimento era transmitido por correias e engrenagens de forma a ser aproveitado como trabalho útil, como acionar teares mecânicos ou mover hélices de barcos. A mecanização da antiga manufatura permitiu um incremento imenso na produtividade da mão-de-obra humana, que passou a trabalhar de forma menos penosa que no início da revolução industrial. A larga escala de produção permitiu um barateamento dos produtos e uma renda extra vinda do exterior para o Reino Unido por via das exportações industriais.

Do ponto de vista da literatura científica pesquisada, ela é vasta e contraditória, conforme os artigos de revisão de Payne (2010) e Ozturk (2010). Eles consideraram a possível ligação de causalidade entre crescimento do PIB e o consumo de energia. Enquanto Payne (2010) fez uma meta-análise entre os diferentes estudos, obtendo como resultado que a maioria deles apontavam para uma neutralidade ou não causalidade entre essas duas variáveis, Ozturk (2010) parte da hipótese de que há uma relação de causalidade entre as mesmas, sendo que o aumento de energia seria causa do crescimento do PIB. Porém, eles alertam para a necessidade de que se inclua na metodologia dados sobre outros fatores e que se façam testes de colinearidade e outros de forma a evitar possíveis falhas nos testes econométricos.

A literatura científica é simultaneamente vasta e contraditória, como se vê em WoldeRufael e Menyah (2010), Han, Yoo e Kwak (2004), Korsakienè, Tvaronavic̃ienè e Smaliukienè (2014), Lim e Yoo (2013), Ozturk (2010), Yang (2000), Greening, Greene e Diglio (2000), Pao e Fu (2013), Santos et al. (2013), Afgan et al. (1998), Smulders e Nooij (2003), Boyd e Pang (2000), Apergis e Payne (2010), Hu e Wang (2006), Chen, Kuo e Chen (2007), Hsiao, Wang e Hsiao (1985), Jorgenson (1984), Payne (2010), Hong e Su (2010), Cleveland, Kaufmann e 
Stern (2000). Ou mesmo Meyar-Naimi e Vaez-Zadeh (2012), Bullard, Penner e Pilati (1978), FIRJAN (2011), Shiu e Lam (2004), Sari e Soytas (2007), Lee (2006), Hudson e Jorgenson (1975), Bhagavana e Din (1980), Stern (2000), EWI (2010), Berk et al. (2006), CNI (2011), Matthes (2012). Sabe-se porém que é preciso ter como gerar a energia suficiente para mover a indústria, a preços competitivos:

Electricity prices (excluding VAT) for small and medium-sized enterprises, published by Eurostat, represent one of the most significant costs of inputs and therefore directly affect industry competitiveness. Fonte: European Comission(2013)

Ou seja, "o preço da eletricidade [...] para pequenos e médias empresas [...] representa um dos custos de insumos mais significativos e portanto afetam diretamente a competitividade"(tradução nossa).

O gŕafico 4 mostra a participação (em KTOE) dos países no consumo industrial de energia. Como se vê, o crescimento da participação da China é compatível com o crescimento da sua indústria.

Figura 4 - Participação dos principais países no consumo de energia para a indústria (em KTOE)

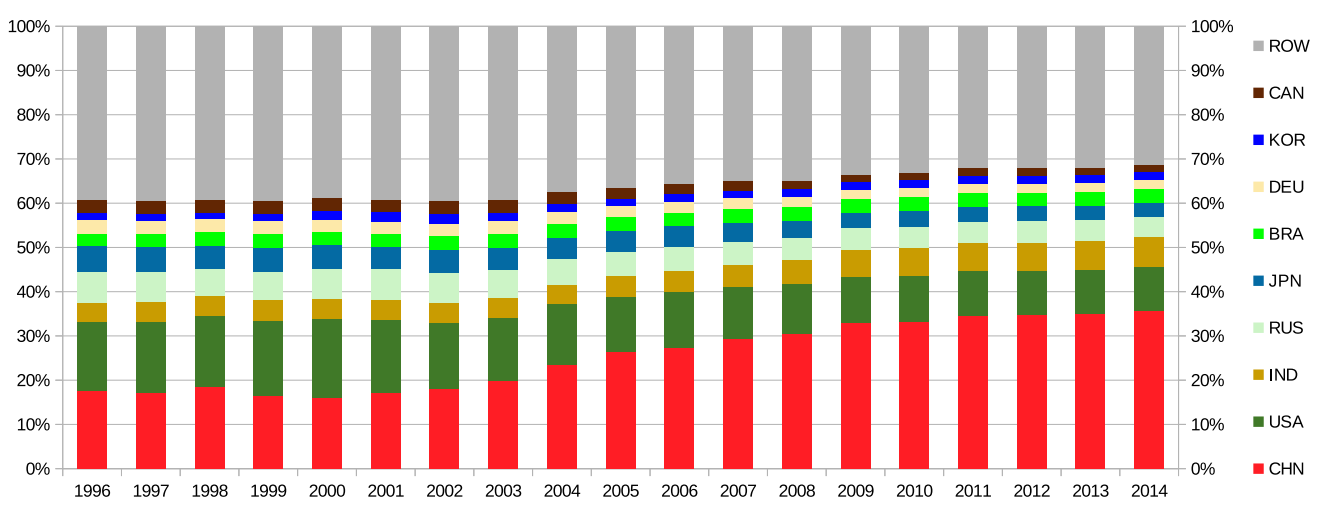

A participação da China no consumo mundial de energia (em KTOE) destinado à industria cresceu na medida do crescimento da sua produção industrial e do seu PIB. E necessário averiguar se houve aumento na eficiência do uso de energia, ou seja, se a atualização da plataforma de produção industrial foi capaz de reduzir a quantidade de energia necessária por quantidade produzida.

Fonte: elaborado pelo autor a partir da compilação de dados da IEA (2016).

A Federação das Indústrias do Estado do Rio de Janeiro (FIRJAN) fez um amplo estudo sobre o custo da energia elétrica para a indústria brasileira, chagando à conclusão que o custo da energia no Brasil é muito superior à média dos nossos principais parceiros comerciais (figura 57.

Já em 2011, a Confederação nacional da indústria (CNI) fez um relatório onde afirma textualmente que os preços da energia estavam subindo acima da inflação, e alertou para a necessidade de que a entrada em operação das novas usinas hidroelétricas entrassem em operação no cronograma planejado, o que, hoje sabemos, não ocorreu:

Entretanto, apesar da elevada base hidráulica e uma posição favorável na era do baixo carbono, a energia deixou de ser uma vantagem competitiva do setor 
Figura 5 - Gráfico com o custo médio da energia por países

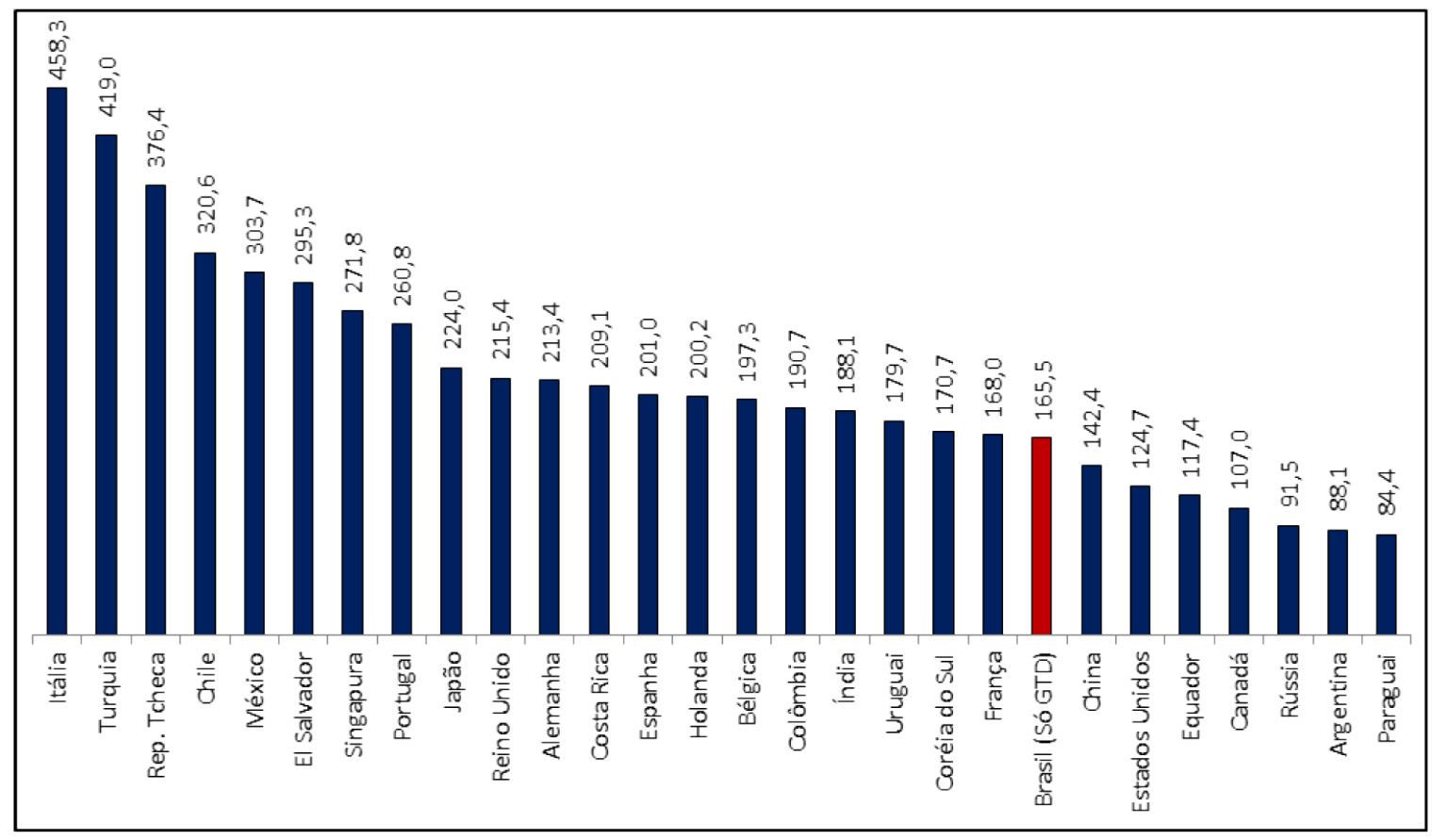

Fonte: FIRJAN (2011).

produtivo brasileiro, tornando-se um sério problema para a indústria nacional. $\mathrm{O}$ custo da energia elétrica tem crescido sistematicamente acima da inflação. Hoje, nossa tarifa de eletricidade é superior a praticada em vários países.

Embora o atendimento à demanda energética nos próximos anos esteja em níveis confortáveis, o País deve manter-se alerta para assegurar a entrada em operação das linhas de transmissão e das usinas nas datas previstas nos cronogramas de instalação. Os projetos de geração hidrelétrica vêm enfrentando entraves socioambientais nos processos de licenciamento, especialmente quando associados a reservatórios para armazenamento de água.

Fonte: (CNI, 2011).

Marconi, Rocha e Magacho (2016) fizeram uma análise input-output e calcularam os índices de multiplicação do produto de cada setor tanto nos setores à montante como dos setores mais à jusante na cadeia de produção.

Segundo von Farfan (2005):

Apesar dos investimentos em autoprodução, os eletrointensivos ainda são dependentes da energia fornecida por grandes geradoras. A indústria do alumínio, por exemplo, tem apenas $12,7 \%$ da sua produção escorada em unidades próprias de geração de energia. No segmento de fabricantes de estanho, o percentual sobe para $86,9 \%$. Já entre os produtores de zinco e níquel-cobalto a autoprodução alcança níveis de 76,3\% e 29,2\%, respectivamente.(VON FARFAN, 2005)

Em seguida, tem-se que:

O termo é usado para designar setores em que a energia elétrica tem grande peso no processo de produção, como acontece no caso do cimento, do papel, do zinco e do níquel. Segundo o Ministério de Minas e Energia, os eletrointensivos somam 408 
empresas, que absorvem $28,8 \%$ de toda a energia consumida no País. No Brasil, o consumo residencial corresponde a $22,6 \%$ do consumo total e o setor industrial representa 46,2\%. Só para se ter uma ideia do quanto a eletricidade é importante para a indústria de alumínio, a produção de uma tonelada do metal consome 14 mil $\mathrm{kWh}$, enquanto uma casa de classe média consome 70 vezes menos (cerca de 200 kWh por mês). As indústrias de ferro-gusa e aço, ferro-ligas, metais nãoferrosos, química e celulose também são classificados como eletrointensivas.(VON FARFAN, 2005)

\subsubsection{Matérias-primas - insumos}

Os insumos intermediários, tanto importados quanto produzidos localmente, são custos de produção que devem ser levados em consideração para se saber quanto cada setor que os consomem conseguem gerar de valor (em termos de renda do trabalho, impostos e lucros para os acionistas).

\subsubsection{Trabalho}

A renda do trabalho (L) é um dos componentes finais do valor agregado por um setor da atividade econômica de uma economia.

\subsubsection{Impostos}

Os tributos são outro elemento que compõe a geração de valor de uma setor econômico para uma economia. Isso permite ao governo obter uma renda que, se poupada, através de um orçamento público equilibrado, deve permitir os investimentos do Estado.

\subsubsection{Capital, investimentos e poupança}

Na equação do PIB deve-se levar em conta que existe uma alocação de capital (K), através do investimento na chamada formação bruta de capital fixo, bem como há um consumo de capital fixo devido à depreciação e obsolescência.

Sabe-se que (I)nvestimentos são iguais à poupança $(\mathrm{S})$, ou seja, só se pode investir aquilo que não se consumiu; ou seja, o que se poupou.

Os investimentos novos são fluxos positivos para o estoque de capita fixo (K), enquanto a depreciação e obsolescência geram um consumo de capital fixo que reduz o valor do estoque de capital (K).

Espera-se que países que possuem mais poupança podem investir mais na produção, através da formação bruta de capital fixo. Outra forma é receber investimentos estrangeiros diretos, ou seja, do capital externo. 
2.2 O custeio-em-sequência na modelagem de insumo-produto

Para a apuração do mapeamento entre os as entradas e saídas será utilizado um método de custeio chamado Custeio-em-sequência (CES), que por sua vez baseia-se em blocos construtivos chamados de Unidade Acumuladora de Custos (UAC), como mostra a figura 6 . Do lado esquerda temos os insumos (energia, mão de obra, matérias primas, etc), do lado esquerdo os (sub)produtos.

Figura 6 - A UAC.

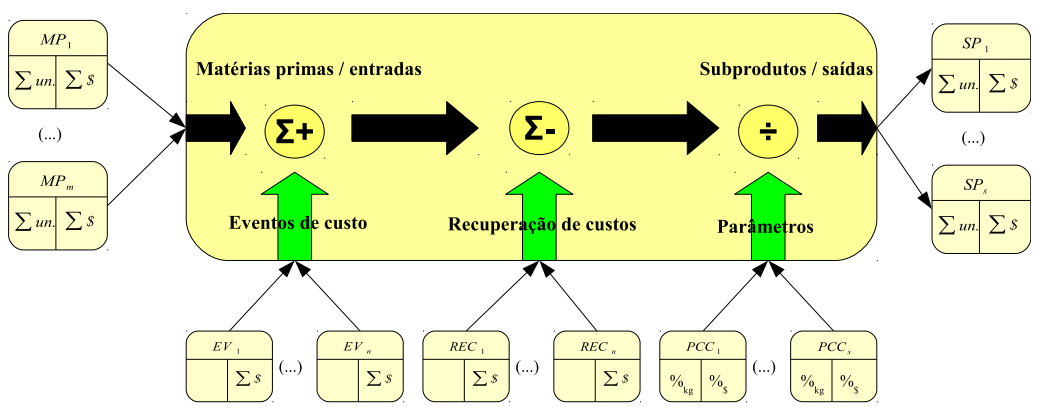

Uma das suas características fundamentais é que a equação de conservação de massas - ou a de energia, em casos especiais - deve ser respeitada. Isto é, dentro de um período $\Delta t$, a soma das massas das matérias primas e insumos $\left(\mathrm{MP}_{1} \ldots \mathrm{MP}_{m}\right)$ deve ser igual à soma das saídas $\left(\mathrm{SP}_{1} \ldots \mathrm{SP}_{s}\right)$.

Fonte: elaborado pelo autor.

Estes blocos se interligam em cada dimensão e em d dimensões que sejam necessárias, de maneira auto-similar, ou seja, fractal. Utilizando o sistema de custeio-em-sequência, tem-se que o bloco de análise, que se baseia em valor monetário e em balanço de massas, tem-se o bloco construtivo mostrado na figura 7 .

ten Raa e Mohnen (1994) fazem uma análise de eficiência e competitividade a partir dessa técnica de análise, tendo em vista as vantagens comparativas. Para cada indústria, os autores derivaram os coeficientes de insumo-produto em duas etapas. Em primeiro lugar, determinaram os coeficientes de insumo-produto para as entradas agregadas: capital (K), trabalho (L), de energia (E) e materiais (M) (vide figura 7). Em segundo lugar, determinaram os coeficientes de insumo-produto para a entrada de cada tipo de entrada de energia por unidade de entrada total de energia e a entrada de cada tipo de entrada não energético por unidade de insumo não energético total.

A figura 8 mostra que a oferta agregada é fruto da produção doméstica mais as exportações, enquanto a demanda agregada envolve o consumo e as exportações. A diferença é a poupança (= investimentos).

Nesse trabalho será utilizado um modelo estrutural, que levará em conta os fatores Trabalho, Energia, Capital e Matérias-primas. Além disso, o método de Leontief da análise insumo-produto permite que sejam calculados diversos índices e variáveis derivadas, de modo que as variações do $\mathrm{PIB}$ poderão ser devidamente equacionadas em todos os fatores relevantes. 
Figura 7 - A UAC pode ser utilizada para evidenciar o valor adicionado por cada atividade econômica classificada pelo ISIC.

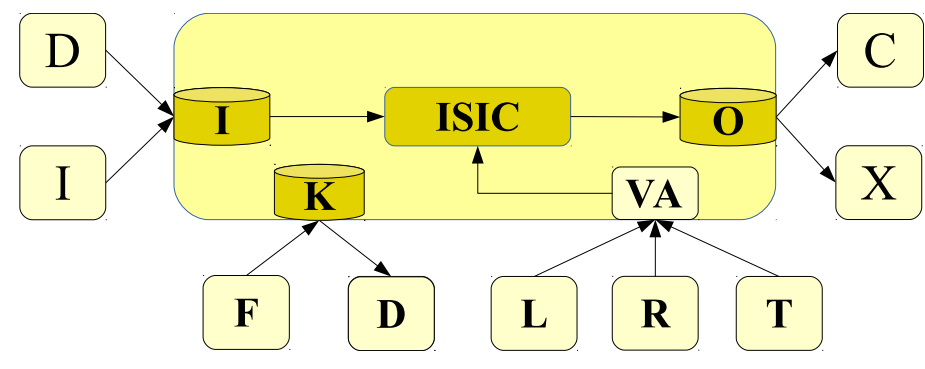

D e I são insumos comprados no mercado doméstico (D) ou importados (I). Existe um estoque de capital fixo (K) que sofre depreciação (D) e / ou é acrescentado pala chamada Formação Bruta de Capital Fixo (F). Os fatores de produção são processados pela atividade econômica (ISIC). Os produtos da atividade econômica podem ser consumidos (C) ou exportados (X). O valor agregado é formado pela remuneração do capital próprio (R), pelos salários pagos (L) e pelos impostos (T).

Fonte: elaborado pelo autor.

Figura 8 - Diagrama da economia do ponto de vista da oferta, demanda e investimentos agregados

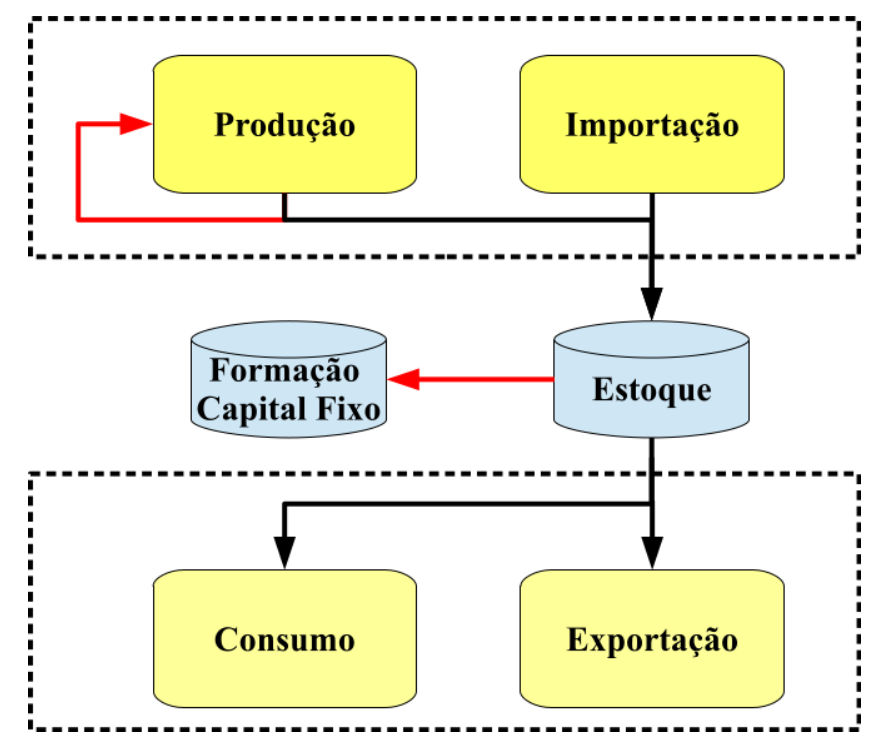

Fonte: elaborado pelo autor. 


\section{METODOLOGIA DA PESQUISA}

\subsection{Método}

Uma das formas para se tentar responder à pergunta da pesquisa, que diz respeito à comparação entre os preços e a produtividade dos fatores, que influenciam a variação do PIB. Para que essa comparação seja possível, é importante trabalhar com produtos padronizados, commodities. No caso do Brasil, especificamente, há enormes reservas de minérios que são exportados sob a forma processada ou semi-processada. Há uma indústria siderúrgica que, conforme notícias recentes, vem perdendo competitividade e, em muitos casos, estão sendo desativadas por serem eletro-intensivas e devido à escassez e consequente alto custo deste insumo.

\subsubsection{Vertentes da pesquisa}

Segundo (ABBOTT, 2004), existem três vertentes de pesquisa: sintático, semântico e pragmático (figura 9).

Essa pesquisa tem duas vertentes: numa ela é pragmática, no sentido de que busca extrair dos dados da realidade, tal como ela se apresenta. Em outra, busca extrair desses dados, devidamente modelados, informações relevantes para a compreensão dos mecanismos de geração de valor dentro de uma cadeia global de produção e consumo.

Figura 9 - Os três principais eixos que determinam os diferentes tipos de pesquisa

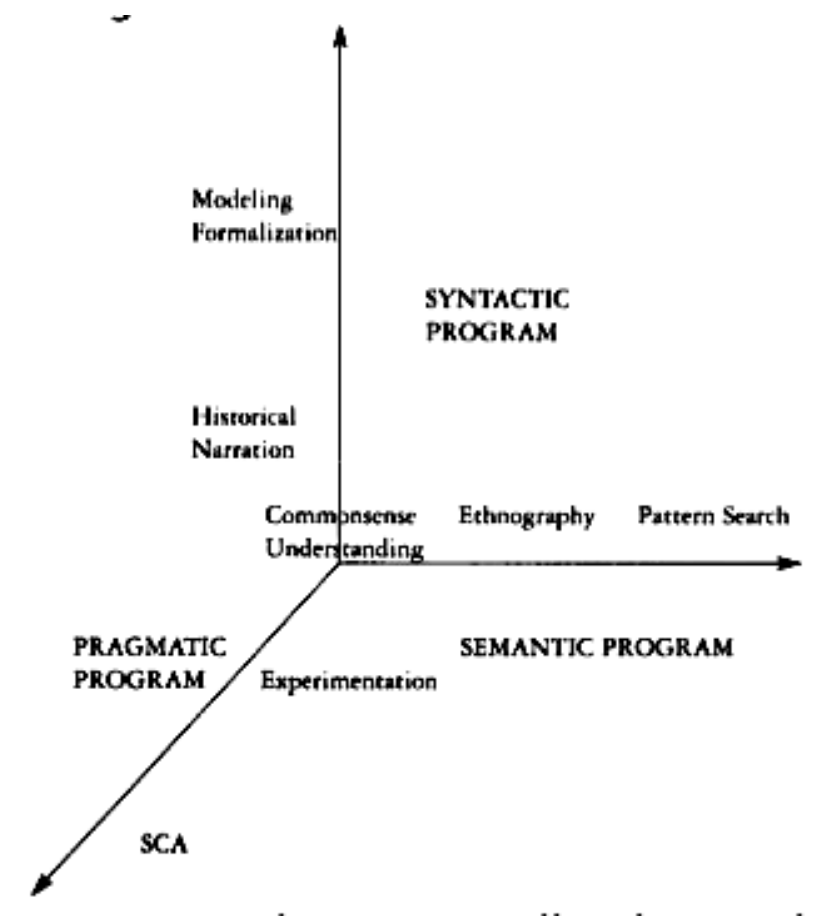

Fonte: (ABBOTT, 2004, p. 29) 
Figura 10 - Os quatro paradigmas de pesquisa segundo Burrell e Morgan (1979)

Table 1

Paradigm Differences Affecting Theory Building

\begin{tabular}{|c|c|c|c|}
\hline $\begin{array}{c}\text { Interpretivist } \\
\text { Paradlgm }\end{array}$ & $\begin{array}{l}\text { Radical } \\
\text { Eumanist } \\
\text { Paradigm }\end{array}$ & $\begin{array}{c}\text { Radlcal } \\
\text { Structuralist } \\
\text { Paradigm }\end{array}$ & $\begin{array}{l}\text { Functionalist } \\
\text { Paradigm }\end{array}$ \\
\hline $\begin{array}{l}\text { Goals } \\
\text { To DESCRIBE and } \\
\text { EXPLAIN in order to } \\
\text { DIAGNOSE and } \\
\text { UNDERSTAND }\end{array}$ & $\begin{array}{l}\text { Goals } \\
\text { To DESCRIBE and } \\
\text { CRITLUE in order to } \\
\text { CHANGE (achieve } \\
\text { freedom through } \\
\text { revision of } \\
\text { consciousness) }\end{array}$ & $\begin{array}{l}\text { Goals } \\
\text { To IDENTIFY sources of } \\
\text { domination and } \\
\text { PERSUADE in order to } \\
\text { GUIDE revolutionary } \\
\text { practices (achieve } \\
\text { freedom through } \\
\text { revision of structures) }\end{array}$ & $\begin{array}{l}\text { Goals } \\
\text { To SEARCH for } \\
\text { regularities and TEST } \\
\text { in order to PREDICT } \\
\text { and CONTROL }\end{array}$ \\
\hline $\begin{array}{l}\text { Theorotical Concerns } \\
\text { SOCIAL CON- } \\
\text { STRUCTION } \\
\text { OF REALITY } \\
\text { REIFICATION } \\
\text { PROCESS } \\
\text { INTERPRETATION }\end{array}$ & $\begin{array}{l}\text { Theoretical Concerns } \\
\text { SOCIAL CON- } \\
\text { STRUCTION } \\
\text { OF REALTY } \\
\text { DISTORTION } \\
\text { INTERESTS SERVED }\end{array}$ & $\begin{array}{l}\text { Theorstical Concerns } \\
\text { DOMINATION } \\
\text { ALIENATION } \\
\text { MACRO FORCES } \\
\text { EMANCIPATION }\end{array}$ & $\begin{array}{l}\text { Theoretical Concerns } \\
\text { RELATIONSHIPS } \\
\text { CAUSATION } \\
\text { GENERALIZATION }\end{array}$ \\
\hline $\begin{array}{l}\text { Thoory-Building } \\
\text { Approachos } \\
\text { DISCOVERY through } \\
\text { CODE ANALYSIS }\end{array}$ & $\begin{array}{l}\text { Theory-Building } \\
\text { Approaches } \\
\text { DISCLOSURE } \\
\text { through } \\
\text { CRITICAL } \\
\text { ANALYSIS }\end{array}$ & $\begin{array}{l}\text { Thoory-Building } \\
\text { Approachos } \\
\text { LIBERATION through } \\
\text { STRUCTURAL } \\
\text { ANALYSIS }\end{array}$ & $\begin{array}{l}\text { Theory-Bullding } \\
\text { Approachos } \\
\text { REFINEMENT } \\
\text { through } \\
\text { CAUSAL } \\
\text { ANALYSIS }\end{array}$ \\
\hline
\end{tabular}

Fonte: BURRELL; MORGAN, 1979).

Portanto, partindo de um contexto descritivo e pragmático, tenta-se verificar a capacidade de modelar uma cadeia global de valor através de hipergrafos, extraindo informações relevantes, o que a coloca, no seu objetivo final, dentro do paradigma sintático e semântico.

\subsubsection{Natureza da pesquisa}

Esta pesquisa é caracterizada como quantitativa, por utilizar-se de dados numéricos e processar estes dados numéricos através de um modelo computacional. É também uma pesquisa empírica, um quase-experimento pois trata-se de construir um modelo a partir de base da dados históricos.

É descritiva e interpretativa (figura 10, pois busca mostrar a evolução de diversas variáveis, em diferentes anos e países. É também explicativa, na medida em que busca determinar, através da dinâmica estrutural dos diversos países dentro de uma cadeia global de produção e consumo, o peso dos diversos fatores para a geração de valor. Trata-se de verificar se a modelagem da economia, com todos os atores de uma cadeia mundial de produção, pode permitir a determinação dos fatores que levam determinados países a terem melhor desempenho que outros ao longo do tempo. 


\subsubsection{Técnicas de pesquisa}

Serão utilizadas diversas técnicas de análise longitudinal, tais como análise multivariada em painel e análise de redes.

A análise multivariada longitudinal (no tempo e o espaço) visa identificar quais são os fatores mais relevantes para o crescimento econômico, de forma a testar a hipótese de que a disponibilidade de fontes de energia a preços mais baixos aumenta a competitividade e o valor gerado pelas indústrias eletrointensivas. Para tornar viável a comparação, serão analisados os dados de exportação do sistema harmonizado (HS) na cadeia produtiva de commodities de ferro.

A escolha dessa commodity, em especial, deve-se ao fato de que o sistema de comércio internacional, registrado pelo sistema harmonizado (HS), possui um código específico para o minério de ferro e seus derivados, de modo que a disponibilidade de dados justifica a escolha. Se tratam de produtos padronizados (commodities), cujo preço é definido o mercado competitivo internacional, e que. segundo a regra econômica, deveria ter o mesmo valor em qualquer moeda, levando-se em consideração os fretes e possíveis barreiras comerciais tarifárias. Além disso, trata-se de uma indústria madura, onde diferenças tecnológicas são menos relevantes. Por fim, os seus insumos principais também são commodities e energia, o que permite fazer comparações realmente significativas.

\subsubsection{A técnica da revisão sistemática da literatura}

A revisão sistemática de literatura é uma técnica bastante utilizada em ciências da saúde, e que tem sido utilizada nas outras ciências e que permite garantir um rigor metodológico na seleção dos artigos a serem revisados, buscando aumentar a probabilidade de que os artigos relevantes para o problema de pesquisa sejam selecionados e revisados, evitando dois possíveis erros de seleção:

- selecionar artigos inadequados ou

- deixar de selecionar artigos importantes.

Além disto, a revisão de literatura deve permitir que os leitores possam reproduzir a pesquisa bibliográfica que foi feita, chegando aos mesmos resultados reportados na pesquisa. Durante a fase de revisão da literatura, foram utilizadas diversas expressões de buscas nas seguintes bases de dados de bibliografia científica: ISI Web of Science, Scopus, EBSCOHost, Google Scholar, etc. O fluxograma da seleção dos artigos revisados é mostrada na figura 11.

Foi feita uma busca pelas palavras-chave e suas combinações nas diversas bases científicas (google acadêmico, scopus, sciencedirect, etc). Como resultado, obteve-se uma lista com milhares de artigos científicos que foram então analisados seguindo-se o fluxo mostrado na figura 11 . 
Figura 11 - Fluxogramas que representam o processo de coleta e seleção das referências bibliográficas. O primeiro processo $(1 \mathrm{a} . . .1 \mathrm{c})$ representa a busca nas bases científicas pelas palavras chave.

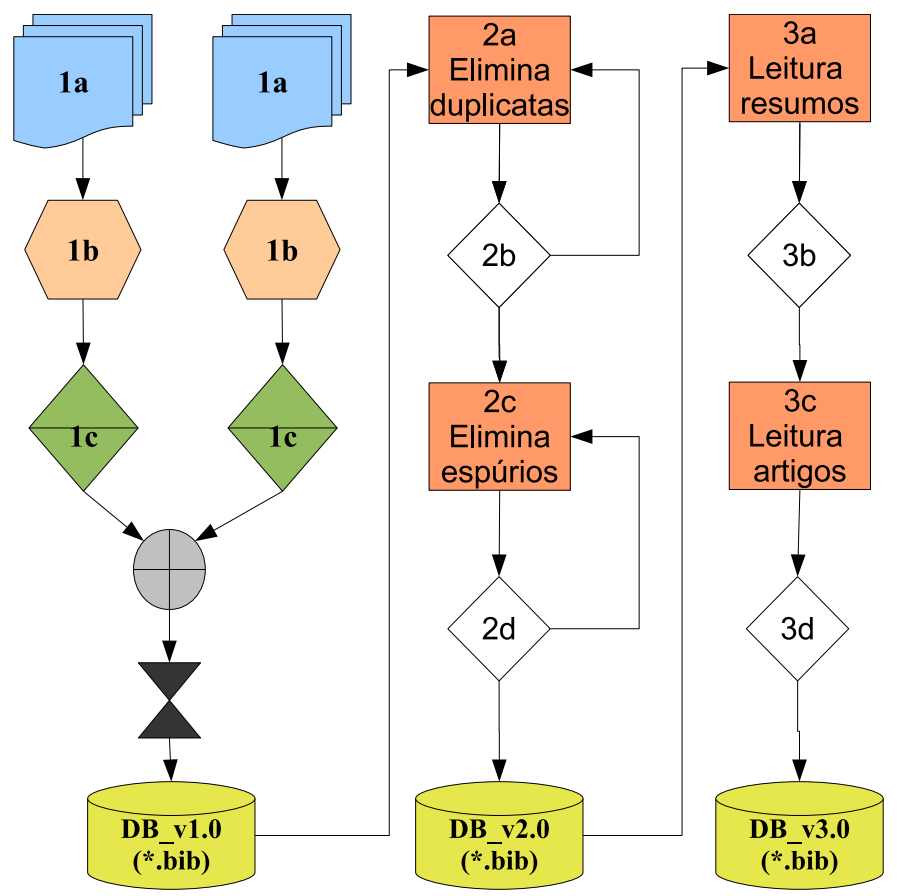

Fonte: elaborado pelo autor.

3.1.3.2 Análise de hipergrafos (redes) (network statistical analysis) da cadeia global de produção/consumo do ferro e aço e seus derivados

Uma rede é o tipo mais geral de grafo. Grafo é uma estrutura matemática que possui nós e arestas ligando esses pontos entre si. Um exemplo simples de rede é mostrado na figura 12. As arestas podem ser direcionais ou bidirecionais. Um exemplo de rede com nós geograficamente posicionados no mapa mundi é mostrado adiante na figura 36 .

Redes de computadores, genes e doenças, comércio internacional, análise de redes sociais, industriais, de inovação. A lista de aplicações é interminável e aumenta a cada dia.

Do ponto de vista da ciência da computação, grafos são estruturas de dados mais gerais, portanto, flexíveis. Através dos grafos pode-se criar quase todo outro tipo mais específico de estrutura: desde as mais simples, como listas, árvores, filas, até as mais complexas, tais como árvores, banco de dados em triplas, etc.

As estatísticas de rede que podem ser calculadas são:

- Intermediação (betweness)

- Vetor de Valores singulares da centralidade (eigenvector)

- Nível da página (pagerank)

A intermediação (betweness) é uma medida de "conectividade", do quão importante é cada nó para que outros pontos consigam sair de um e chegar ao outro passando por necessariamente 
Figura 12 - Um exemplo de grafo onde os nós são pessoas e as arestas são ligações entre essas pessoas.

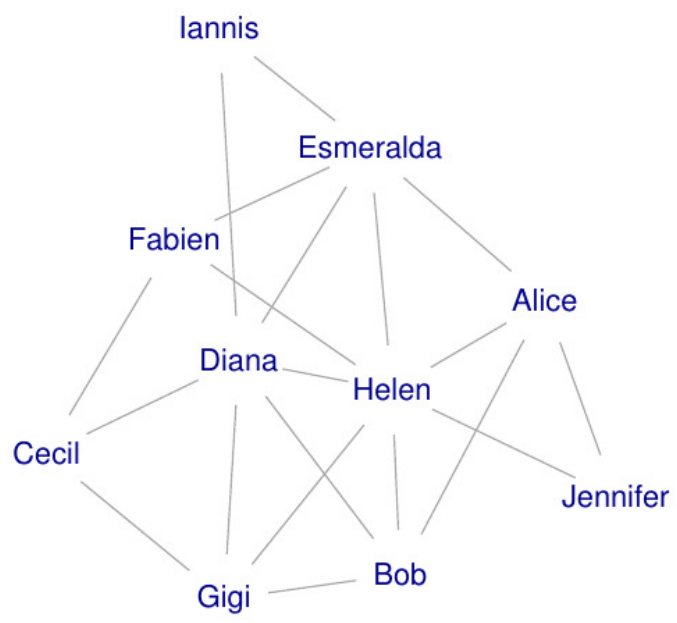

Fonte: elaborado pelo autor.

Figura 13 - A transformação de bits (pedaços de informação) em dados e depois em conhecimento.

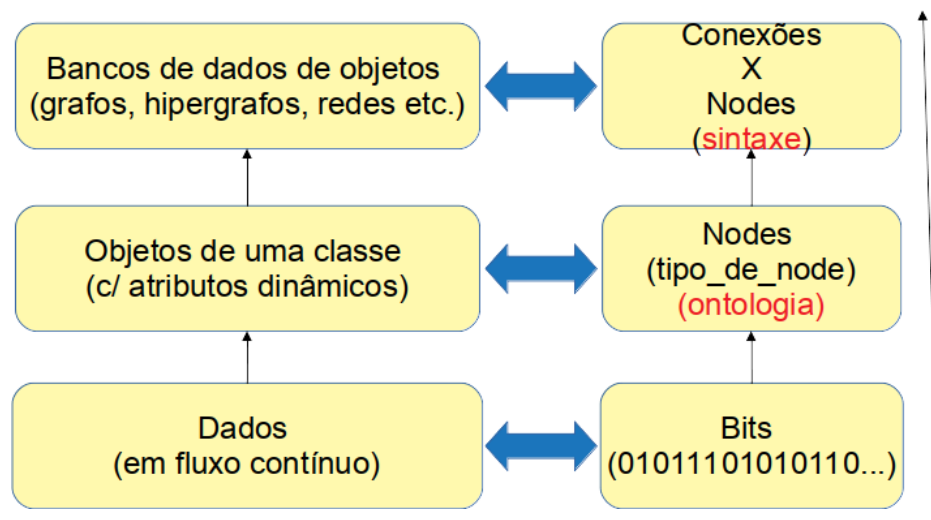

Fonte: elaborado pelo autor.

ele. Na figura 14 tem-se um exemplo de medida de intermediação.

$\mathrm{O}$ vetor de valores singulares (eigenvector) são medidas da carga fatorial, possuindo a vantagem de que o somatório das cargas fatoriais é igual a 1, possuindo, portanto, um resultado que é uma medida padronizada. Em exemplo é mostrado na figura 15 .

Matematicamente, define-se o vetor de valores singulares (eigenvector) como descrito na eq. 3.1:

$$
E_{v}=\frac{1}{\lambda} \sum_{i=1}^{V} A_{i v} E_{i} \quad, \quad A_{x}=\lambda x
$$


Figura 14 - Valores de intermediação da centralidade do grafo usado como exemplo.

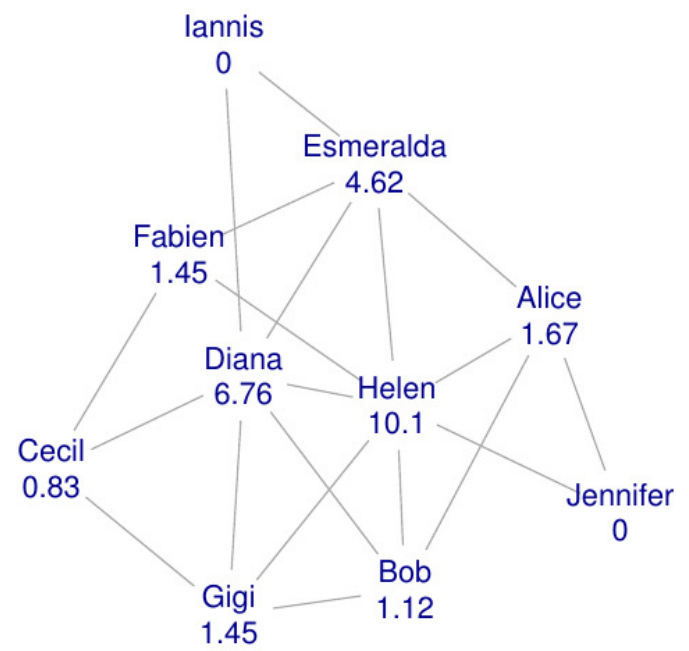

Fonte: elaborado pelo autor.

Figura 15 - Vetor de valores singulares da centralidade (eigenvector) do grafo usado como exemplo.

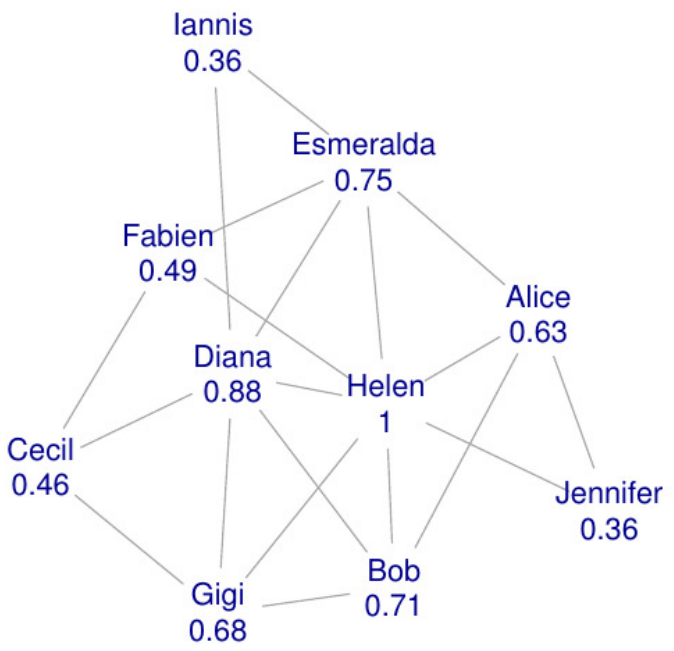

Fonte: elaborado pelo autor.

3.1.3.3 As técnicas de análise multivariada: modelagem, calibração do modelo, simulações, otimização da calibração do modelo

Dado um conjunto de equações com múltiplas variáveis, todas elas relacionando variáveis segundo um determinado modelo de comportamento teórico, o conjunto de coeficientes de cada variável (dimensão) são correspondentes ao seu peso para a variável independente. Assim, dado o modelo de Leontiev, que faz a ligação entre as variáveis independentes (que são os insumos) e os produtos (valor) gerados por cada conjunto de empresas desse setor, é possível equacionar o 
Figura 16 - Exemplo de triplas formando uma rede (grafos complexos) que permite a extração de conhecimento.

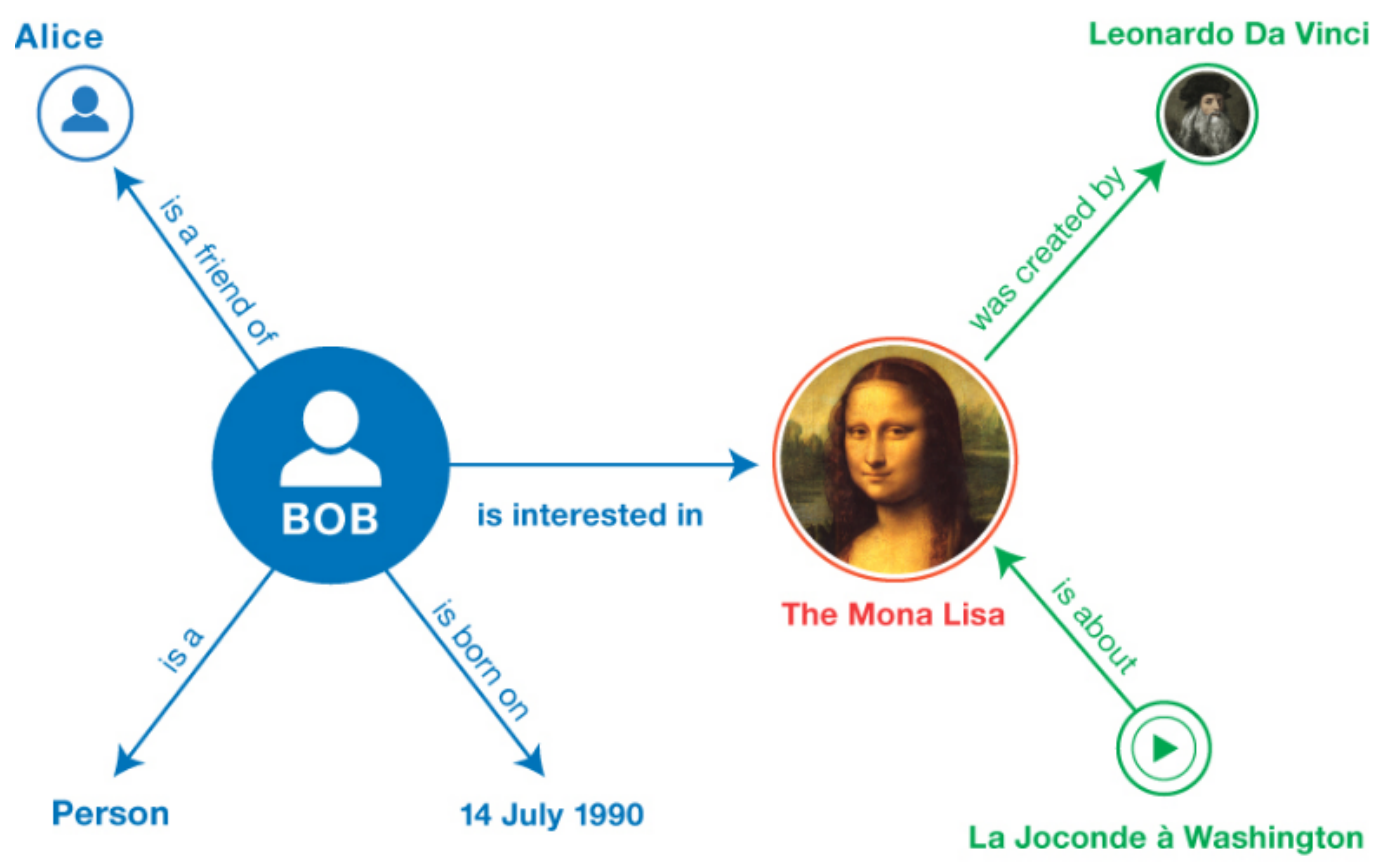

<https://www.w3.org/TR/rdf11-primer/\#section-triple>

Fonte: W3C - Consórcio Wold Wide Web.

valor gerado por cada setor pela ótica do produto, tal como foi demonstrado na seção 2.1.1.

3.2 Software e hardware utilizados para o processamento dos dados

Os dados foram coletados das diversas bases de dados discutidas na secção 3.5.1, através de consultas JSON ou através do download de arquivos delimitados (.csv). Foram armazenados num banco de dados relacional MySQL, primeiramente na forma que foram coletados, e depois normalizados e trazidos base um base única, consolidada, de variáveis atributos de objetos, tanto estáticos quanto dinâmicos.

O tratamento estatístico foi feito com o software R. Foram usados pacotes tais como igraph (algoritmos de análise de redes e grafos), glm (algoritmos generalizados de ajuste de modelos lineares), etc.

Os softwares rodaram em um cluster de máquinas de múltiplos núcleos (multicores). Foram ligados utilizado um roteador preparado para o máximo desemprenho esperado: 1000Mbps pela conexão cabeada. Um XEON de oito cores independentes, rodando o Linux Debian 9, foi utilizado como coordenador da rede. Os processos foram coordenados a partir de um programa em Python. Os outros dois computadores, um com 8 núcleos e outro dual-core, trabalharam em conjunto com o master de forma a agilizar o processamento em paralelo (multiprocessamento), 
quando possível.

Foi necessário criar programas capazes de tratar paralelamente algumas tarefas, o que está longe de ser uma tarefa trivial. Por outro lado, por mais memória de trabalho (RAM) que se tenha, a simples importação de um arquivo muito grande, delimitado por separadores, e seu posterior tratamento, requer uma rotina feita sob medida, pois está-se tratando de importar para a memória 1TB de dados, por exemplo.

Os modernos computadores possuem muita memória em disco, em alguns casos SSD, mas a memória RAM é um fator limitador importante, pois, quando muito, se tem 32GB de RAM. Isso implica adaptar as rotinas para manter na memória apenas ponteiros para indicar a localização dos dados no disco, sem ter que importa-los para a memória de trabalho (RAM).

Além disso, embora a ciência de dados (data science) tenha evoluído bastante, a obtenção e reconciliação dos dados, e sua posterior visualização, implicam ter que criar um modelo capaz de lidar com dados inexistentes ou em múltiplas unidades distintas, a escolha da melhor forma de visualização já é uma disciplina em si mesma.

Os principais programas utilizados para a obtenção e consolidação da base de dados estão em apêndices ao final desse trabalho.

\subsection{Modelagem gráfica da formação do produto pela ótica da produção}

A figura 17 mostra uma modelagem feita a partir da teoria dos grafos.

\subsection{Formulação dos pressupostos da pesquisa}

Da literatura existente é possível extrair algumas proposições, tidas como verdadeiras, de modo que seja possível comparar e evidenciar possíveis discrepâncias na dinâmica estrutural dos diferentes atores de uma cadeia global de geração de valor.

\subsubsection{Desenvolvimento das proposições}

Proposição 1 - disponibilidade de energia farta e barata aumenta a competitividade industrial.

A literatura científica é abundante e contraditória no que diz respeito a essa questão. Alguns mostram que combustíveis fósseis baratos e abundantes, como é o caso do momento atual (maio de 2016), dificultam os investimentos em energia limpa e desestimulam os esforços na busca de alternativas "limpas"ou não poluentes. Argumentam que o impulso que levou ao desenvolvimento dos carros elétricos como o fabricado pela marca Tesla, por exemplo, se deu no o período em que os preços do petróleo estavam elevados (acima de USD 100,00 o barril), deixa de existir numa conjuntura como a atual.

Independentemente disso, muitos investimentos em geração de energia se dão de forma planejada e estruturada em conjunto com as indústrias que irão consumir essa nova capacidade 
Figura 17 - Grafo do sistema de fluxos e estoques envolvidos na medição do produto pela ótica da produção
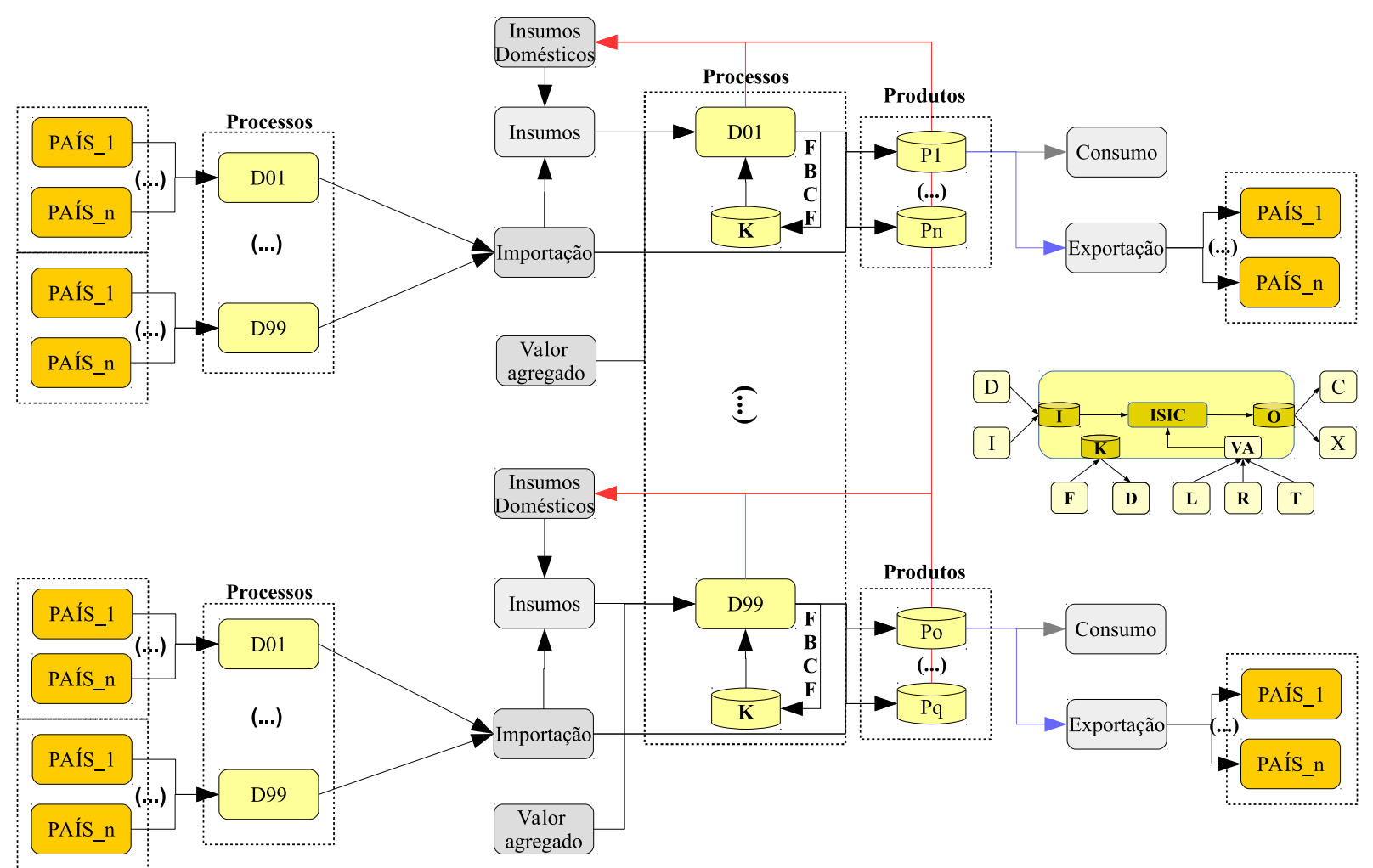

Fonte: elaborado pelo autor. Todos os direitos reservados.

de geração de energia, o que torna problemático identificar a relação de causalidade entre oferta, preço, aumento na demanda e competitividade.

Além disso, a implantação de um novo parque gerador, que leva a novas indústrias, por sua vez induz um novo incentivo à expansão, o que torna essas variáveis extremamente correlacionadas.

Entretanto, países que tem farta geração de energia, como é o caso da Alemanha, que exporta grandes quantidades de energia para o resto do continente europeu, tendem a ter uma economia industrial altamente competitiva. Do lado contrário, o Brasil, mesmo tendo grandes reservas de minérios, os exporta com baixo valor agregado.

Para testar essa proposição deve-se levar em conta as taxas de câmbio e outros fatores. Entretanto, a mesma taxa de câmbio que pode facilitar as exportações deveria, por outro lado, tornar mais caras as importações, o que deveria levar a um incentivo à industrialização das commodities no próprio país, ao invés de importar produtos de maior valor agregado. Isso pode servir para demonstrar que a taxa de câmbio não é suficiente para explicar a competitividade da indústria.

A revisão de literatura evidencia que existe uma forte relação entre a produtividade dos fatores, a competitividade e o crescimento do PIB (e.g.Berndt e Khaled (1979), Bonelli (2005), Jorgenson (1984), Stern (2000), Negri e Cavalcante (2014), Ellery Jr. (2014)). 
Através da análise em painel, de forma transversal no espaço (entre países e regiões) e no tempo, pode ser possível, usando a modelagem por insumo-produto de Leontiev (detalhada na seção 2.1.1), identificar quais são os fatores mais relevantes para a competitividade e a geração de valor com uma determinada commodity.

Proposição 2 - o aumento da produtividade da energia gera aumento na produtividade da mão de obra.

Assim como na proposição anterior, o aumento na produtividade do fator de produção energia pode ser indutor de uma maior produtividade da mão-de-obra, porque leva a uma maior automação e mecanização dos processos produtivos, o que leva, por sua vez, a uma capacidade de produção maior com menos uso da mão-de-obra humana. Dessa forma, um aumento na produtividade do fator energia pode levar a uma maior produtividade no fator mão de obra.

Proposição 3 - cada tipo de energia, dado o estágio tecnológico e a escala existente, tem custo e um riscos esperados possíveis de serem calculados.

Num mundo em que a economia não pode mais gerar gases poluentes e/ou que causem ou alimentem o aquecimento global, torna-se necessário quantificar os custos e riscos de cada tipo de energia vis a vis os seus benefícios. A contribuição esperada desse trabalho é a de mensurar os custos de tratamento dos resíduos em relação à quantidade de energia produzida e seu valor, assim como os riscos sócio-ambientais.

Proposição 4 - o principal gargalo para o desenvolvimento do Brasil é o custo da energia decorrente de sua escassez.

Se as proposições anteriores são verdadeiras, deve ser possível identificar qual(is) os fatores de produção (capital, insumos, matérias-primas, energia, trabalho) e fatores externos (taxa de câmbio, investimentos estrangeiros, poupança e investimentos, etc) que representam gargalos para o desenvolvimento econômico do Brasil, especialmente no que diz respeito ao baixo valor agregado das exportações de commodities metálicas como as derivadas do minério de ferro.

\subsection{Dados}

As principais bases de dados utilizadas nessa pesquisa estão mostradas no quadro 1 . 
Quadro 1 - Principais de bases de dados utilizadas

\begin{tabular}{|l|l|l|}
\hline COMTRADE & Bancos de dados de transações de commodities entre países & UN \\
\hline $\begin{array}{l}\text { STAN -Structural } \\
\text { Analysis }\end{array}$ & $\begin{array}{l}\text { Bancos de dados de transações segundo o modelo entrada } \\
\text { saída }\end{array}$ & OCDE \\
\hline INDSTAT & $\begin{array}{l}\text { Estatísticas de horas trabalhadas e preço da não de obra por } \\
\text { país e indústria. }\end{array}$ & UNIDO \\
\hline WBAL & $\begin{array}{l}\text { Dados de energia em fluxo desde a produção até o destino } \\
\text { (em TJ e Mtoe). }\end{array}$ & IEA \\
\hline WIOD & Modelagem de entrada saída entre países. & Noruega \\
\hline $\begin{array}{l}\text { Steel Statistical } \\
\text { Yearbook }\end{array}$ & $\begin{array}{l}\text { Dados de importação, transformação, consumo e exportação } \\
\text { de ferro e aço. }\end{array}$ & WorldSteel \\
\hline
\end{tabular}

\subsubsection{Obtenção dos dados}

\subsubsection{A base de dados COMTRADE}

Os dados do fluxo de commodities utilizados para se obter os dados dessa pesquisa foram obtidos pela base de dados UNSD (2014) produzido pela Organização das Nações Unidas (ONU), Foram os dados de exportação entre os países e algumas regiões especiais, conforme código International Standards organization (ISO) de três letras conforme mostrado no anexo 6.

\subsubsection{A base de dados STAN da OCDE}

A Organização para a Cooperação e Desenvolvimento Econômico (OCDE) disponibiliza uma análise de insumo-produto de países selecionados, o que tornou mais simples a obtenção desses dados. A base de dados STAN (Structural Analysis) da OCDE possui todas as linhas e colunas das matrizes, permitindo obter os valores que compõem oPIB em unidades monetárias, tanto nas suas próprias moedas quanto em United States dollar (USD), Até as matrizes de Leontief e a sua inversa estão disponíveis. Infelizmente, a OCDE parou de coletar dados dos outros países exceto dos seus próprios membros. A última base de dados que possui dados do Brasil é de 2011. Isso restringiu muito a análise que poderia ser feita. Em substituição, a WIOD continua realizando esse trabalho, porém o nível de agregação é muito alto, considerando todos os metais, não apenas o setor de ferro e aço. São dois os setores de interesse: o C27 - metais básicos e C28 - metais fabricados.

\subsubsection{A base de dados BTDIXE da OCDE}

Foi utilizada a base de dados de transações de comércio bilateral por indústria (classificação ISIC rev. 3 e 4) e uso final ((OECD, 2018b; OECD, 2018a) ) para mapear a cadeia mundial de geração de valor da indústria do ferro e do aço. Essa base tem 64.265.708 de registros ocupando $42,3 \mathrm{~GB}$ no formato csv. Isso forçou o uso de ferramentas capazes de normalizar essa base de 
dados sem trazê-la para a memória RAM, o que seria inviável. O procedimento está detalhado na seção B.3 dos apêndices.

\subsubsection{A base de dados WBIG do IEA}

A International Energy Agency (IEA) disponibiliza a base de dados IEA (2015), que contém dados históricos da maioria de países do mundo, com dados sobre as fontes, a produção, a distribuição e o uso da energia. Isso é relevante porque esses dados, dados em quantidades (e unidades) físicas, como TJ ou KTOE, sofrerão transformações e a geração de variáveis derivadas, tais como o cálculo do preço médio, o da eficiência, etc. $\mathrm{O}$ arquivo bruto da base de dados WBIG foi baixado pela internet e tem um tamanho de 16,5 GB e 121.189.600 registros. Isso forçou o uso de ferramentas capazes de normalizar essa base de dados sem trazê-la para a memória RAM, o que seria inviável. O procedimento está detalhado na seçãoB.2 dos apêndices.

\subsubsection{A base de dados INDSTAT}

Os custos da mão de obra, o número de horas trabalhadas por cada setor foram obtidos da base de dados INDSTAT mantida pela United Nations Industrial Developement Organization (UNIDO).

Existem duas versões dessa base INDSTAT: 2 e 4 dígitos. A base mais completa, de 2 dígitos, infelizmente não tem o detalhamento analítico necessário. A outra, por outro lado, é mais detalhada, porém os dados sobre a maioria dos países só estão disponíveis para acesso até 2007. Isso obrigou a juntar as duas bases, de forma a que uma completasse a outra. Por estar normalizada e não ser muito completa, essa base não foi muito útil. A INDSTAT consolidada (2 e 4 dígitos), possui 979031 registros.

\subsubsection{A base de dados da WorldSteel}

Os dados de produção física da indústria de ferro e do aço são coletados e organizados pela World Steel Association (WorldSteel), Os dados foram obtidos a partir da extração realizada sobre os anuários estatísticos produzidos por essa associação ((WORLDSTEEL, 2007, WORLDSTEEL, 2017)). Os dados estão resumidos nas tabelas apresentadas no apêndice B.1.

\subsubsection{Tratamento dos dados}

Para a realização desta pesquisa, foi necessária a consolidação de várias bases de dados macroeconômicos, balanços de energia, dados de exportação e preços de commodities, como se vê na seção 3.5.1, bem como sua variação ao longo do tempo, de forma a verificar o impacto das taxas câmbio, preços das commodities, balanço energético e preços das diversas formas de 
energia disponíveis sobre o crescimento econômico de cada país em relação ao conjunto. Foram realizadas diversas etapas, conforme se detalha nas seções a seguir.

\subsubsection{Classificação e seleção dos dados}

A necessidade de correlacionar as atividades econômicas, de acordo com a classificação adotada para a medição do PIB, com os produtos e serviços decorrentes dessas atividades, classificados sob outros critérios, é, em si, um desafio. Enquanto as atividades econômicas são normalmente classificadas segundo a classificação ISIC (rev. 3 e 4), os produtos e serviços são classificados de pelo menos três formas principais: sistema harmonizado (HS), SITC e CPC.

De acordo com o documento produzido pelas Nações Unidas:

173. The relationship between ISIC, on the one hand, and the product classifications HS, CPC and SITC, on the other, is based on the fact that the product classifications in principle combine in one category goods or services that are normally produced in only one industry as defined in ISIC. In HS, this origin criterion was respected as far as possible at the time of its development. In some cases - for instance, when it seemed impossible that a customs officer could make the distinction - the principle was not applied. Still, most headings and subheadings of HS contain goods that are generally produced in only one ISIC category. There are frequent exceptions in some areas, however, where outputs do not enter international trade to a large degree. For instance, raw and processed agricultural products may be combined in HS since the international trade of raw and unprocessed products is negligible. Still, raw and processed products are outputs of distinct industries in ISIC, which makes a strict link between these classifications impossible. In addition, the arrangement of headings and subheadings of HS follows criteria that are quite different from industrial origin and the structure of CPC or SITC. (UNITED NATIONS, 2008)

Esse problema é especialmente relevante para essa pesquisa porque a modelagem da cadeia de produção do aço, em conjunto com as quantidades físicas produzidas, exportadas ou importadas, implica a consolidação dos dados das atividades econômicas que os produziram (que estão num conjunto de bases de dados que usam classificações ISIC), com outros dados que estão em outras bases de dados codificados de diferentes formas (HS na COMTRADE, base de comércio internacional, p.ex.).

174. The differences between CPC, HS and SITC result from the fact that they were created for different purposes. HS is the detailed classification for international trade of transportable goods, while SITC is a more aggregated classification for analytical purposes, with the same scope as HS. The scope of CPC exceeds that of HS and SITC, in that it is intended to cover the production, trade and consumption of all goods and services. Both CPC and SITC, Rev.3, regroup HS categories, albeit in dif- ferent ways. SITC follows a traditional order in which the materials used, the stage of processing and the end-use are the main considerations. CPC arranges its categories in groups that are similar to ISIC categories. This does not mean, however, that all goods are grouped according to their industrial origin. (UNITED NATIONS, 2008) 
Figura 18 - O coeficiente de concentração de Gini.

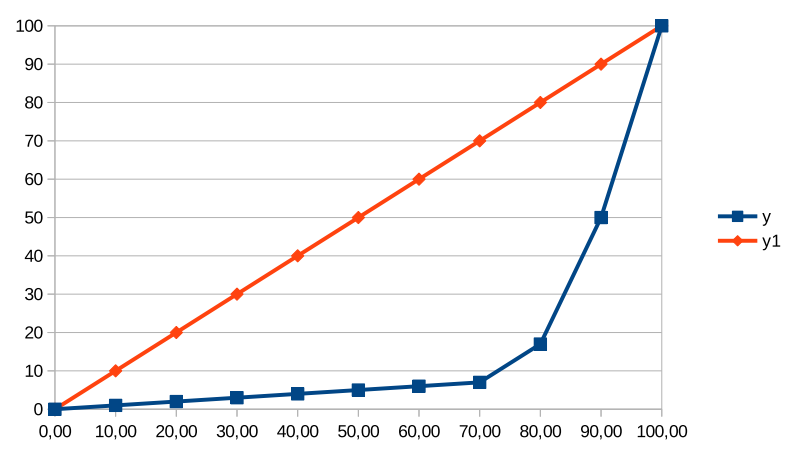

Fonte: elaborado pelo autor.

\subsubsection{Reconciliação dos dados}

É possível que duas ou mais bases de dados possuam valores distintos ou em diferentes níveis de agregação ou de grandeza. Torna-se necessário, portanto, reconciliar os dados de forma a verificar a consistência entre as diferentes fontes.

\subsubsection{Cálculo das variáveis derivadas}

Uma vez coletados, tratados e reconciliados, os dados primários são utilizados para o cálculo dos dados derivados, tais como participação na produção e consumo, classificação dos diferentes países quanto a sua posição na cadeia de geração de valor, tais como exportador de minério, produtor de aço, consumidor de aço, etc.

Além dos chamados multiplicadores, é possível identificar concentração de mercado ao longo da cadeia, bem como sua evolução no tempo, através do coeficiente Gini, que é calculado a partir da diferença entre a distribuição acumulada uniforme (equiprobabilismo) e a distribuição acumulada empírica (figura 18).

O coeficiente Gini se aproxima de 0 (zero) quando a distribuição acumulada tende à uniforme, e tende a 1 (um) quanto mais concentrados estiverem os dados.

\subsubsection{Padronização das variáveis}

As diferentes variáveis, tanto os dados brutos como os secundários, precisam estar organizados e padronizados de forma a evitar possíveis erros, bem como para possibilitar a extração de informações relevantes para os objetivos da pesquisa.

\subsubsection{Estatísticas descritivas das variáveis}

A base de dados, uma vez produzida, é utilizada para produzir um visão da dinâmica dos diferentes países na cadeia global de geração de valor do ferro e do aço. 


\subsubsection{Escolha da estratégia para visualização}

A escolha da forma de exibir os resultados é uma disciplina à parte. Um gráfico, feito de uma maneira, a partir dos mesmos dados, permite perceber determinados fatos relevantes que de outra maneira passariam desapercebidos. 


\section{RESULTADOS E DISCUSSÃO}

\subsection{A indústria do ferro / aço}

\subsubsection{O processo de produção do aço}

Figura 19 - O processo do aço da Arcelor Mittal - Tubarão/RS

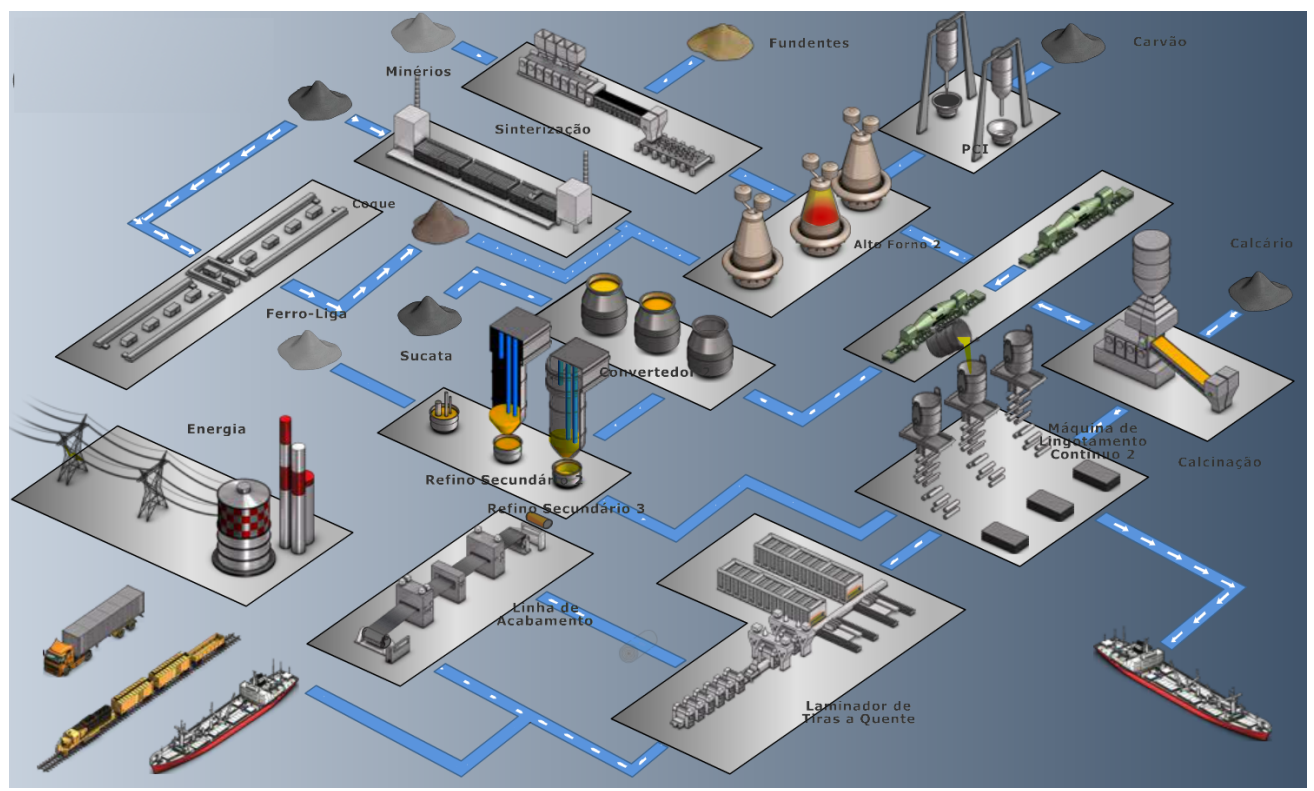

Fonte: Arcelor Mittal ().

A figura 19 mostra a cadeia de produção do ferro/aço da siderúrgica de Tubarão, no Rio Grande do Sul. A indústria do ferro/aço será utilizada nessa pesquisa porque a base de dados da COMTRADE, de comércio internacional de commodities, é a mais completa série de dados que utiliza o sistema harmonizado (HS), e o minério de ferro e seus derivados semi-processados e processados possuem códigos bem mais completos que a mesma base que usa outros sistemas de classificação. Outra vantagem do uso dessa commodity reside no fato de que seu preço é definido no mercado competitivo internacional, de forma que se torna mais simples a comparação da competitividade dos fatores de produção entre os diversos países.

Portanto, o uso de uma mercadoria com características padronizadas (commodity), com preço definido dia-a-dia pelo mercado internacional e cujos dados de comércio estão devidamente registrados nas bases de dados por um período bastante longo de tempo, isso é uma vantagem ao eliminar uma série de variáveis que poderiam distorcer os resultados.

A economia busca, dentre outras coisas, identificar os fatores que levam um país à geração de riqueza e consequente aumento da renda das famílias; em outras palavras, ao desenvolvimento econômico e à prosperidade (e.g. Vasconcelos (2014), Besanko et al. (2013)).Do ponto de vista macroeconômico, diversos pensadores se debruçaram sobre as vantagens comparativas, curva de produção e custo e produtividade dos fatores de produção (capital, trabalho, matérias-primas e 
energia). A estratégia competitiva internacional é o tópico que se apresenta como mais relevante para obter as respostas à pergunta formulada e que se busca responder com essa pesquisa.

4.1.2 Análise dinâmica da produção de minério de ferro

A tabela 3 mostra a produção de minério de ferro por regiões blocos econômicos.

Tabela 3 - Produção de minério de ferro entre 1997 e 2016 (1000t)

\begin{tabular}{rrrrrrrrrrr}
\hline Ano & $\begin{array}{l}\text { Europe } \\
\text { (other) }\end{array}$ & EU(28) & $\begin{array}{l}\text { Middle } \\
\text { East }\end{array}$ & Africa & N.Am. & C.I.S. & Asia & S.Am. & Oceania & World \\
\hline 1997 & 6.479 & 24.308 & 7.020 & 50.276 & 111.710 & 137.381 & 198.671 & 220.485 & 167.478 & $\mathbf{9 2 4 . 3 8 6}$ \\
1998 & 5.828 & 23.785 & 12.320 & 49.396 & 112.150 & 132.749 & 190.582 & 214.290 & 165.424 & $\mathbf{9 0 6 . 5 7 6}$ \\
1999 & 5.883 & 21.678 & 12.420 & 44.599 & 103.290 & 138.599 & 184.432 & 218.300 & 155.303 & $\mathbf{8 8 4 . 5 6 5}$ \\
2000 & 6.004 & 23.340 & 12.390 & 49.209 & 110.346 & 157.502 & 182.762 & 239.030 & 178.992 & $\mathbf{9 5 9 . 6 5 0}$ \\
2001 & 5.738 & 22.183 & 10.333 & 49.795 & 82.493 & 151.994 & 184.262 & 242.416 & 182.776 & $\mathbf{9 3 2 . 0 4 6}$ \\
2002 & 5.391 & 22.969 & 10.529 & 51.821 & 92.344 & 158.725 & 197.244 & 258.021 & 188.950 & $\mathbf{9 8 6 . 0 2 1}$ \\
2003 & 4.682 & 24.354 & 11.385 & 53.302 & 93.067 & 171.165 & 223.980 & 278.198 & 213.944 & $\mathbf{1 . 0 7 4 . 0 7 8}$ \\
2004 & 5.243 & 24.863 & 12.746 & 54.322 & 94.779 & 181.246 & 268.850 & 305.387 & 236.997 & $\mathbf{1 . 1 8 4 . 4 3 3}$ \\
2005 & 8.032 & 25.923 & 14.828 & 55.326 & 96.112 & 181.839 & 349.544 & 329.058 & 259.775 & $\mathbf{1 . 3 2 0 . 4 3 8}$ \\
2006 & 8.430 & 26.118 & 18.134 & 57.098 & 97.711 & 195.428 & 445.044 & 357.132 & 277.341 & $\mathbf{1 . 4 8 2 . 4 3 6}$ \\
2007 & 6.758 & 27.629 & 22.000 & 56.393 & 97.502 & 201.290 & 619.518 & 373.647 & 300.698 & $\mathbf{1 . 7 0 5 . 4 3 4}$ \\
2008 & 7.497 & 26.543 & 32.000 & 63.264 & 98.674 & 188.402 & 565.118 & 384.219 & 351.842 & $\mathbf{1 . 7 1 7 . 5 5 9}$ \\
2009 & 6.855 & 20.046 & 33.000 & 70.060 & 71.350 & 175.662 & 481.490 & 335.999 & 396.161 & $\mathbf{1 . 5 9 0 . 6 2 2}$ \\
2010 & 9.854 & 27.751 & 35.549 & 69.059 & 101.399 & 196.208 & 592.849 & 405.959 & 435.218 & $\mathbf{1 . 8 7 3 . 8 4 7}$ \\
2011 & 10.250 & 28.701 & 38.260 & 69.976 & 104.606 & 202.845 & 587.659 & 435.640 & 479.689 & $\mathbf{1 . 9 5 7 . 6 2 7}$ \\
2012 & 11.937 & 29.188 & 43.497 & 86.087 & 108.317 & 201.099 & 481.905 & 420.008 & 522.427 & $\mathbf{1 . 9 0 4 . 4 6 5}$ \\
2013 & 14.032 & 30.018 & 48.693 & 96.453 & 112.681 & 205.711 & 500.476 & 418.840 & 612.057 & $\mathbf{2 . 0 3 8 . 9 6 2}$ \\
2014 & 12.874 & 31.000 & 48.451 & 109.265 & 115.744 & 199.518 & 361.766 & 426.481 & 748.980 & $\mathbf{2 . 0 5 4 . 0 7 8}$ \\
2015 & 11.400 & 27.450 & 39.370 & 82.343 & 103.495 & 195.298 & 278.371 & 454.216 & 814.403 & $\mathbf{2 . 0 0 6 . 3 4 6}$ \\
2016 & 9.700 & 29.400 & 40.100 & 87.400 & 100.700 & 189.038 & 320.200 & 471.700 & 843.900 & $\mathbf{2 . 0 9 2 . 1 3 8}$ \\
\hline
\end{tabular}

Fonte: Produzido pelo autor pela compilação de dados da WorldSteel (2007).

A produção mundial saiu de 924Mt de minério de ferro em 1997 para 2092 Mt em 2016.

Ou seja, mais que dobrou. Entretanto, como se verá mais adiante, a produção de aço bruto cresceu principalmente na China, que tomou mercado de todos os outros países do mundo. 
O gráfico 20 evidencia que a produção mundial de minério de ferro mais que dobrou entre os anos de 1997 e 2016, sendo que o grande crescimento se deu na Austrália.

Figura 20 - Produção mundial de minério de ferro entre 1996 e 2016 (em 1000t)

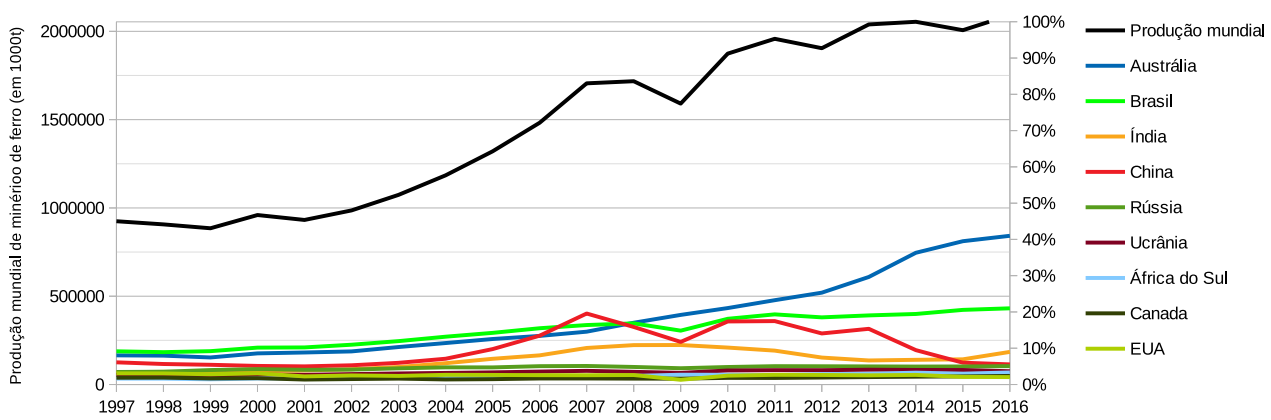

Fonte: elaborado pelo autor pela compilação de dados da WorldSteel (2007), WorldSteel (2017).

O que se percebe é que a China aumentou sua produção de minério de ferro de 1997 até 2007. A partir de 2007 a China parece ter abandonado a mineração de ferro e se concentrou em importar minério de ferro de outros países, principalmente da Austrália.

O gráfico 21 evidencia que a Austrália,Brasil e Índia são responsáveis pela produção de cerca de $70 \%$ do minério de ferro do mundo.

Figura 21 - Participação na produção mundial de minério de ferro entre 1996 e 2016

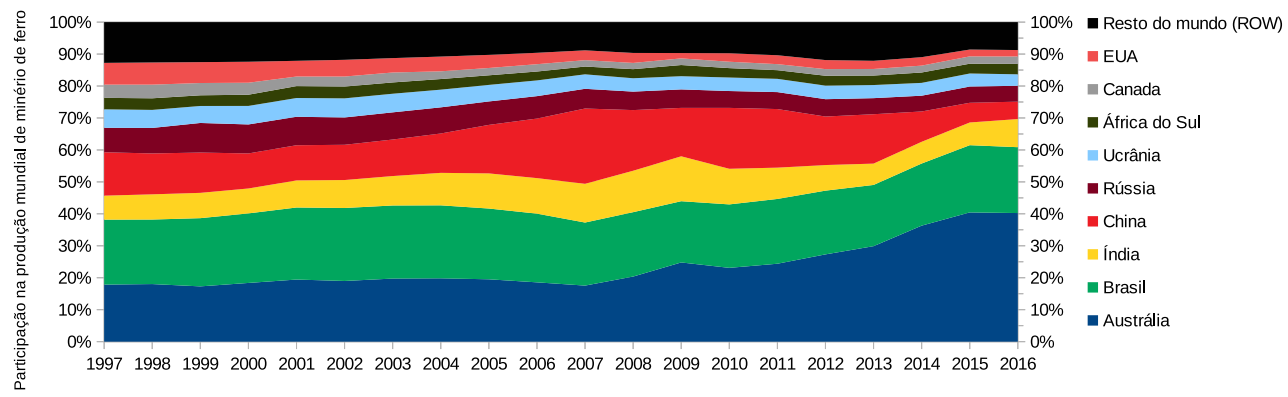

Fonte: elaborado pelo autor pela compilação de dados da WorldSteel (2007), WorldSteel (2017).

A partir de 2007 houve uma queda na participação da China e da Rússia na participação na produção de minério de ferro. 


\subsubsection{A exportação de minério de ferro}

A exportação do minério de ferro é concentrada na Austrália e no Brasil, como se poder ver nos gráficos $22 \mathrm{e} 23$.

Figura 22 - Exportação mundial de minério de ferro entre 1996 e 2016 (1000t)

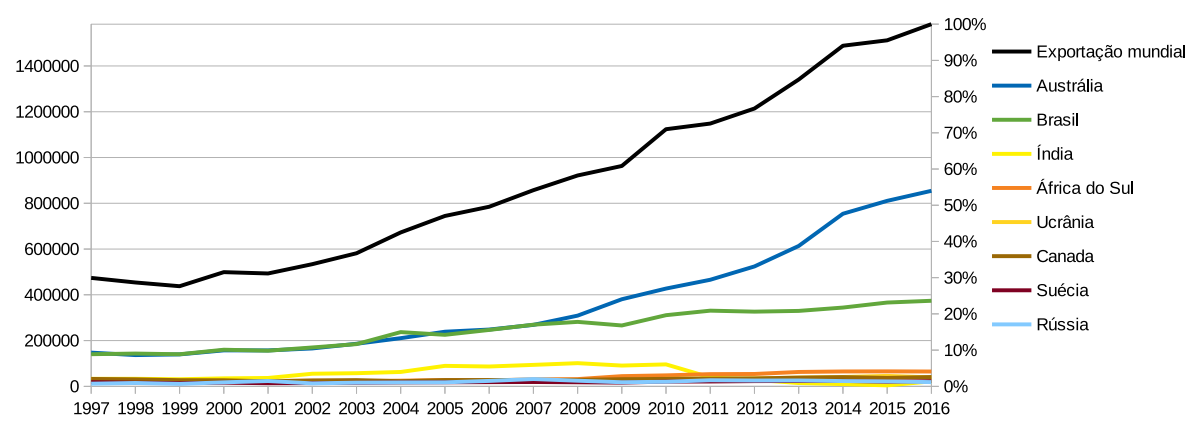

Fonte: elaborado pelo autor pela compilação de dados da WorldSteel (2007), WorldSteel (2017).

Como se vê no gráfico 23, Austrália, Brasil e Índia representam $80 \%$ das exportações mundiais de minério de ferro.

Figura 23 - Participação na exportação mundial de minério de ferro entre 1996 e 2016

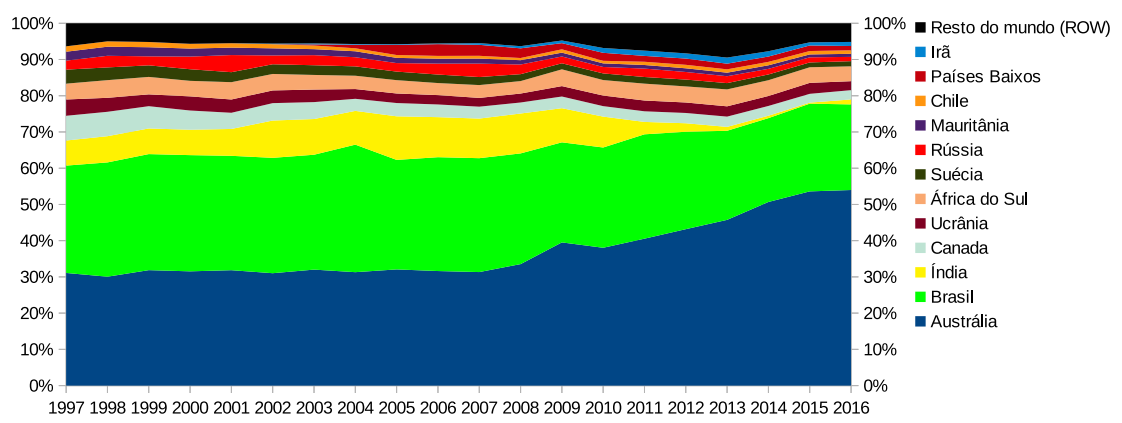

Fonte: elaborado pelo autor pela compilação de dados da WorldSteel (2007), WorldSteel (2017). 


\subsubsection{A importação de minério de ferro}

A importação do minério de ferro foi se concentrando cada vez mais na China, como se poder ver nos gráficos $24 \mathrm{e} 25$.

Figura 24 - Importação mundial de minério de ferro entre 1996 e 2016 (1000t)

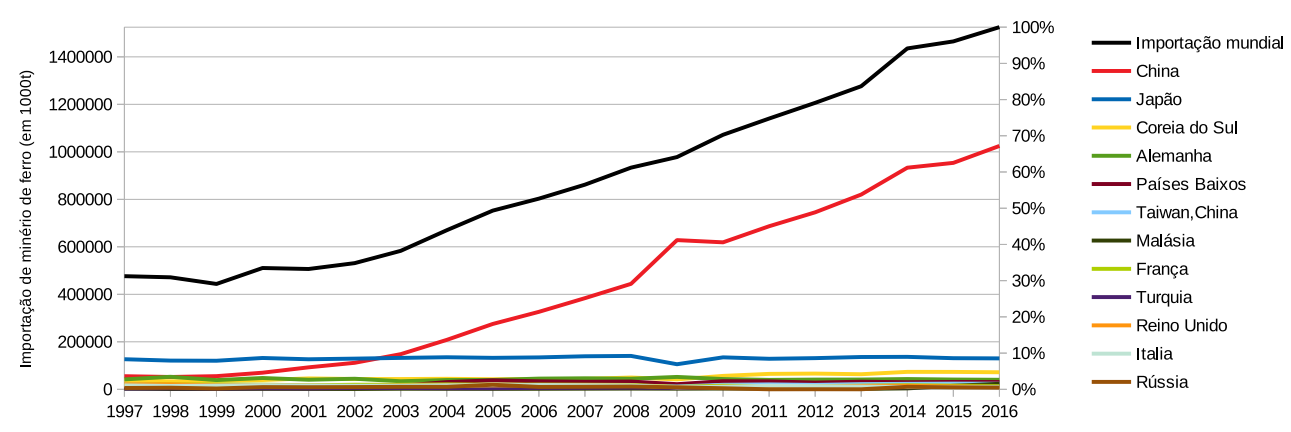

Fonte: elaborado pelo autor pela compilação de dados da WorldSteel (2007), WorldSteel (2017).

A participação no total as importações de minério de ferro foi sendo cada vez mais concentrada na China, Japão e Coreia do Sul, que representam juntas 80\% das importações de minério de ferro do mundo, como se poder ver no gráfico 23.

Figura 25 - Participação na importação mundial de minério de ferro entre 1996 e 2016

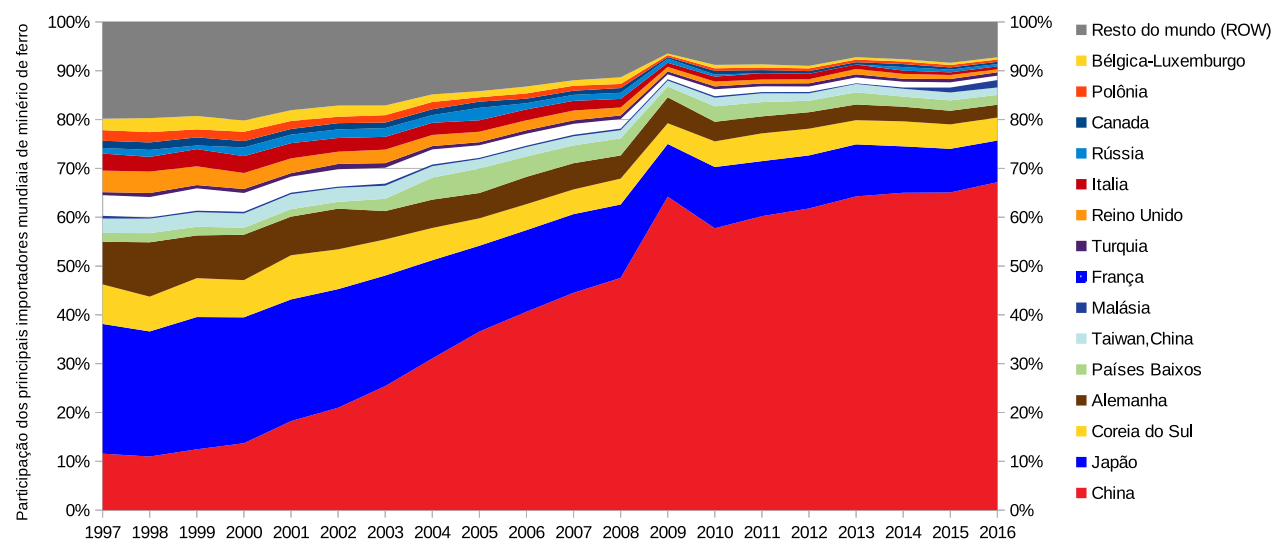

Fonte: elaborado pelo autor pela compilação de dados da WorldSteel $\sqrt{2007), \text { WorldSteel }}(2017)$. 


\subsubsection{A produção de aço bruto}

Uma análise dos dados da tabela 20 mostra que a China aumentou a sua participação na produção da aço bruto mundial de 10\% em 1996 para 50\% em 2016.

\subsubsection{Análise da dinâmica da produção de aço bruto por regiões, continentes, blocos, etc}

Figura 26 - Participação dos países, blocos e regiões na produção mundial de aço bruto entre 1996 e 2016

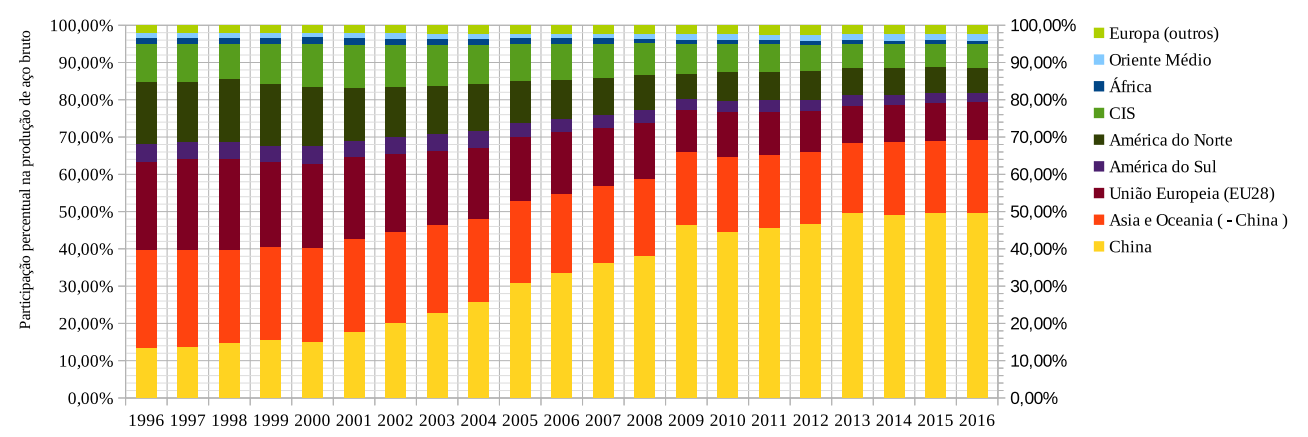

Fonte: elaborado pelo autor pela compilação de dados da WorldSteel 2007, WorldSteel 2017).

Como se vê nos gráficos 26 e 27, mesmo com a queda da produção mundial havida em 2010, mesmo assim a China manteve seus níveis de produção de aço bruto e sua participação relativa na produção de aço bruto.

Figura 27 - Gráfico da produção mundial de aço bruto por países, blocos e regiões entre 1996 e 2016

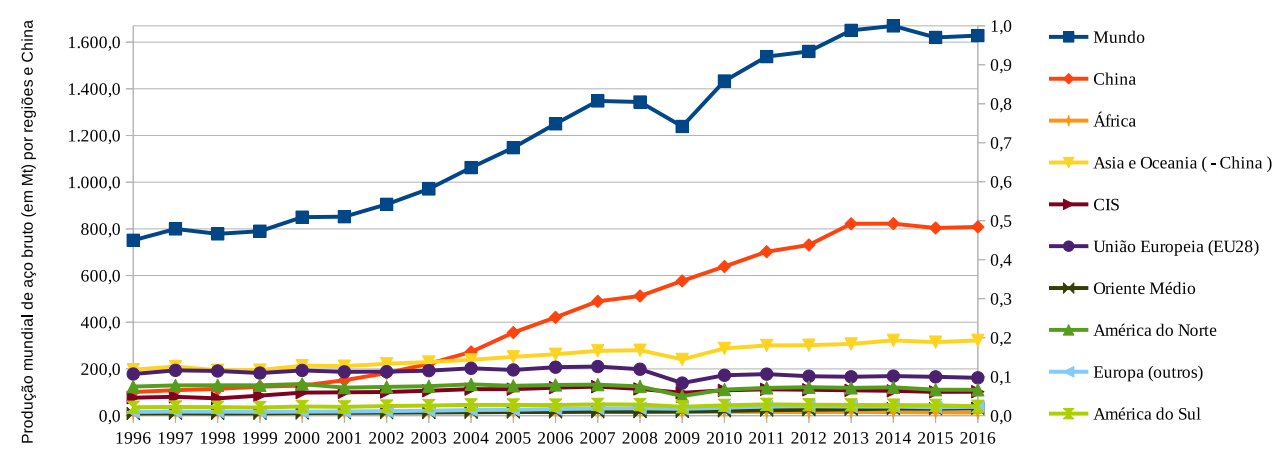

Fonte: elaborado pelo autor pela compilação de dados da WorldSteel (2007), WorldSteel (2017). 


\subsubsection{Análise da dinâmica da produção de aço bruto por países}

Como se vê nos gráficos $29 \mathrm{e} 28$, mesmo com a queda da produção mundial havida em 2010, mesmo assim a China manteve seus níveis de produção de aço bruto e sua participação relativa na produção de aço bruto até aumentou.

Figura 28 - Gráfico da produção mundial de aço bruto por países entre 1996 e 2016 (em 100t)

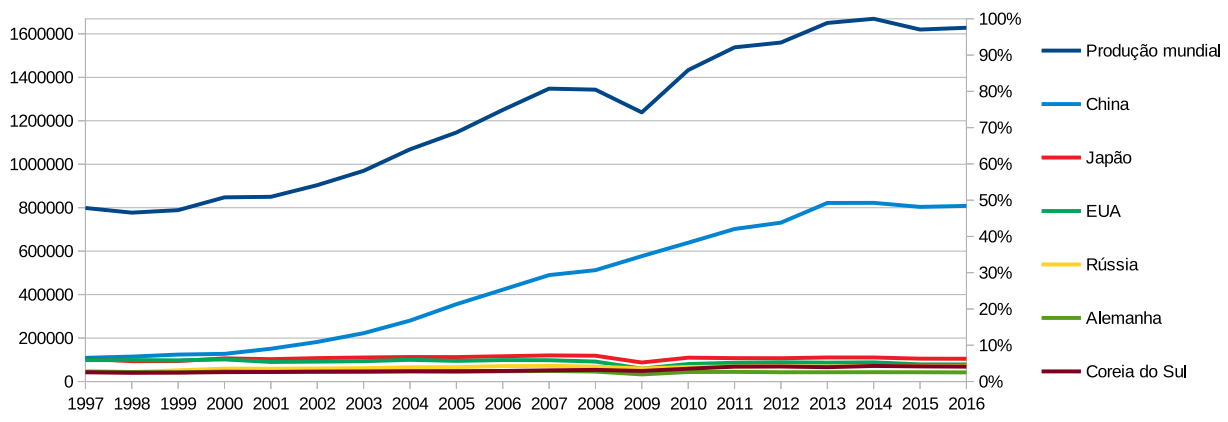

Fonte: elaborado pelo autor pela compilação de dados da WorldSteel (2007), WorldSteel (2017).

Figura 29 - Participação dos países na produção mundial de aço bruto entre 1996 e 2016

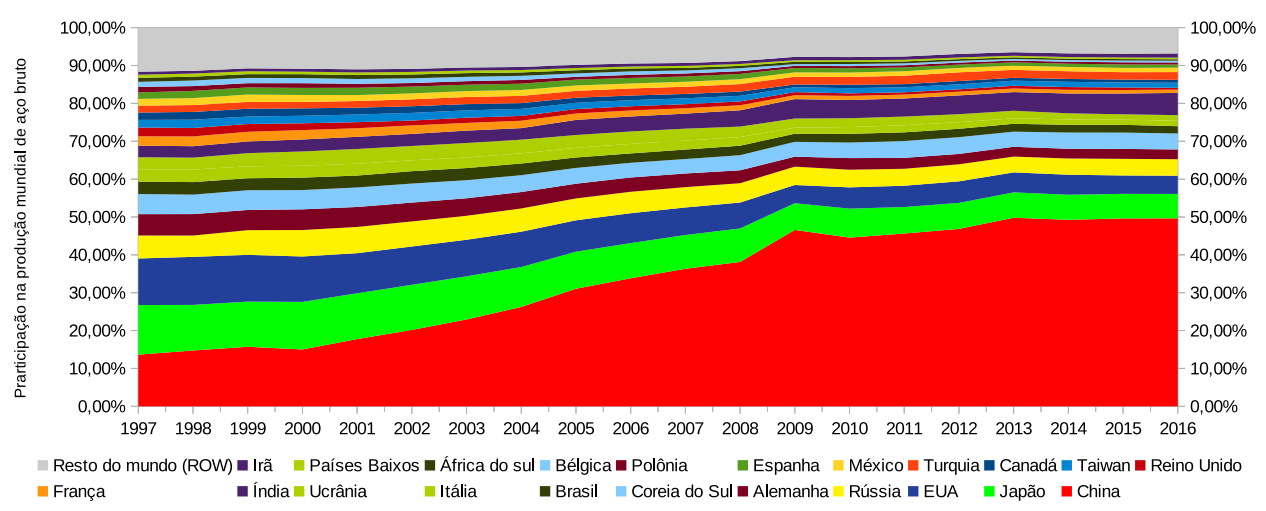

Fonte: elaborado pelo autor pela compilação de dados da WorldSteel (2007), WorldSteel (2017). 


\subsubsection{A dinâmica do consumo do aço bruto}

O gráfico evidencia os efeitos globais da crise de 2008. Do ponto de vista do consumo global, o mundo já vinha reduzindo o ritmo de crescimento do consumo entre 2007-2008, mas a queda no consumo aparente de aço bruto aconteceu em 2008-2009, retomando o crescimento de 2009 a 2014, quando volta a oscilar para baixo. Do ponto de vista da China, houve uma redução no seu consumo aparente de aço bruto somente após 2013.

Figura 30 - Gráfico do consumo aparente de aço bruto por países entre 1996 e 2016 (em 1000t)

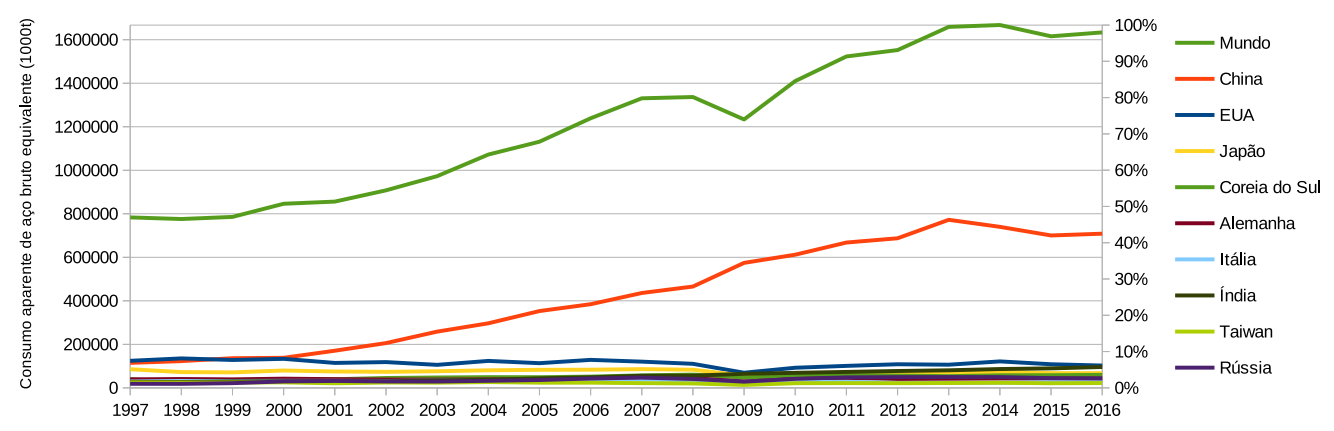

Fonte: elaborado pelo autor pela compilação de dados da WorldSteel (2007), WorldSteel (2017).

Como se vê no gráfico 30 , mesmo com a queda da produção e do consumo mundial de aço bruto, havida após 2010, e da queda do consumo aparente da China a partir de 2013, medido em aço bruto equivalente, ainda assim a China manteve sua participação relativa do consumo aparente global de aço bruto, que até aumentou durante e após a crise de 2008.

Figura 31 - Participação dos países no consumo de aço bruto entre 1996 e 2016

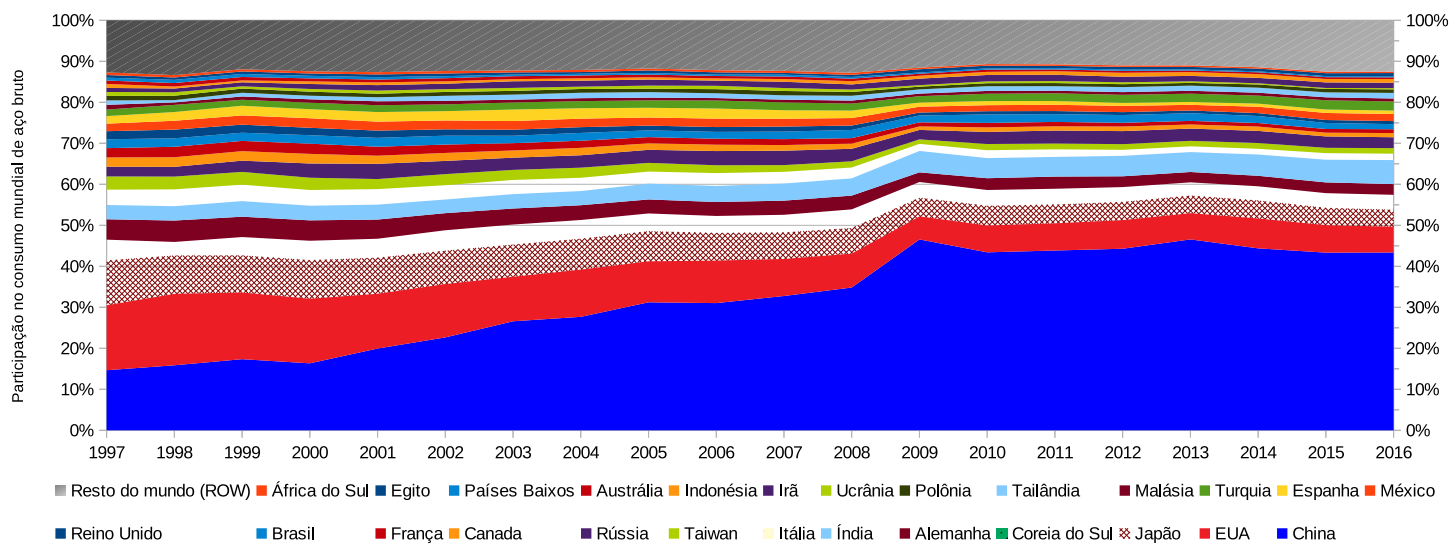

Fonte: elaborado pelo autor pela compilação de dados da WorldSteel (2007), WorldSteel (2017). 


\subsubsection{A dinâmica da exportação de produtos (semi-)acabados aço bruto}

A exportação de produtos (semi-)acabados de aço também manteve uma dinâmica de concentração em um conjunto de países. Mais uma vez a China se destaca, como mostra o gráfico 32. O gráfico da participação dos principais exportadores de produtos (semi-)acabados

Figura 32 - Gráfico da exportação de produtos (semi-)acabados de aço por países entre 1996 e 2016 (em 1000t)

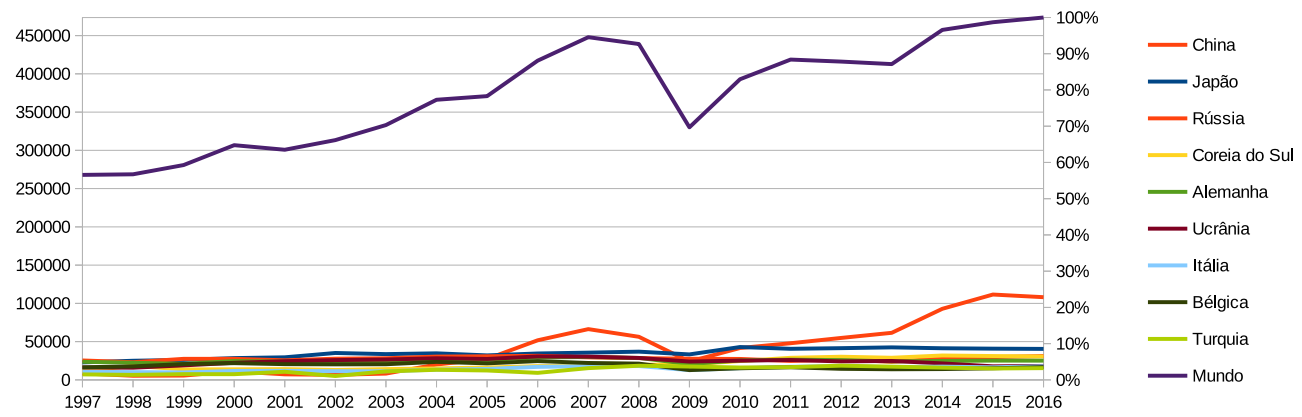

Fonte: elaborado pelo autor pela compilação de dados da WorldSteel (2007), WorldSteel (2017).

de aço (gráfico 33) mostra de forma ainda mais eloquente a concentração havida. Os cinco

Figura 33 - Gráfico da participação na exportação de produtos (semi-)acabados de aço entre 1996 e 2016

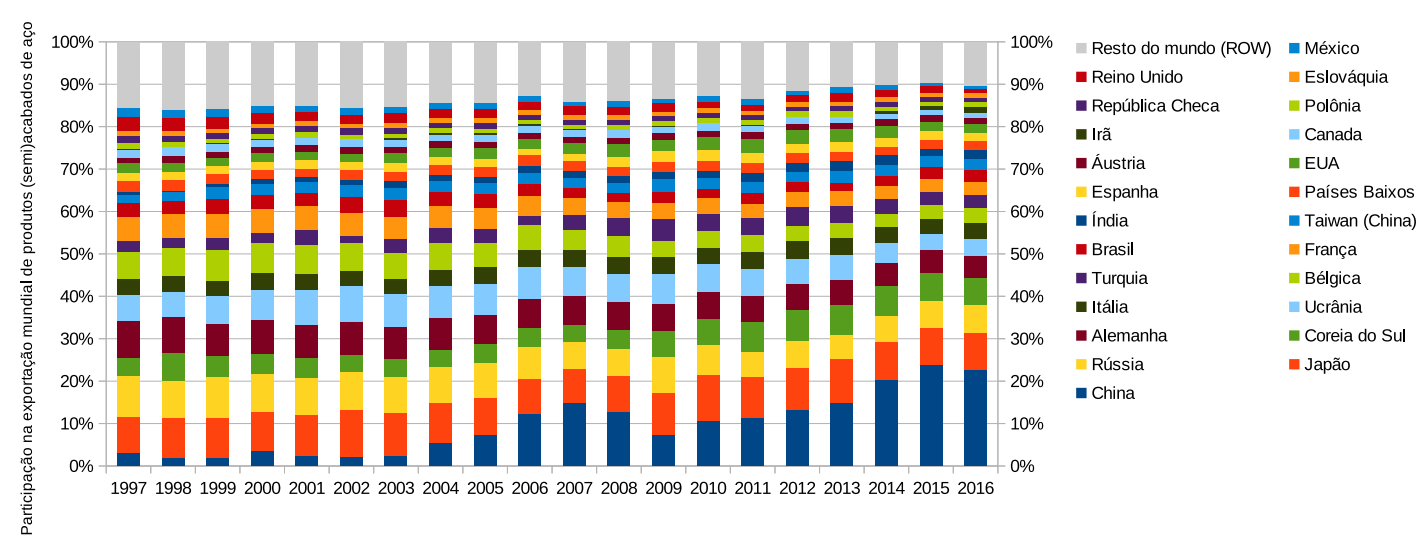

Fonte: elaborado pelo autor pela compilação de dados da WorldSteel 2007), WorldSteel 2017).

principais exportadores de produtos (semi-)acabados do mundo - Japão, China, Rússia, Coreia do Sul e Alemanha -, saíram de uma participação no comércio global de cerca de $35 \%$ para quase $50 \%$, sendo que a China cresceu de $3 \%$ para $32 \%$. Desses cinco países, apenas a China teve crescimento expressivo na participação global de exportações. A Coreia do Sul também teve sua participação aumentada em alguns pontos percentuais. 


\subsubsection{A cadeia mundial do ferro e do aço como um jogo}

Do ponto de vista da economia, quando se tem recursos monopolizados ou oligopolizados em uma cadeia de produção e consumo, como essa estrutura que se revelou a partir da aplicação da metodologia proposta na cadeia do ferro e do aço, o que se tem é um jogo geopolítico, que, nesse caso específico, já se tornou uma guerra comercial.

Figura 34 - Resumo da cadeia de produção do ferro e aço

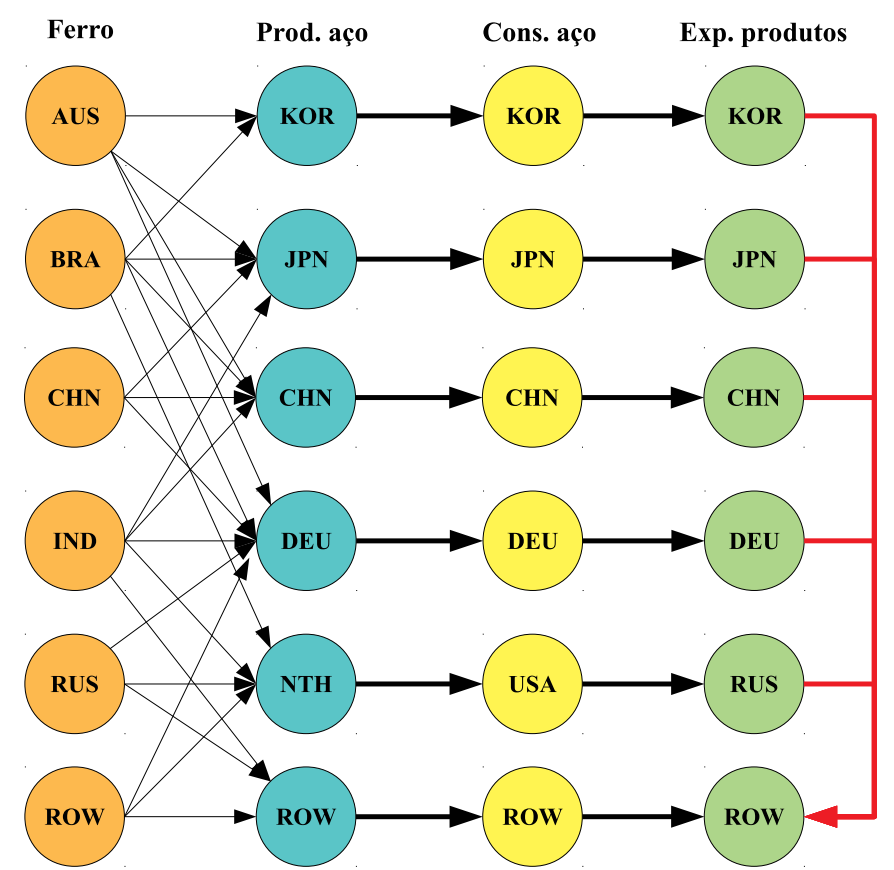

Fonte: elaborado pelo autor pela compilação de dados da WorldSteel (2007), WorldSteel 2017).

Apenas 3 (três) países são grandes exportadores de minério de ferro, enquanto apenas 1 (um), a China, produz a metade do aço. A figura 34 mostra que, dentre todos os países do mundo, restam no máximo 8 (oito) para disputar o jogo. Trata-se, por óbvio, de um jogo matemático e geopolítico, que inclusive já se transformou em uma guerra comercial aberta. 
4.1.9 A produtividade energética da produção de aço

O gráfico 35 mostra a produtividade em relação à média mundial, em termos percentuais.

Figura 35 - Gráfico de produtividade energética da produção de aço bruto (em TJ/Mt) em relação à média mundial

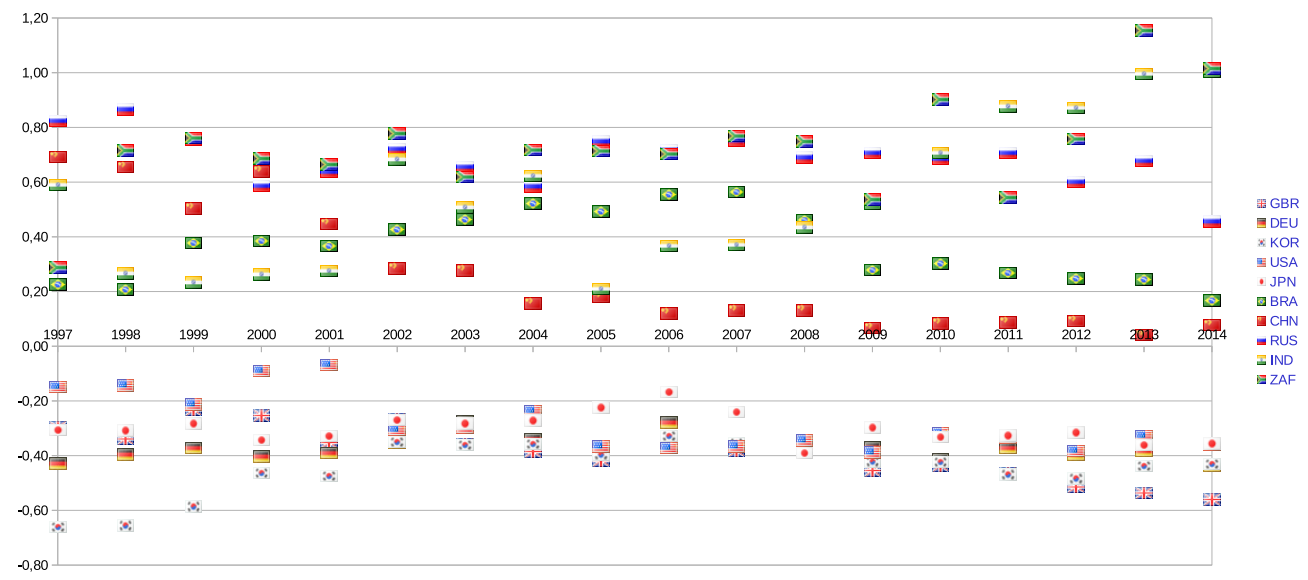

Fonte: elaborado pelo autor pela compilação de dados da WorldSteel (2007), WorldSteel (2017) e IAEA (2013).

A China vem consistentemente se aproximando da média mundial de consumo de energia (em TJ) por Mt de aço bruto produzido, como fica claro na tabela 4 e no gráfico 35. Outros países mostram um comportamento inverso ao da China, como a Índia, que tem piorado muito seu desempenho em relação à média mundial, que tem se mantido estável em torno de 14 TJ/Mt.

Esse aumento de produtividade energética da China tem dois fatores como causa:

- a China passou a comprar da Austrália e do Brasil a maior parte do minério de ferro que processa, deixando de lado suas próprias reservas;

- ao mesmo tempo, passou a usar meios mais eficientes e menos poluentes de geração de calor, abandonando o carvão em favor do gás natural e das siderúrgicas movidas a energia termonuclear. 
Tabela 4 - Tabela de consumo de energia (em TJ) por quantidade física de aço bruto produzida (em Mt)

\begin{tabular}{|c|c|c|c|c|c|c|c|c|c|c|c|c|c|c|c|c|c|c|}
\hline País (ISO3) & 1997 & 1998 & 1999 & 2000 & 2001 & 2002 & 2003 & 2004 & 2005 & 2006 & 2007 & 2008 & 2009 & 2010 & 2011 & 2012 & 2013 & 2014 \\
\hline GBR & 9 & 9 & 10 & 10 & 8 & 9 & 8 & 7 & 7 & 8 & 7 & 8 & 7 & 7 & 7 & 6 & 6 & 6 \\
\hline ESP & 9 & 8 & 8 & 9 & 10 & 9 & 10 & 10 & 9 & 7 & 7 & 7 & 6 & 6 & 7 & 7 & 7 & 6 \\
\hline TWN & 7 & 7 & 8 & 8 & 7 & 7 & 7 & 7 & 7 & 7 & 7 & 7 & 7 & 7 & 7 & 7 & 7 & 6 \\
\hline NLD & 9 & 8 & 8 & 8 & 8 & 8 & 8 & 7 & 7 & 7 & 6 & 6 & 8 & 6 & 6 & 7 & 7 & 6 \\
\hline DEU & 8 & 8 & 8 & 8 & 8 & 8 & 9 & 8 & 8 & 8 & 7 & 8 & 8 & 8 & 8 & 8 & 8 & 7 \\
\hline KOR & 5 & 5 & 5 & 7 & 7 & 8 & 8 & 8 & 7 & 8 & 7 & 8 & 8 & 7 & 7 & 7 & 7 & 7 \\
\hline BEL & 12 & 12 & 12 & 13 & 14 & 10 & 10 & 9 & 9 & 7 & 8 & 8 & 9 & 8 & 7 & 8 & 8 & 7 \\
\hline ITA & 9 & 8 & 8 & 9 & 9 & 9 & 9 & 9 & 9 & 8 & 7 & 7 & 8 & 8 & 7 & 8 & 7 & 7 \\
\hline USA & 11 & 12 & 10 & 12 & 12 & 8 & 8 & 9 & 8 & 7 & 7 & 8 & 8 & 9 & 9 & 8 & 8 & 8 \\
\hline JPN & 9 & 9 & 9 & 8 & 8 & 9 & 9 & 9 & 9 & 10 & 9 & 7 & 9 & 9 & 9 & 9 & 8 & 8 \\
\hline POL & 16 & 16 & 15 & 14 & 14 & 14 & 13 & 12 & 12 & 10 & 10 & 9 & 8 & 8 & 8 & 9 & 9 & 8 \\
\hline MEX & 13 & 14 & 13 & 11 & 11 & 10 & 10 & 10 & 11 & 11 & 10 & 11 & 10 & 10 & 10 & 10 & 9 & 9 \\
\hline FRA & 12 & 11 & 9 & 8 & 9 & 9 & 9 & 8 & 9 & 10 & 10 & 9 & 10 & 10 & 10 & 9 & 10 & 11 \\
\hline WLD & 13 & 14 & 13 & 13 & 13 & 12 & 12 & 12 & 12 & 12 & 11 & 12 & 13 & 13 & 13 & 13 & 12 & 13 \\
\hline CAN & 13 & 13 & 13 & 12 & 12 & 12 & 11 & 12 & 12 & 13 & 12 & 12 & 16 & 13 & 14 & 13 & 13 & 14 \\
\hline $\mathrm{CHN}$ & 23 & 22 & 19 & 21 & 18 & 15 & 15 & 14 & 14 & 13 & 13 & 14 & 14 & 14 & 14 & 14 & 13 & 14 \\
\hline BRA & 16 & 16 & 18 & 18 & 17 & 17 & 17 & 18 & 18 & 18 & 18 & 18 & 17 & 17 & 16 & 16 & 15 & 15 \\
\hline RUS & 24 & 25 & 22 & 20 & 21 & 20 & 20 & 19 & 21 & 20 & 20 & 21 & 22 & 22 & 22 & 21 & 21 & 19 \\
\hline UKR & 13 & 13 & 11 & 10 & 11 & 11 & 10 & 17 & 17 & 16 & 18 & 19 & 18 & 17 & 17 & 17 & 15 & 19 \\
\hline IND & 21 & 17 & 16 & 16 & 16 & 20 & 18 & 19 & 15 & 16 & 16 & 18 & 20 & 22 & 24 & 24 & 24 & 26 \\
\hline ZAF & 17 & 23 & 23 & 22 & 21 & 21 & 19 & 21 & 21 & 20 & 20 & 21 & 20 & 24 & 20 & 23 & 26 & 26 \\
\hline ROW & 15 & 14 & 13 & 12 & 12 & 11 & 11 & 12 & 10 & 11 & 13 & 14 & 12 & 14 & 14 & 13 & 13 & 14 \\
\hline
\end{tabular}

Fonte: elaborado pelo autor pela compilação de dados da WorldSteel (2007), WorldSteel (2017) e IAEA (2013). 
4.1.10 Análise da rede internacional de comércio commodities de ferro / aço

A figura 36 mostra os principais exportadores de commodities derivados de minério de ferro.

Isso mostra alguns aspectos mais intrigantes: os países que possuem as maiores reservas do mundo, como o Brasil e Austrália, não são os que mais exportam as commodities de maior valor agregado. Ao contrário, países com suas reservas de carvão e minério de ferro exauridas, como a Alemanha e suas minas do vale do rio Rurh, ou mesmo o Japão, que não possui reservas próprias de minério, conseguem exportar, em dólares norte-americanos, mais do que os países como o Brasil.

A China, por outro lado, que já foi uma grande mineradora de ferro, reduziu drasticamente sua produção de minério de ferro e de carvão, ao tempo em que substituiu suas antigas siderúrgicas para utilizar o calor gerado por gás natural ou eletricidade produzida em usinas nucleares. Isso já provocou um impacto significativo em termos de redução na emissão de poluentes.

Países que compram o minério de ferro do Brasil, ao invés de produzirem internamente, conseguiram melhorar significativamente a sua competitividade industrial. Isso é particularmente relevante no caso em análise porque trata-se de uma cadeia mais à montante em relação às outras atividades industriais. 
Figura 36 - Gráfico do fluxo internacional de comércio de commodities de minério de ferro

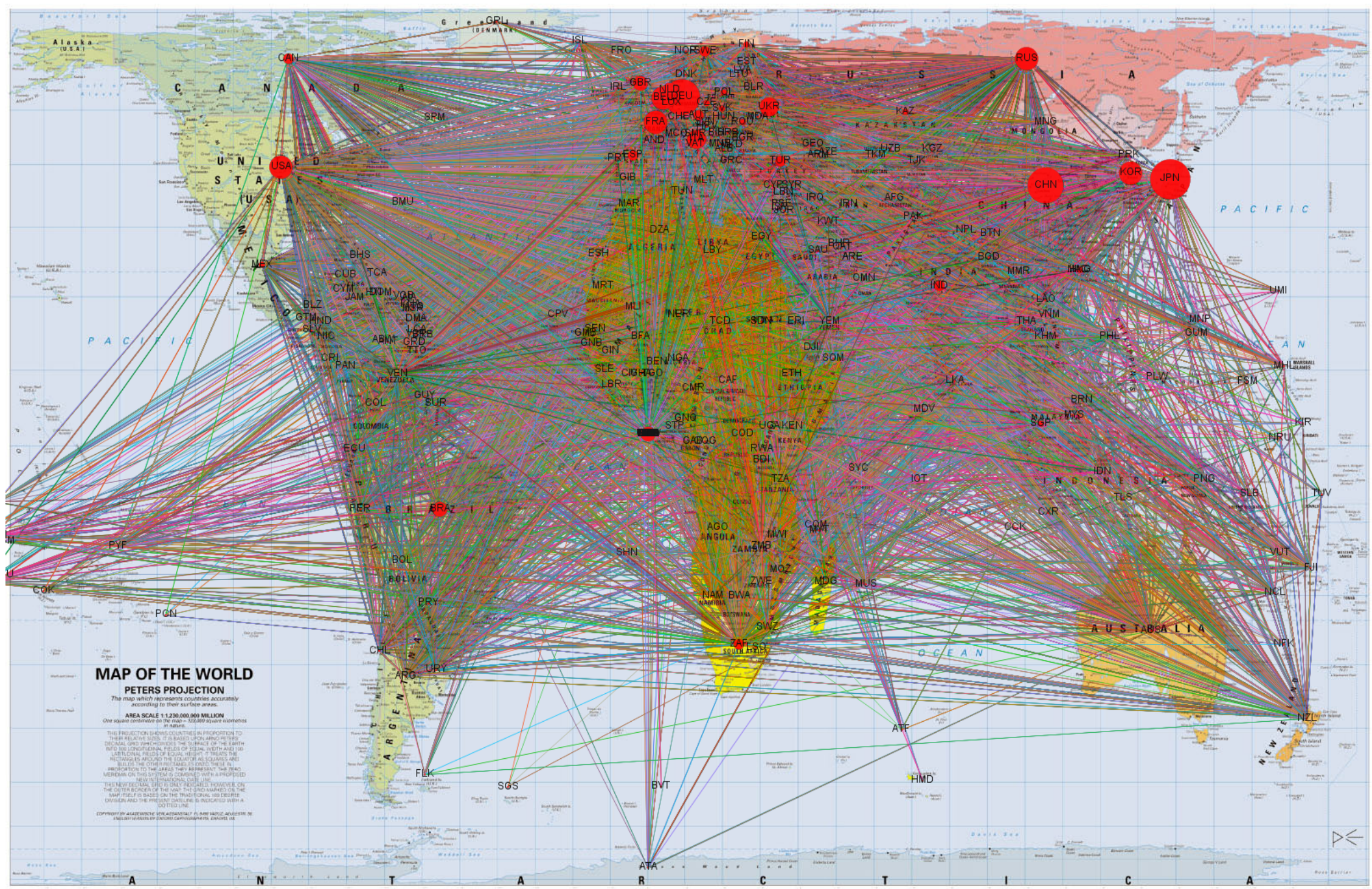

Fonte: elaborado pelo autor com dados do UNSD (2014) (HS 72XX). 


\section{CONCLUSÕES E LIMITAÇÕES DA PESQUISA}

Foi feita uma revisão sistemática da literatura acerca do tema da pesquisa. Foi feita uma modelagem através de hipergrafos da cadeia global do ferro e do aço, o que permitiu reconciliar e tratar a grande quantidade de dados, oriundas de diferentes bases de dados, cobrindo diferentes intervalos de tempo, com os dados brutos disponíveis em diferentes formatos de arquivo e em diferentes unidades de medida.

Após essa análise e da escolha das melhores formas de visualização, foi possível extrair alguns elementos (informações relevantes) sobre a cadeia global de geração de valor do ferro e do aço não triviais.

5.1 Principais descobertas do estudo de caso da cadeia do ferro e do aço

- Em 20 anos, a China tornou-se a maior produtora e consumidora de aço do mundo, importando e processando a maior parte do minério de ferro extraído dos principais exportadores, que são Austrália e Brasil.

- Esse crescimento da produção chinesa foi acompanhado de uma perda na participação relativa de praticamente todos os outros países do mundo na produção de aço.

- Os maiores produtores mundiais de minério bruto exportado para a China são a Austrália e o Brasil.

- O Brasil só exporta minério bruto.

- O aumento da produção de minério na Austrália foi maior que o do Brasil. Portanto, o crescimento da China foi possível, em sua maior parte, graças ao aumento do suprimento da Austrália.

- O consumo de energia por quantidade física de aço bruto produzido tem se mantido estável em torno de $14 \mathrm{TJ} / \mathrm{Mt}$. Essa seria a produtividade (em unidades físicas) do fator energia.

- De 1997 a 2014, a China conseguiu aumentar a sua produtividade energética, chegando cada vez mais próximo da média mundial. Entre os anos 2000 e 2002 houve um salto de produtividade, que saiu de $21 \mathrm{TJ} / \mathrm{Mt}$ para $15 \mathrm{TJ} / \mathrm{Mt}$.

Esses elementos, dentre os inúmeros outros que podem ser obtidos a partir da base consolidada, deixam claro que da análise da dinâmica estrutural, feita sobre uma modelo da cadeia global através de hipergrafos, permite extrair informações relevantes e capazes de explicar os elementos da realidade. 


\subsection{Limitações da pesquisa}

Em virtude das discrepâncias e / ou falta de dados analíticos específicos sobre a cadeia analisada, tanto em termos de período temporal quanto de países cujos dados estão disponíveis, diversas análises não puderam ser realizadas. Especificamente em relação ao PIB, as bases mais completas no período não têm o nível de análise específico necessário. Já as que possuem o nível de análise não possuem a mesma abrangência em termos de países. Além disso, diversas análises poderiam ser feitas, como por exemplo os efeitos da eficiência física, termos de insumo / produto, quanto em termos de monetários.

\subsection{Considerações finais}

A modelagem estrutural permitiu uma análise da dinâmica da cadeia de valor analisada, ainda que limitada pelas contingências já mencionadas. Foi possível extrair informações relevantes para entender as questões geopolíticas por trás da guerra comercial entre os EUA e a China, por exemplo.

Essa modelagem por hipergrafos pode ser útil para a análise de outras cadeias globais de geração de valor. A base de dados consolidada pode ser melhor explorada e aperfeiçoada, de modo a extrair mais informações, ainda mais relevantes, que não conseguiu-se fazer nesse trabalho.

A metodologia para a modelagem, tratamento, consolidação da bases de dados e análise e visualização de dados proposta é a maior contribuição desse trabalho, permite a obtenção de informações capazes de guiar políticas de desenvolvimento industrial a partir das lições oferecidas pela análise da dinâmica estrutural de uma cadeia global de produção e consumo. Um bom modelo permite não só explicar a dinâmica passada, as causas e consequências, como também permite simular e explorar possibilidades, elaborar políticas mais adequadas e uma tomada de decisão mais eficaz.

A recente guerra comercial entre a China e os EUA, em termos de embargos comerciais, restrições a compras de aço, dentre outras ações, pode ser compreendida a partir dessa análise. Dado o enorme ganho de escala e a grande participação da China na produção industrial mundial, é difícil para os EUA conseguirem reverter essa posição.

Toda análise, esses fatos recentes deixam claro, precisa levar em consideração os interesses em jogo, as questões geopolíticas e de divisão internacional do trabalho e da renda, que moldam ou influenciam as decisões microeconômicas dos agentes. A análise dos dados pode fornecer pistas para a compreensão da realidade, mas somente à luz da história e dos interesses dos governos e dos diferentes agentes. 


\section{REFERÊNCIAS}

ABBOTT, A. Methods of Discovery: Heuristics for the Social Sciences (Contemporary Societies Series). London, U.K.: W. W. Norton \& Company, 2004. Paperback. ISBN 0393978141.

AFGAN, N. H. et al. Sustainable energy development. Renewable and Sustainable Energy Reviews, Pergamon, 1998.

APERGIS, N.; PAYNE, J. E. A panel study of nuclear energy consumption and economic growth. Energy Economics, Elsevier BV, v. 32, n. 3, p. 545-549, Maio 2010. ISSN 0140-9883.

ARCELOR MITTAL. Fluxo de produção da planta siderurgica da Arcelor Mittal em

Tubarão / RS,. Internet. Imagem. Disponível em: <http://tubarao.arcelormittal.com/quemsomos/usina/fluxo-producao/index.asp $>$. Acesso em: 12-jun-2015.

BERK, M. et al. Sustainable energy: trade-offs and synergies between energy security, competitiveness and environment. [S.1.], 2006.

BERNDT, E. R.; KHALED, M. S. Parametric productivity measurement and choice among flexible functional forms. Journal of Political Economy, The University of Chicago Press, v. 87 , n. $6,1979$.

BESANKO, D. et al. Economics of Strategy. 6. ed. [S.1.]: Wiley, 2013.

BESS, R.; AMBARGIS, Z. O. Input-output models for impact analysis: Suggestions for practitioners using RIMS II multipliers. 2023.

BHAGAVANA, M. R.; DIN, A. M. The input-output structure of energy and resources in forestry and associated industries. Energy Economics, 1980.

BONELLI, R. Productivity performance in developing countries: Country case studies. 2005.

BOYD, G. A.; PANG, J. X. Estimating the linkage between energy effciencyand productivity. Energy Policy, 2000.

BULLARD, C. W.; PENNER, P. S.; PILATI, D. A. Net energy analysis: Handbook for combining process and input-output analysis. Resources and Energy, Norlh-Holland Publishing Company, 1978.

BURRELL, G.; MORGAN, G. Sociological Paradigms and Organisational Analysis: Elements of the Sociology of Corporate Life. England: Ashgate, 1979.

CHEN, S.-T.; KUO, H.-I.; CHEN, C.-C. The relationship between GDP and electricity consumption in 10 asian countries. Energy Policy, Elsevier BV, v. 35, n. 4, p. 2611-2621, 4 2007. ISSN 0301-4215.

CHRIST, C. F. A review of input-output analysis. In: Input-Output Analysis: An Appraisal. Princeton University Press, 1955. p. 137-192. Disponível em: <http: //www.nber.org/chapters/c2866>. Acesso em: 01-12-2015.

CLEVELAND, C. J.; KAUFMANN, R. K.; STERN, D. I. Aggregation and the role of energy in the economy. Ecological Economics, Elsevier, v. 32, p. 301-307, 2000. 
CO-OPERATION, O. for E.; DEVELOPMENT. The OECD Input-Output Database. [S.1.], 2015.

CONFEDERAÇÃO NACIONAL DA INDÚSTRIA - CNI. A Indústria e o Brasil: Energia e Competitividade na Era do Baixo Carbono. Brasília, DF, 2011.

ELLERY JR., R. Desafios para o cálculo da produtividade total dos fatores. In: NEGRI, F. de; CAVALCANTE, L. R. (org.). Produtividade no Brasil : desempenho e determinantes. Brasília: Instituto de Pesquisa Econômica Aplicada, 2014. v. 1, cap. 2, p. 53-86. Disponível em: <http://www.ipea.gov.br>. Acesso em: 01-12-2015.

EWI. Energy costs in Germany: Developments, drivers and international comparison. [S.1.], 2010.

FEDERAÇÃO DAS INDÚSTRIAS DO ESTADO DO RIO DE JANEIRO - FIRJAN. Quanto Custa a Energia Elética para a Indústria no Brasil? Rio de Janeiro, 2011.

GREENING, L. A.; GREENE, D. L.; DIGLIO, C. Energy effciency and consumption - the rebound effect - a survey. Energy Policy, Elsevier, 2000.

HAN, S.-Y.; YOO, S.-H.; KWAK, S.-J. The role of the four electric power sectors in the korean national economy: an input-output analysis. Energy Policy, Elsevier BV, v. 32, n. 13, p. 1531-1543, Sep 2004. ISSN 0301-4215.

HARE, P. G. Aggregate planning and by means and of input-output and material-balances systems. Journal of Comparative Economic, n. 5, p. 272-291, 1981.

HONG, Y.; SU, H. wei. Can energy price shocks drive long-run technological progress and growth? empirical evidence from korea. IEEE, 2010.

HSIAO, F. S. T.; WANG, M.-C.; HSIAO. Elasticities, ratios and energy modelling. Energy Economics, Butterworth \& Co, 1985.

HU, J.-L.; WANG, S.-C. Total-factor energy efficiency of regions in china. Energy Policy, Elsevier BV, v. 34, n. 17, p. 3206-3217, Nov 2006. ISSN 0301-4215.

HUDSON, E. A.; JORGENSON, D. W. U.S. energy policy and economic growth, 1975-2000. The Bell Journal of Economics and Management Science, v. 5, n. 2, 1975. Disponível em: <http://www.jstor.org/stable/3003118>. Acesso em: 05-jan-2014.

NEGRI, F. de; CAVALCANTE, L. R. (org.). Produtividade no Brasil : desempenho e determinantes. Brasília: Instituto de Pesquisa Econômica Aplicada, 2014. v. 1. 452 p. Disponível em: <http://www.ipea.gov.br>, Acesso em: 01-12-2015.

INTERNATIONAL ATOMIC ENERGY AGENCY. Nuclear technology review 2013. In: . [S.1.], 2013.

INTERNATIONAL ENERGY ORGANIZATION (IEA). Banco de dados, World energy balances. OECD iLibrary, 2015. Internet. Disponível em: $<\mathrm{http}: / / \mathrm{dx} . d o i-$ org.ez67.periodicos.capes.gov.br/10.1787/data-00512-en>. Acesso em: 12-jan-2018.

INTERNATIONAL ENERGY ORGANIZATION (IEA). Banco de dados, Extended world energy balances. OECD iLibrary, 2016. Internet. Disponível em: $</$ http://dx.doiorg.ez67.periodicos.capes.gov.br/10.1787/data-00513-en>. Acesso em: 28/11/2016. 
JORGENSON, D. W. The role and of energy and in productivity and growth. The American Economic Review, American Economic Association, v. 74, n. 2, 1984.

KIM, M. Leontief input-output model. 1973.

KORSAKIENÈ, R.; TVARONAVIC̃IENÈ, M.; SMALIUKIENÈ, R. Impact of energy prices on industrial sector development and export: Lithuania in the context of baltic states. Procedia Social and Behavioral Sciences, Elsevier BV, v. 110, p. 461-469, Jan 2014. ISSN 1877-0428.

LEE, C.-C. The causality relationship between energy consumption and GDP in G-11 countries revisited. Energy Policy, Elsevier BV, v. 34, n. 9, p. 1086-1093, Jun 2006. ISSN 0301-4215.

LEONTIEF, W. Structure of the world economy: Outline of a simple input-output formulation. The Swedish Journal of Economics, JSTOR, v. 76, n. 4, p. 387-401, 1974.

LEONTIEF, W. Input-Output Economics. 2. ed. New York: Oxford University Press, 1986.

LIM, S.-Y.; YOO, S.-H. The impact of electricity price changes on industrial prices and the general price level in korea. Energy Policy, Elsevier BV, v. 61, p. 1551-1555, Oct 2013. ISSN 0301-4215.

MARCONI, N.; ROCHA, I. L.; MAGACHO, G. R. Sectoral capabilities and productive structure: An input-output analysis of the key sectors of the Brazilian economy. Brazilian Journal of Political Economy, scielo, v. 36, p. 470 - 492, 09 2016. ISSN 0101-3157. Disponível em: <http: //www.scielo.br/scielo.php?script=sci_arttext\&pid=S0101-31572016000300470\&nrm=iso $>$. Acesso em: 01-jul-2017.

MATTHES, F. C. The current electricity costs of energy-intensive industries in Germany. [S.1.], 2012.

MESSA, A. Metodologia de cálculo da produtividade total dos fatores e da produtividade da mão de obra. In: NEGRI, F. de; CAVALCANTE, L. R. (org.). Produtividade no Brasil : desempenho e determinantes. Brasília: Instituto de Pesquisa Econômica Aplicada, 2014. v. 1, cap. 3, p. 87-110. Disponível em: <http://www.ipea.gov.br>. Acesso em: 01-12-2015.

MEYAR-NAIMI, H.; VAEZ-ZADEH, S. Sustainable development based energy policy making frameworks, a critical review. Energy Policy, Elsevier BV, v. 43, p. 351-361, Apr 2012. ISSN 0301-4215.

MILLER, R. E.; BLAIR, P. D. Input-output analysis: foundations and extensions. 2. ed. [S.1.]: Cambridge University Press, 2009.

NEGRI, F. de; CAVALCANTE, L. R. Os dilemas e os desafios da produtividade no brasil. In: NEGRI, F. de; CAVALCANTE, L. R. (org.). Produtividade no Brasil : desempenho e determinantes. Brasília: Instituto de Pesquisa Econômica Aplicada, 2014. v. 1, cap. 1, p. 15-52. Disponível em: <http://www.ipea.gov.br>, Acesso em: 01-12-2015.

ORGANIZATION FOR ECONOMIC CO-OPERATION AND DEVELOPMENT (OECD). Banco de dados, STAN Bilateral trade database by industry and end-use category, ISIC Rev. 3. OECD, 2018. Internet. Disponível em: <http://dx.doi.org/10.1787/data-00692-en>. Acesso em: 28/11/2018. 
ORGANIZATION FOR ECONOMIC CO-OPERATION AND DEVELOPMENT (OECD). Banco de dados, STAN Bilateral trade database by industry and end-use category, ISIC Rev. 4. OECDiLibrary, 2018. Internet. Disponível em: <http://dx.doi.org/10.1787/data-00691-en > Acesso em: 28/11/2018.

OZTURK, I. A literature survey on energy-growth nexus. Energy Policy, Elsevier BV, v. 38, n. 1, p. 340-349, Jan 2010. ISSN 0301-4215.

PAO, H.-T.; FU, H.-C. The causal relationship between energy resources and economic growth in Brazil. Energy Policy, Elsevier BV, v. 61, p. 793-801, Oct 2013. ISSN 0301-4215.

PAYNE, J. E. A survey of the electricity consumption-growth literature. Applied Energy, Elsevier BV, v. 87, n. 3, p. 723-731, Mar 2010. ISSN 0306-2619.

RAA, T. ten. The Economics of Input-Output Analysis. [S.1.]: Cambridge University Press, 2005.

SANTOS, R. L. P. d. et al. The importance of nuclear energy for the expansion of Brazil's electricity grid. Energy Policy, Elsevier BV, v. 60, p. 284-289, Sep 2013. ISSN 0301-4215.

SARI, R.; SOYTAS, U. The growth of income and energy consumption in six developing countries. Energy Policy, Elsevier BV, v. 35, n. 2, p. 889-898, Feb 2007. ISSN 0301-4215.

SHIU, A.; LAM, P.-L. Electricity consumption and economic growth in china. Energy Policy, 2004.

SMULDERS, S.; NOOIJ, M. de. The impact of energy conservation on technology and economic growth. Resource and Energy Economics, Elsevier, 2003.

STERN, D. I. A multivariate cointegration analysis of the role of energy in the us and macroeconomy. Energy Economics, 2000.

TEN RAA, T.; MOHNEN, P. Neoclassical input-output analysis. Regional Science and Urban Economics, v. 24, p. 135-158, 1994.

UNITED NATIONS. International Standard Industrial Classification of All Economic Activities (ISIC) - revision 4. New York, 2008. (Statistical papers Series M, 4).

UNITED NATIONS STATISTICS DIVISION (UNSD). Banco de dados, United Nations Comtrade database. New York, 2014. Internet. Disponível em: $\langle$ http://www.comtrade.un.org $\rangle$ Acesso em: 01-12-2015.

VASCONCELOS, M. A. S. de. Economia: micro e macro. 4. ed. [S.1.]: Atlas, 2014.

VON FARFAN, E. Eletrointensivos gastam 30\% da energia do País. 2005. Disponível em: <http://www.eco21.com.br/textos/textos.asp?ID=1190>. Acesso em: 01-ago-2015.

WOLDE-RUFAEL, Y.; MENYAH, K. Nuclear energy consumption and economic growth in nine developed countries. Energy Economics, Elsevier BV, v. 32, n. 3, p. 550-556, May 2010. ISSN 0140-9883.

World Steel Association. Steel Statistical Yearbook - 2007. Belgium, 2007. Disponível em: $<$ https://www.worldsteel.org/en/dam/jcr:5a3cd3bc-79f9-44e5-ac54-ed231832cb21/Steel+ statistical+yearbook+2007.pdf>. Acesso em: 01-dez-2017. 
World Steel Association. Steel Statistical Yearbook - 2017. Belgium, 2017. Disponível em: $<$ https://www.worldsteel.org/en/dam/jcr:3e275c73-6f11-4e7f-a5d8-23d9bc5c508f/Steel+ Statistical+Yearbook+2017.pdf>. Acesso em: 01-dez-2017.

YANG, H.-Y. A note on the causal relationship between energy and GDP in taiwan. Energy Economics, 2000.

ZAMORA, J. Input-Output Model. 2015. 


\section{APÊNDICE A - TABELAS}

A.1 Tabelas da base de dados consolidada

A.1.1 Commodities da cadeia de ferro / aço (HS 72XX)

Tabela 5 - Lista de commodities HS 72XX

\begin{tabular}{lll}
\hline$\#$ & Código HS & Commodity \\
\hline 1 & 7201 & Pig iron and spiegeleisen in primary forms \\
2 & 7202 & Ferro-alloys \\
3 & 7203 & Ferrous products from reduction of iron ore, pure iron \\
4 & 7204 & Ferrous waste or scrap, ingots or iron or steel \\
5 & 7205 & Granules and powders, of pig iron, iron or steel \\
6 & 7206 & Iron and non-alloy steel in primary forms, ingots \\
7 & 7207 & Semi-finished products of iron or non-alloy steel \\
8 & 7208 & Hot-rolled products, iron/steel, width $>600 \mathrm{~mm}$, not clad \\
9 & 7209 & Flat-rolled iron/steel, $>600 \mathrm{~mm}$, not clad, plated, etc \\
10 & 7210 & Flat-rolled iron/steel, $>600 \mathrm{~mm}$, clad, plated or coated \\
11 & 7211 & Flat-rolled iron/steel, $<600 \mathrm{~mm}$, not clad, plated, etc \\
12 & 7212 & Flat-rolled iron/steel, $<600 \mathrm{~mm}$, clad, plated or coated \\
13 & 7213 & Hot rolled bar, rod of iron/steel, in irregular coils \\
14 & 7214 & Iron/steel bar, only forged hot-rolled drawn, extruded \\
15 & 7215 & Bar and rod of iron or non-alloy steel nes \\
16 & 7216 & Angles, shapes and sections of iron or non-alloy steel \\
17 & 7217 & Wire of iron or non-alloy steel \\
18 & 7218 & Stainless steel in primary forms, semi-finish products \\
19 & 7219 & Rolled stainless steel sheet, width $>600 \mathrm{~mm}$ \\
20 & 7220 & Rolled stainless steel sheet, width $<600 \mathrm{~mm}$ \\
21 & 7221 & Bar or rod of stainless steel, hot rolled, coiled \\
22 & 7222 & Bar, rod nes, stainless steel, angles, shapes/sections \\
23 & 7223 & Wire of stainless steel \\
24 & 7224 & Alloy steel in ingots in primary form or semi-finished \\
25 & 7225 & Flat-rolled alloy steel nes, width $>600 \mathrm{~mm}$ \\
26 & 7226 & Flat-rolled alloy steel nes, $<600 \mathrm{~mm}$ wide \\
27 & 7227 & Bar, rod, hot-rolled alloy steel, irregular coils nes \\
28 & 7228 & Bar, rod, angle etc nes, hollow steel drill bars \\
\hline & 7229 & Wire of alloy steel except stainless steel \\
\hline & &
\end{tabular}

Fonte: fornecido pela ISO. 
A.1.2 Tabela de países usados na análise da rede de comércio do ferro / aço

Tabela 6 - Lista de paises/regioes da ISO

\begin{tabular}{|c|c|c|c|}
\hline \# & Código ISO & Sigla ISO3 & Nome \\
\hline 1 & 0 & WLD & World \\
\hline 2 & 4 & AFG & Afghanistan \\
\hline 3 & 31 & AZE & Azerbaijan \\
\hline 4 & 32 & ARG & Argentina \\
\hline 5 & 36 & AUS & Australia \\
\hline 6 & 40 & AUT & Austria \\
\hline 7 & 56 & BEL & Belgium \\
\hline 8 & 76 & BRA & Brazil \\
\hline 9 & 124 & $\mathrm{CAN}$ & Canada \\
\hline 10 & 152 & $\mathrm{CHL}$ & Chile \\
\hline 11 & 156 & $\mathrm{CHN}$ & China \\
\hline 12 & 170 & $\mathrm{COL}$ & Colombia \\
\hline 13 & 203 & CZE & Czech Rep. \\
\hline 14 & 208 & DNK & Denmark \\
\hline 15 & 246 & FIN & Finland \\
\hline 16 & 251 & FRA & France \\
\hline 17 & 276 & DEU & Germany \\
\hline 18 & 300 & GRC & Greece \\
\hline 19 & 344 & $\mathrm{HKG}$ & China, Hong Kong SAR \\
\hline 20 & 348 & HUN & Hungary \\
\hline 21 & 364 & IRN & Iran \\
\hline 22 & 376 & ISR & Israel \\
\hline 23 & 381 & ITA & Italy \\
\hline 24 & 392 & JPN & Japan \\
\hline 25 & 398 & KAZ & Kazakhstan \\
\hline 26 & 408 & PRK & Dem. People's Rep. of Korea \\
\hline 27 & 410 & KOR & Rep. of Korea \\
\hline 28 & 442 & LUX & Luxembourg \\
\hline 29 & 458 & MYS & Malaysia \\
\hline 30 & 484 & MEX & Mexico \\
\hline 31 & 490 & OAS & Other Asia, nes \\
\hline 32 & 528 & NLD & Netherlands \\
\hline 33 & 530 & ANT & Neth. Antilles \\
\hline 34 & 579 & NOR & Norway \\
\hline
\end{tabular}




\begin{tabular}{|c|c|c|c|}
\hline & Lista de paise & /regioes da Is & (continuação) \\
\hline$\#$ & Código ISO & Sigla ISO3 & Nome \\
\hline 35 & 600 & PRY & Paraguay \\
\hline 36 & 604 & PER & Peru \\
\hline 37 & 616 & POL & Poland \\
\hline 38 & 620 & PRT & Portugal \\
\hline 39 & 643 & RUS & Russian Federation \\
\hline 40 & 699 & IND & India \\
\hline 41 & 703 & SVK & Slovakia \\
\hline 42 & 705 & SVN & Slovenia \\
\hline 43 & 710 & ZAF & South Africa \\
\hline 44 & 716 & ZWE & Zimbabwe \\
\hline 45 & 724 & ESP & Spain \\
\hline 46 & 752 & SWE & Sweden \\
\hline 47 & 757 & $\mathrm{CHE}$ & Switzerland \\
\hline 48 & 764 & THA & Thailand \\
\hline 49 & 792 & TUR & Turkey \\
\hline 50 & 804 & UKR & Ukraine \\
\hline 51 & 826 & GBR & United Kingdom \\
\hline 52 & 842 & USA & USA \\
\hline 53 & 858 & URY & Uruguay \\
\hline 54 & 860 & UZB & Uzbekistan \\
\hline 55 & 862 & VEN & Venezuela \\
\hline 56 & 24 & AGO & Angola \\
\hline 57 & 44 & BHS & Bahamas \\
\hline 58 & 48 & BHR & Bahrain \\
\hline 59 & 68 & BOL & Bolivia (Plurinational State of) \\
\hline 60 & 104 & MMR & Myanmar \\
\hline 61 & 132 & $\mathrm{CPV}$ & Cabo Verde \\
\hline 62 & 144 & LKA & Sri Lanka \\
\hline 63 & 178 & $\mathrm{COG}$ & Congo \\
\hline 64 & 188 & CRI & Costa Rica \\
\hline 65 & 192 & CUB & Cuba \\
\hline 66 & 196 & CYP & Cyprus \\
\hline 67 & 204 & $\mathrm{BEN}$ & Benin \\
\hline 68 & 214 & DOM & Dominican Rep. \\
\hline 69 & 218 & ECU & Ecuador \\
\hline 70 & 222 & SLV & El Salvador \\
\hline 71 & 233 & EST & Estonia \\
\hline
\end{tabular}




\begin{tabular}{|c|c|c|c|}
\hline & . & $\mathrm{s}$ da & (continuação) \\
\hline$\#$ & Código ISO & Sigla ISO3 & Nome \\
\hline 72 & 242 & FJI & Fiji \\
\hline 73 & 288 & GHA & Ghana \\
\hline 74 & 320 & GTM & Guatemala \\
\hline 75 & 340 & HND & Honduras \\
\hline 76 & 360 & IDN & Indonesia \\
\hline 77 & 372 & IRL & Ireland \\
\hline 78 & 384 & CIV & Côte d'Ivoire \\
\hline 79 & 388 & JAM & Jamaica \\
\hline 80 & 400 & JOR & Jordan \\
\hline 81 & 404 & KEN & Kenya \\
\hline 82 & 414 & KWT & Kuwait \\
\hline 83 & 422 & $\mathrm{LBN}$ & Lebanon \\
\hline 84 & 440 & LTU & Lithuania \\
\hline 85 & 504 & MAR & Morocco \\
\hline 86 & 524 & NPL & Nepal \\
\hline 87 & 554 & NZL & New Zealand \\
\hline 88 & 558 & NIC & Nicaragua \\
\hline 89 & 566 & NGA & Nigeria \\
\hline 90 & 586 & PAK & Pakistan \\
\hline 91 & 591 & PAN & Panama \\
\hline 92 & 608 & PHL & Philippines \\
\hline 93 & 634 & QAT & Qatar \\
\hline 94 & 682 & SAU & Saudi Arabia \\
\hline 95 & 686 & SEN & Senegal \\
\hline 96 & 702 & SGP & Singapore \\
\hline 97 & 704 & VNM & Viet Nam \\
\hline 98 & 740 & SUR & Suriname \\
\hline 99 & 760 & SYR & Syria \\
\hline 100 & 768 & TGO & Togo \\
\hline 101 & 780 & TTO & Trinidad and Tobago \\
\hline 102 & 784 & ARE & United Arab Emirates \\
\hline 103 & 788 & TUN & Tunisia \\
\hline 104 & 818 & EGY & Egypt \\
\hline 105 & 834 & TZA & United Rep. of Tanzania \\
\hline 106 & 470 & MLT & Malta \\
\hline 107 & 12 & DZA & Algeria \\
\hline 108 & 50 & BGD & Bangladesh \\
\hline
\end{tabular}




\begin{tabular}{|c|c|c|c|}
\hline & Lista de pais & gio & (continuação) \\
\hline$\#$ & Código ISO & Sigla ISO3 & Nome \\
\hline 109 & 84 & BLZ & Belize \\
\hline 110 & 136 & CYM & Cayman Isds \\
\hline 111 & 180 & COD & Dem. Rep. of the Congo \\
\hline 112 & 266 & GAB & Gabon \\
\hline 113 & 328 & GUY & Guyana \\
\hline 114 & 332 & HTI & Haiti \\
\hline 115 & 508 & MOZ & Mozambique \\
\hline 116 & 533 & ABW & Aruba \\
\hline 117 & 92 & VGB & Br. Virgin Isds \\
\hline 118 & 148 & TCD & Chad \\
\hline 119 & 191 & HRV & Croatia \\
\hline 120 & 258 & PYF & French Polynesia \\
\hline 121 & 466 & MLI & Mali \\
\hline 122 & 662 & LCA & Saint Lucia \\
\hline 123 & 670 & VCT & Saint Vincent and the Grenadines \\
\hline 124 & 585 & PLW & Palau \\
\hline 125 & 748 & SWZ & Swaziland \\
\hline 126 & 52 & $\mathrm{BRB}$ & Barbados \\
\hline 127 & 212 & DMA & Dominica \\
\hline 128 & 231 & ETH & Ethiopia \\
\hline 129 & 262 & DJI & Djibouti \\
\hline 130 & 268 & GEO & Georgia \\
\hline 131 & 270 & GMB & Gambia \\
\hline 132 & 430 & LBR & Liberia \\
\hline 133 & 434 & LBY & Libya \\
\hline 134 & 516 & NAM & Namibia \\
\hline 135 & 736 & SDN & Fmr Sudan \\
\hline 136 & 854 & BFA & Burkina Faso \\
\hline 137 & 894 & $\mathrm{ZMB}$ & Zambia \\
\hline 138 & 51 & ARM & Armenia \\
\hline 139 & 100 & BGR & Bulgaria \\
\hline 140 & 166 & CCK & Cocos Isds \\
\hline 141 & 642 & ROU & Romania \\
\hline 142 & 140 & $\mathrm{CAF}$ & Central African Rep. \\
\hline 143 & 454 & MWI & Malawi \\
\hline 144 & 478 & MRT & Mauritania \\
\hline 145 & 480 & MUS & Mauritius \\
\hline
\end{tabular}




\begin{tabular}{|c|c|c|c|}
\hline & $\mathrm{P}$ & 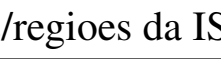 & (continuação) \\
\hline$\#$ & Código ISO & Sigla ISO3 & Nome \\
\hline 146 & 512 & $\mathrm{OMN}$ & Oman \\
\hline 147 & 624 & GNB & Guinea-Bissau \\
\hline 148 & 732 & ESH & Western Sahara \\
\hline 149 & 887 & YEM & Yemen \\
\hline 150 & 112 & BLR & Belarus \\
\hline 151 & 428 & LVA & Latvia \\
\hline 152 & 60 & BMU & Bermuda \\
\hline 153 & 498 & MDA & Rep. of Moldova \\
\hline 154 & 796 & TCA & Turks and Caicos Isds \\
\hline 155 & 226 & GNQ & Equatorial Guinea \\
\hline 156 & 308 & GRD & Grenada \\
\hline 157 & 324 & GIN & Guinea \\
\hline 158 & 562 & NER & Niger \\
\hline 159 & 688 & SRB & Serbia \\
\hline 160 & 694 & SLE & Sierra Leone \\
\hline 161 & 184 & $\mathrm{COK}$ & Cook Isds \\
\hline 162 & 28 & ATG & Antigua and Barbuda \\
\hline 163 & 120 & CMR & Cameroon \\
\hline 164 & 368 & IRQ & Iraq \\
\hline 165 & 417 & KGZ & Kyrgyzstan \\
\hline 166 & 450 & MDG & Madagascar \\
\hline 167 & 659 & KNA & Saint Kitts and Nevis \\
\hline 168 & 674 & SMR & San Marino \\
\hline 169 & 540 & NCL & New Caledonia \\
\hline 170 & 8 & ALB & Albania \\
\hline 171 & 352 & ISL & Iceland \\
\hline 172 & 800 & UGA & Uganda \\
\hline 173 & 807 & MKD & TFYR of Macedonia \\
\hline 174 & 531 & CUW & Curaçao \\
\hline 175 & 690 & SYC & Seychelles \\
\hline 176 & 838 & FRE & Free Zones \\
\hline 177 & 882 & WSM & Samoa \\
\hline 178 & 86 & IOT & Br. Indian Ocean Terr. \\
\hline 179 & 499 & MNE & Montenegro \\
\hline 180 & 598 & PNG & Papua New Guinea \\
\hline 181 & 70 & $\mathrm{BIH}$ & Bosnia Herzegovina \\
\hline 182 & 626 & TLS & Timor-Leste \\
\hline
\end{tabular}




\begin{tabular}{lllll}
\multicolumn{4}{c}{ Lista de paises/regioes da ISO } & (continuação) \\
\hline$\#$ & Código ISO & Sigla ISO3 & Nome & \\
\hline 183 & 660 & AIA & Anguilla & \\
184 & 729 & SDN & Sudan & \\
\hline
\end{tabular}

Fonte: fornecido pela ISO.

A.1.3 Tabela de atividades econômicas ISIC v4

Tabela 7 - Tabela de classificação hieráquica de atividades econômicas ISIC v. 4

\begin{tabular}{|c|c|c|c|c|}
\hline Reg. & Reg. pai & TagISIC & Description & Descrição \\
\hline 0 & 0 & 0 & ISICv4 Total & ISICv4 Total \\
\hline 1 & 0 & A & $\begin{array}{l}\text { Agriculture, forestry and } \\
\text { fishing }\end{array}$ & $\begin{array}{l}\text { Agricultura, silvicultura e pe- } \\
\text { cuária }\end{array}$ \\
\hline 2 & 1 & 1 & Agriculture & Agricultura e pecuária \\
\hline 3 & 1 & 2 & Forestry & Silvicultura \\
\hline 4 & 1 & 3 & Fishing & Pesca \\
\hline 5 & 0 & $\mathrm{~B}$ & Mining and quarrying & Mineração e pedreiras \\
\hline 6 & 5 & 5 & Mining of coal and lignite & Mineração de carvão e lignina \\
\hline 7 & 5 & 6 & $\begin{array}{l}\text { Extraction of crude petroleum } \\
\text { and natural gas }\end{array}$ & $\begin{array}{l}\text { Extração de petróleo e gás na- } \\
\text { tural }\end{array}$ \\
\hline 8 & 5 & 7 & Mining of metal ores & $\begin{array}{l}\text { Mineração de minérios metá- } \\
\text { licos }\end{array}$ \\
\hline 9 & 8 & 71 & Mining of iron ores & $\begin{array}{l}\text { Mineração de minérios de } \\
\text { ferro }\end{array}$ \\
\hline 10 & 8 & 72 & $\begin{array}{l}\text { Mining of non-ferrous metal } \\
\text { ores }\end{array}$ & $\begin{array}{l}\text { Mineração de minérios não- } \\
\text { ferrosos }\end{array}$ \\
\hline 11 & 5 & 8 & Other mining and quarrying & $\begin{array}{l}\text { Outras atividades de minera- } \\
\text { ção e pedreira }\end{array}$ \\
\hline 12 & 5 & 9 & $\begin{array}{l}\text { Mining support service activi- } \\
\text { ties }\end{array}$ & $\begin{array}{l}\text { Atividades de serviço de su- } \\
\text { porte à mineração }\end{array}$ \\
\hline 13 & 0 & $\mathrm{C}$ & Manufacturing & Manufatura / indústria \\
\hline 14 & 13 & 10 & Manufacture of food products & Indústria de alimentos \\
\hline 15 & 13 & 11 & Manufacture of beverages & Indústria de bebidas \\
\hline 16 & 13 & 12 & $\begin{array}{l}\text { Manufacture of tobacco pro- } \\
\text { ducts }\end{array}$ & Indústria de tabaco \\
\hline 17 & 13 & 13 & Manufacture of textiles & Indústria têxtil \\
\hline 18 & 13 & 14 & $\begin{array}{l}\text { Manufacture of wearing appa- } \\
\text { rel }\end{array}$ & Fabricação de vestuário \\
\hline
\end{tabular}

Continua.. 
Tabela de classificação hieráquica de atividades econômicas ISIC v. 4

\begin{tabular}{|c|c|c|c|c|}
\hline Reg. & Reg. pai & TagISIC & Description & Descrição \\
\hline 19 & 13 & 15 & $\begin{array}{l}\text { Manufacture of leather and re- } \\
\text { lated products }\end{array}$ & $\begin{array}{l}\text { Fabricação de couro e produ- } \\
\text { tos afins }\end{array}$ \\
\hline 20 & 13 & 16 & $\begin{array}{l}\text { Manufacture of wood and of } \\
\text { products of wood and cork, ex- } \\
\text { cept furniture; manufacture of } \\
\text { articles of straw and plaiting } \\
\text { materials }\end{array}$ & $\begin{array}{l}\text { Fabricação de madeira e de } \\
\text { produtos de madeira e cortiça, } \\
\text { exceto móveis; fabricação de } \\
\text { artigos de palha e de cestaria }\end{array}$ \\
\hline 21 & 13 & 17 & $\begin{array}{l}\text { Manufacture of paper and pa- } \\
\text { per products }\end{array}$ & $\begin{array}{l}\text { Fabricação de papel e produ- } \\
\text { tos de papel }\end{array}$ \\
\hline 22 & 13 & 18 & $\begin{array}{l}\text { Printing and reproduction of } \\
\text { recorded media }\end{array}$ & $\begin{array}{l}\text { Impressão e reprodução de mí- } \\
\text { dia gravada }\end{array}$ \\
\hline 23 & 13 & 19 & $\begin{array}{l}\text { Manufacture of coke and refi- } \\
\text { ned petroleum products }\end{array}$ & $\begin{array}{l}\text { Fabricação de coque e produ- } \\
\text { tos petrolíferos refinados }\end{array}$ \\
\hline 24 & 13 & 20 & $\begin{array}{l}\text { Manufacture of chemicals and } \\
\text { chemical products }\end{array}$ & $\begin{array}{l}\text { Fabricação de produtos quími- } \\
\text { cos e produtos químicos }\end{array}$ \\
\hline 25 & 13 & 21 & $\begin{array}{l}\text { Manufacture of pharmaceuti- } \\
\text { cals, medicinal chemical and } \\
\text { botanical products }\end{array}$ & $\begin{array}{l}\text { Fabricação de produtos farma- } \\
\text { cêuticos, produtos químicos } \\
\text { medicinais e botânicos }\end{array}$ \\
\hline 26 & 13 & 22 & $\begin{array}{l}\text { Manufacture of rubber and } \\
\text { plastics products }\end{array}$ & $\begin{array}{l}\text { Fabricação de produtos de bor- } \\
\text { racha e plásticos }\end{array}$ \\
\hline 27 & 13 & 23 & $\begin{array}{l}\text { Manufacture of other non- } \\
\text { metallic mineral products }\end{array}$ & $\begin{array}{l}\text { Fabricação de outros produtos } \\
\text { minerais não metálicos }\end{array}$ \\
\hline 28 & 13 & 24 & Manufacture of basic metals & Fabricação de metais básicos \\
\hline 29 & 28 & 241 & $\begin{array}{l}\text { Manufacture of basic iron and } \\
\text { steel }\end{array}$ & $\begin{array}{l}\text { Fabricação de ferro e aço bási- } \\
\cos \end{array}$ \\
\hline 30 & 28 & 242 & $\begin{array}{l}\text { Manufacture of basic precious } \\
\text { and other non-ferrous metals }\end{array}$ & $\begin{array}{l}\text { Fabricação de metais precio- } \\
\text { sos e outros metais não ferro- } \\
\text { sos }\end{array}$ \\
\hline 31 & 28 & 243 & Casting of metals & Fundição de metais \\
\hline 32 & 31 & 2431 & Casting of iron and steel & Fundição de ferro e aço \\
\hline 33 & 31 & 2432 & Casting of non-ferrous metals & $\begin{array}{l}\text { Fundição de metais não ferro- } \\
\text { sos }\end{array}$ \\
\hline 34 & 13 & 25 & $\begin{array}{l}\text { Manufacture of fabricated me- } \\
\text { tal products, except machinery } \\
\text { and equipment }\end{array}$ & $\begin{array}{l}\text { Fabricação de produtos metáli- } \\
\text { cos fabricados, exceto máqui- } \\
\text { nas e equipamentos }\end{array}$ \\
\hline
\end{tabular}

Continua.. 
Tabela de classificação hieráquica de atividades econômicas ISIC v. 4

\begin{tabular}{|c|c|c|c|c|}
\hline Reg. & Reg. pai & TagISIC & Description & Descrição \\
\hline 35 & 13 & 26 & $\begin{array}{l}\text { Manufacture of compu- } \\
\text { ter, electronic and optical } \\
\text { products }\end{array}$ & $\begin{array}{l}\text { Fabricação de produtos infor- } \\
\text { máticos, eletrônicos e ópticos }\end{array}$ \\
\hline 36 & 13 & 27 & $\begin{array}{l}\text { Manufacture of electrical } \\
\text { equipment }\end{array}$ & $\begin{array}{l}\text { Fabricação de equipamentos } \\
\text { elétricos }\end{array}$ \\
\hline 37 & 13 & 28 & $\begin{array}{l}\text { Manufacture of machinery } \\
\text { and equipment n.e.c. }\end{array}$ & $\begin{array}{l}\text { Fabricação de máquinas e } \\
\text { equipamentos n.e.c. }\end{array}$ \\
\hline 38 & 13 & 29 & $\begin{array}{l}\text { Manufacture of motor vehi- } \\
\text { cles, trailers and semi-trailers }\end{array}$ & $\begin{array}{l}\text { Fabrico de veículos automó- } \\
\text { veis, reboques e semirrebo- } \\
\text { ques }\end{array}$ \\
\hline 39 & 13 & 30 & $\begin{array}{l}\text { Manufacture of other trans- } \\
\text { port equipment }\end{array}$ & $\begin{array}{l}\text { Fabricação de outro equipa- } \\
\text { mento de transporte }\end{array}$ \\
\hline 40 & 13 & 31 & Manufacture of furniture & Fabricação de móveis \\
\hline 41 & 13 & 32 & Other manufacturing & Outra fabricação \\
\hline 42 & 13 & 33 & $\begin{array}{l}\text { Repair and installation of ma- } \\
\text { chinery and equipment }\end{array}$ & $\begin{array}{l}\text { Reparação e instalação de má- } \\
\text { quinas e equipamentos }\end{array}$ \\
\hline 43 & 0 & $\mathrm{D}$ & $\begin{array}{l}\text { Electricity, gas, steam and air } \\
\text { conditioning supply }\end{array}$ & $\begin{array}{l}\text { Suprimento de eletricidade, } \\
\text { gás, vapor e ar condicionado }\end{array}$ \\
\hline 44 & 0 & $\mathrm{E}$ & $\begin{array}{l}\text { Water supply; sewerage, } \\
\text { waste management and } \\
\text { remediation activities }\end{array}$ & $\begin{array}{l}\text { Fornecimento de água, esgoto, } \\
\text { gerenciamento de resíduos e } \\
\text { atividades de remediação }\end{array}$ \\
\hline 45 & 0 & $\mathrm{~F}$ & Construction & Construção \\
\hline 46 & 0 & $\mathrm{G}$ & $\begin{array}{l}\text { Wholesale and retail trade; re- } \\
\text { pair of motor vehicles and mo- } \\
\text { torcycles }\end{array}$ & $\begin{array}{l}\text { Vendas no atacado e varejo; } \\
\text { reparo de automotores e moto- } \\
\text { cicletas }\end{array}$ \\
\hline 47 & 0 & $\mathrm{H}$ & Transportation and storage & Transporte e armazenamento \\
\hline 48 & 0 & $\mathrm{I}$ & $\begin{array}{l}\text { Accommodation and food ser- } \\
\text { vice activities }\end{array}$ & $\begin{array}{l}\text { Atividades de hospedagem e } \\
\text { alimentação }\end{array}$ \\
\hline 49 & 0 & $\mathrm{~J}$ & $\begin{array}{l}\text { Information and communica- } \\
\text { tion }\end{array}$ & Informação e comunicação \\
\hline 50 & 0 & $\mathrm{~K}$ & $\begin{array}{l}\text { Financial and insurance activi- } \\
\text { ties }\end{array}$ & Seguros e finanças \\
\hline 51 & 0 & $\mathrm{~L}$ & Real estate activities & Imobiliárias \\
\hline 52 & 0 & M & $\begin{array}{l}\text { Professional, scientific and te- } \\
\text { chnical activities }\end{array}$ & $\begin{array}{l}\text { Atividades profissionais, cien- } \\
\text { tíficas e técnicas }\end{array}$ \\
\hline
\end{tabular}

Continua.. 
Tabela de classificação hieráquica de atividades econômicas ISIC v. 4

\begin{tabular}{|c|c|c|c|c|}
\hline Reg. & Reg. pai & TagISIC & Description & Descrição \\
\hline 53 & 0 & $\mathrm{~N}$ & $\begin{array}{l}\text { Administrative and support } \\
\text { service activities }\end{array}$ & $\begin{array}{l}\text { Atividades de suporte e admi- } \\
\text { nistração }\end{array}$ \\
\hline 54 & 0 & $\mathrm{O}$ & $\begin{array}{l}\text { Public administration and de- } \\
\text { fense; compulsory social secu- } \\
\text { rity }\end{array}$ & $\begin{array}{l}\text { Administração pública e de- } \\
\text { fesa; previdência compulsória }\end{array}$ \\
\hline 55 & 0 & $\mathrm{P}$ & Education & Educação \\
\hline 56 & 0 & Q & $\begin{array}{l}\text { Human health and social work } \\
\text { activities }\end{array}$ & $\begin{array}{l}\text { Saúde humana e assistência } \\
\text { social }\end{array}$ \\
\hline 57 & 0 & $\mathrm{R}$ & $\begin{array}{l}\text { Arts, entertainment and recre- } \\
\text { ation }\end{array}$ & $\begin{array}{l}\text { Artes, entretenimento e recre- } \\
\text { ação }\end{array}$ \\
\hline 58 & 0 & $\mathrm{~S}$ & Other service activities & Outras atividades de serviço \\
\hline 59 & 0 & $\mathrm{~T}$ & $\begin{array}{l}\text { Activities of households } \\
\text { as employers; undifferen- } \\
\text { tiated goods- and services- } \\
\text { producing activities of } \\
\text { households for own use }\end{array}$ & $\begin{array}{l}\text { Atividade de empregador do- } \\
\text { méstico; bens indiferenciados } \\
\text { - e serviços - produção para } \\
\text { uso próprio }\end{array}$ \\
\hline 60 & 0 & $\mathrm{U}$ & $\begin{array}{l}\text { Activities of extraterritorial or- } \\
\text { ganizations and bodies }\end{array}$ & $\begin{array}{l}\text { Atividades de organizações } \\
\text { extraterritoriais e corpos }\end{array}$ \\
\hline
\end{tabular}

Fonte: compilado pelo autor com dados da UNIDO.

A.2 Tabelas analíticas da produção de ferro e aço

\section{A.2.1 Produção mundial de minério de ferro}

A tabela 8 mostra a produção anual de minério de ferro de um conjunto de países que representam mais que 95\% da produção entre os anos de 1997 e 2007, enquanto a tabela 9 apresenta os dados entre os anos de 2008 e 2016. 
Tabela 8 - Produção de minério de ferro entre 1997 e 2007

\begin{tabular}{lrrrrrrrrrrr}
\hline \hline Paises_Anos & $\mathbf{1 9 9 7}$ & $\mathbf{1 9 9 8}$ & $\mathbf{1 9 9 9}$ & $\mathbf{2 0 0 0}$ & $\mathbf{2 0 0 1}$ & $\mathbf{2 0 0 2}$ & $\mathbf{2 0 0 3}$ & $\mathbf{2 0 0 4}$ & $\mathbf{2 0 0 5}$ & $\mathbf{2 0 0 6}$ & $\mathbf{2 0 0 7}$ \\
\hline Australia & 165000 & 163300 & 153000 & 176300 & 181140 & 187210 & 211997 & 234697 & 257525 & 275091 & 298974 \\
Brazil & 187950 & 183050 & 188740 & 208830 & 210000 & 225100 & 245600 & 270522 & 292400 & 318629 & 336526 \\
India & 69400 & 71660 & 70220 & 74946 & 79210 & 86400 & 99100 & 120600 & 145500 & 165000 & 206939 \\
China & 125490 & 116038 & 111498 & 105257 & 102601 & 108758 & 122710 & 145749 & 200329 & 276441 & 401904 \\
Russia & 70870 & 72340 & 81853 & 86982 & 83046 & 84347 & 91368 & 96978 & 96828 & 103810 & 104953 \\
Ukraine & 53376 & 51066 & 47139 & 55622 & 54679 & 58897 & 62496 & 65542 & 68541 & 73010 & 77429 \\
SouthAfrica & 33230 & 32950 & 29510 & 33710 & 34760 & 36484 & 38086 & 39274 & 39542 & 41195 & 41559 \\
Canada & 38240 & 38720 & 34040 & 35930 & 27930 & 30902 & 33322 & 28596 & 30125 & 34094 & 34085 \\
UnitedStates & 62970 & 62930 & 57750 & 63090 & 45780 & 51500 & 48479 & 54700 & 54300 & 52900 & 52500 \\
Iran & 7000 & 12300 & 12400 & 12370 & 10313 & 10529 & 11385 & 12746 & 14828 & 18134 & 22000 \\
Sweden & 21893 & 20930 & 18853 & 20557 & 19486 & 20281 & 21498 & 22272 & 23256 & 23302 & 24713 \\
Mauritania & 11700 & 11400 & 10400 & 11450 & 10300 & 9600 & 10100 & 10719 & 10700 & 11127 & 11917 \\
Venezuela & 18660 & 17230 & 17000 & 17420 & 19030 & 20890 & 19195 & 20021 & 21179 & 22100 & 20650 \\
Kazakhstan & 13133 & 9336 & 9607 & 14898 & 14269 & 15481 & 17301 & 18726 & 16470 & 18608 & 18908 \\
Mexico & 10500 & 10500 & 11500 & 11326 & 8783 & 9942 & 11265 & 11483 & 11687 & 10718 & 10916 \\
\hline WLD & $\mathbf{9 2 4 3 8 6}$ & $\mathbf{9 0 6 5 7 6}$ & $\mathbf{8 8 4 5 6 5}$ & $\mathbf{9 5 9 6 5 0}$ & $\mathbf{9 3 2 0 4 6}$ & $\mathbf{9 8 6 0 2 1}$ & $\mathbf{1 0 7 4 0 7 8}$ & $\mathbf{1 1 8 4 4 3 3}$ & $\mathbf{1 3 2 0 4 3 8}$ & $\mathbf{1 4 8 2 4 3 6}$ & $\mathbf{1 7 0 5 4 3 4}$ \\
\hline Sum & $\mathbf{8 8 9 4 1 2}$ & $\mathbf{8 7 3 7 5 0}$ & $\mathbf{8 5 3 5 1 0}$ & $\mathbf{9 2 8 6 8 8}$ & $\mathbf{9 0 1 3 2 7}$ & $\mathbf{9 5 6 3 2 1}$ & $\mathbf{1 0 4 3 9 0 2}$ & $\mathbf{1 1 5 2 6 2 5}$ & $\mathbf{1 2 8 3 2 1 0}$ & $\mathbf{1 4 4 4 1 5 9}$ & $\mathbf{1 6 6 3 9 7 3}$ \\
Sum $(\boldsymbol{\%})$ & $\mathbf{9 6 \%}$ & $\mathbf{9 6 \%}$ & $\mathbf{9 6 \%}$ & $\mathbf{9 7 \%}$ & $\mathbf{9 7 \%}$ & $\mathbf{9 7 \%}$ & $\mathbf{9 7 \%}$ & $\mathbf{9 7 \%}$ & $\mathbf{9 7 \%}$ & $\mathbf{9 7 \%}$ & $\mathbf{9 8 \%}$ \\
\hline ROW & $\mathbf{3 4 9 7 4}$ & $\mathbf{3 2 8 2 6}$ & $\mathbf{3 1 0 5 5}$ & $\mathbf{3 0 9 6 2}$ & $\mathbf{3 0 7 1 9}$ & $\mathbf{2 9 7 0 0}$ & $\mathbf{3 0 1 7 6}$ & $\mathbf{3 1 8 0 8}$ & $\mathbf{3 7 2 2 8}$ & $\mathbf{3 8 2 7 7}$ & $\mathbf{4 1 4 6 1}$ \\
\hline \hline
\end{tabular}

Fonte: Produzido pelo autor pela compilação de dados da WorldSteel (2007). 
Tabela 9 - Produção de minério de ferro entre 2008 e 2016

\begin{tabular}{lrrrrrrrrr}
\hline \hline Paises_Anos & $\mathbf{2 0 0 8}$ & $\mathbf{2 0 0 9}$ & $\mathbf{2 0 1 0}$ & $\mathbf{2 0 1 1}$ & $\mathbf{2 0 1 2}$ & $\mathbf{2 0 1 3}$ & $\mathbf{2 0 1 4}$ & $\mathbf{2 0 1 5}$ & $\mathbf{2 0 1 6}$ \\
\hline Australia & 349822 & 394068 & 432779 & 477332 & 520032 & 608900 & 745735 & 811239 & 841800 \\
Brazil & 346000 & 305000 & 372000 & 397000 & 380086 & 391100 & 399400 & 422547 & 431400 \\
India & 223000 & 223600 & 209000 & 191800 & 152600 & 136100 & 139700 & 142500 & 184500 \\
China & 325882 & 240999 & 357000 & 358900 & 289000 & 315200 & 194700 & 123500 & 113700 \\
Russia & 99272 & 92050 & 99060 & 103805 & 103337 & 102497 & 101448 & 101973 & 104007 \\
Ukraine & 71807 & 65827 & 79170 & 81189 & 80826 & 83696 & 82409 & 81966 & 74967 \\
SouthAfrica & 48983 & 55423 & 55000 & 52900 & 59000 & 60600 & 66920 & 61380 & 68100 \\
Canada & 33386 & 32972 & 37501 & 37101 & 39401 & 41841 & 44196 & 45954 & 48700 \\
UnitedStates & 53600 & 26700 & 49900 & 54700 & 54000 & 52000 & 54300 & 43100 & 42000 \\
Iran & 32000 & 33000 & 35549 & 38260 & 43497 & 48693 & 48451 & 39370 & 40100 \\
Sweden & 23848 & 17680 & 25292 & 26113 & 26540 & 27285 & 28144 & 24600 & 26900 \\
Mauritania & 11222 & 11400 & 11109 & 11176 & 11170 & 12531 & 13306 & 11600 & 13500 \\
Venezuela & 21463 & 14900 & 14331 & 16348 & 16347 & 7831 & 5854 & 8251 & 12000 \\
Kazakhstan & 17295 & 17785 & 17921 & 17636 & 16722 & 19373 & 15546 & 11359 & 10064 \\
Mexico & 11688 & 11677 & 13998 & 12806 & 14916 & 18840 & 17248 & 14441 & 10000 \\
WLD & $\mathbf{1 7 1 7 5 5 9}$ & $\mathbf{1 5 9 0 6 2 2}$ & $\mathbf{1 8 7 3 8 4 7}$ & $\mathbf{1 9 5 7 6 2 7}$ & $\mathbf{1 9 0 4 4 6 5}$ & $\mathbf{2 0 3 8 9 6 2}$ & $\mathbf{2 0 5 4 0 7 8}$ & $\mathbf{2 0 0 6 3 4 6}$ & $\mathbf{2 0 9 2 1 3 8}$ \\
Sum & $\mathbf{1 6 6 9 2 6 8}$ & $\mathbf{1 5 4 3 0 8 1}$ & $\mathbf{1 8 0 9 6 1 0}$ & $\mathbf{1 8 7 7 0 6 6}$ & $\mathbf{1 8 0 7 4 7 4}$ & $\mathbf{1 9 2 6 4 8 7}$ & $\mathbf{1 9 5 7 3 5 7}$ & $\mathbf{1 9 4 3 7 8 0}$ & $\mathbf{2 0 2 1 7 3 8}$ \\
Sum $(\boldsymbol{\%})$ & $\mathbf{9 7 \%}$ & $\mathbf{9 7 \%}$ & $\mathbf{9 7 \%}$ & $\mathbf{9 6 \%}$ & $\mathbf{9 5 \%}$ & $\mathbf{9 4 \%}$ & $\mathbf{9 5 \%}$ & $\mathbf{9 7 \%}$ & $\mathbf{9 7 \%}$ \\
ROW & $\mathbf{4 8 2 9 1}$ & $\mathbf{4 7 5 4 1}$ & $\mathbf{6 4 2 3 7}$ & $\mathbf{8 0 5 6 1}$ & $\mathbf{9 6 9 9 1}$ & $\mathbf{1 1 2 4 7 5}$ & $\mathbf{9 6 7 2 1}$ & $\mathbf{6 2 5 6 6}$ & $\mathbf{7 0 4 0 0}$ \\
\hline \hline
\end{tabular}

Fonte: Produzido pelo autor pela compilação de dados da WorldSteel (2017). 
A.2.2 Importação mundial de minério de ferro

A tabela 12 mostra a Importaçao mundial anual de minério de ferro por países entre os anos de 1997 a 2007, enquanto a tabela 13 apresenta os dados entre os anos de 2008 e 2016. 
Tabela 10 - Importação mundial de minério de ferro entre 1997 e 2007 (em 1000 t)

Continua

\begin{tabular}{|c|c|c|c|c|c|c|c|c|c|c|c|}
\hline Paises & 1997 & 1998 & 1999 & 2000 & 2001 & 2002 & 2003 & 2004 & 2005 & 2006 & 2007 \\
\hline Japan & 126601 & 120782 & 120107 & 131733 & 126297 & 129088 & 132081 & 134884 & 132285 & 134287 & 138928 \\
\hline China & 55106 & 51771 & 55274 & 69971 & 92393 & 111423 & 148128 & 208089 & 275260 & 326303 & 383618 \\
\hline Germany & 41687 & 52530 & 38802 & 47503 & 40095 & 44298 & 33876 & 38861 & 39061 & 44850 & 46194 \\
\hline SouthKorea & 38592 & 33612 & 35400 & 38980 & 45875 & 43311 & 43069 & 44225 & 42250 & 42807 & 43668 \\
\hline UnitedKingdom & 21033 & 20765 & 17030 & 16779 & 15352 & 13316 & 16118 & 15299 & 16205 & 16441 & 17365 \\
\hline France & 20176 & 19735 & 20304 & 19690 & 16707 & 19015 & 19040 & 20773 & 19498 & 19892 & 19364 \\
\hline UnitedStates & 18599 & 17009 & 14244 & 15677 & 10645 & 12453 & 12497 & 11757 & 12992 & 11470 & 9389 \\
\hline Italy & 16663 & 14165 & 15615 & 17619 & 15814 & 14898 & 15232 & 16715 & 17552 & 17845 & 17013 \\
\hline Taiwan,China & 14043 & 14042 & 13237 & 14900 & 15571 & 15242 & 15608 & 15667 & 14579 & 15459 & 16035 \\
\hline Belgium-Luxembourg & 11159 & 13494 & 12165 & 11830 & 11223 & 12192 & 11578 & 10438 & 9390 & 11370 & 9662 \\
\hline Poland & 10337 & 9982 & 7327 & 9739 & 8261 & 6946 & 8744 & 9990 & 6782 & 8576 & 8747 \\
\hline Netherlands & 8596 & 8831 & 7911 & 7334 & 7703 & 7370 & 14705 & 30279 & 37637 & 33562 & 31501 \\
\hline CzechRepublic & 7383 & 7395 & 5357 & 6637 & 6887 & 6807 & 8221 & 9387 & 6802 & 7985 & 5046 \\
\hline Canada & 7081 & 7201 & 7311 & 6566 & 5906 & 6845 & 6648 & 7979 & 9562 & 7551 & 7269 \\
\hline Romania & 6625 & 6569 & 4171 & 5049 & 3900 & 6200 & 6978 & 6609 & 6601 & 5166 & 6260 \\
\hline Spain & 5858 & 6584 & 6283 & 6265 & 6641 & 6158 & 5766 & 6107 & 6248 & 5511 & 5719 \\
\hline Russia & 5396 & 6751 & 3327 & 9189 & 8799 & 9326 & 10489 & 10536 & 19208 & 10116 & 10682 \\
\hline Austria & 5103 & 4910 & 4349 & 5426 & 5345 & 5775 & 5668 & 5783 & 4488 & 8413 & 9006 \\
\hline Argentina & 5054 & 5470 & 4143 & 5074 & 4477 & 5219 & 6322 & 5407 & 6671 & 6686 & 6586 \\
\hline Philippines & 4800 & 4800 & 4000 & 4300 & 4300 & 4676 & 4320 & 3573 & 4000 & 3818 & 2627 \\
\hline OtherEurope & 4580 & 4441 & 4721 & 4600 & 3761 & 6102 & 7456 & 7163 & 8028 & 8803 & 13298 \\
\hline SlovakRepublic & 4505 & 3975 & 4270 & 4742 & 4629 & 5130 & 5665 & 5279 & 5510 & 6692 & 5854 \\
\hline Finland & 3732 & 3993 & 3819 & 3865 & 3916 & 3779 & 4212 & 3793 & 4216 & 3481 & 3156 \\
\hline Australia & 3250 & 2600 & 2004 & 1857 & 1804 & 1990 & 1282 & 2284 & 1547 & 3144 & 4217 \\
\hline Bahrain & 3163 & 2020 & 1755 & 3291 & 1836 & 2931 & 3290 & 3723 & 4146 & 3363 & 2910 \\
\hline Iran & 3000 & 1700 & 1800 & 2400 & 3000 & 1845 & 538 & 597 & 657 & 1421 & 1038 \\
\hline Turkey & 2951 & 3858 & 2973 & 4110 & 3550 & 5776 & 5474 & 4574 & 4621 & 5587 & 6088 \\
\hline Mexico & 2800 & 4000 & 3900 & 3065 & 2292 & 2709 & 3645 & 4354 & 4181 & 3864 & 3127 \\
\hline SaudiArabia & 2700 & 3300 & 3500 & 4550 & 4430 & 4676 & 4320 & 4100 & 9722 & 5546 & 4931 \\
\hline Malaysia & 2618 & 1072 & 1356 & 1736 & 1568 & 1257 & 2436 & 2185 & 1891 & 2145 & 2677 \\
\hline Ukraine & 2124 & 3430 & 4683 & 7417 & 6341 & 4986 & 7618 & 3338 & 2950 & 2097 & 3482 \\
\hline Indonesia & 1871 & 1311 & 2070 & 2159 & 1292 & 1319 & 1622 & 1996 & 1548 & 1761 & 1737 \\
\hline Egypt & 1804 & 2200 & 2200 & 3400 & 3255 & 3529 & 4393 & 4347 & 4516 & 4435 & 4435 \\
\hline
\end{tabular}


Tabela 10 - Importação mundial de minério de ferro entre 1997 e 2007 (em 1000 t)

Continuação

\begin{tabular}{|c|c|c|c|c|c|c|c|c|c|c|c|}
\hline Paises & 1997 & 1998 & 1999 & 2000 & 2001 & 2002 & 2003 & 2004 & 2005 & 2006 & 2007 \\
\hline TrinidadandTobago & 1689 & 1700 & 2300 & 2460 & 3338 & 3177 & 3248 & 3779 & 3900 & 4284 & 2894 \\
\hline Pakistan & 1650 & 1378 & 1645 & 1477 & 1442 & 1500 & 1452 & 1041 & 2111 & 1309 & 1078 \\
\hline Bulgaria & 1638 & 1706 & 1700 & 1800 & 1300 & 1500 & 1725 & 1725 & 1426 & 1785 & 923 \\
\hline Hungary & 1453 & 2048 & 1744 & 2098 & 2184 & 1690 & 1777 & 1749 & 1211 & 988 & 967 \\
\hline Libya & 1348 & 1700 & 1600 & 2100 & 1532 & 1652 & 1884 & 2312 & 3100 & 2309 & 2309 \\
\hline Serbia & 1067 & 53 & 1259 & 302 & 23 & 119 & 1804 & 2057 & 2880 & 3000 & 3000 \\
\hline India & 800 & 600 & 700 & 510 & 300 & 282 & 457 & 1019 & 1266 & 806 & 1122 \\
\hline Qatar & 600 & 600 & 500 & 500 & 400 & 309 & 368 & 431 & 1300 & 1399 & 471 \\
\hline Norway & 562 & 530 & 489 & 188 & 188 & 207 & 178 & 532 & 527 & 216 & 180 \\
\hline OtherMiddleEast & 155 & & & 510 & 2 & & & 622 & 619 & 382 & 382 \\
\hline OtherSouthAmerica & 150 & 150 & 150 & 261 & 300 & 160 & 160 & 252 & 193 & 210 & 0 \\
\hline OtherAfrica & 143 & 80 & 80 & 200 & 197 & 0 & 0 & 135 & 46 & 617 & 333 \\
\hline Sweden & 103 & 69 & 69 & 94 & 109 & 116 & 111 & 100 & 98 & 82 & 70 \\
\hline OtherAsia & 96 & & & 4646 & 5118 & 0 & 0 & 986 & 773 & 1748 & 1250 \\
\hline Kazakhstan & 48 & 209 & & & & & & & & 183 & 1229 \\
\hline Denmark & 6 & 3 & 3 & 3 & 5 & & 1 & 2 & 4 & 3 & 43 \\
\hline OtherE.U. & & & & & & & & & & & 5 \\
\hline OtherCIS & & & & & & & & & & & 0 \\
\hline OtherNorthAmerica & & & & & & & & & & & 0 \\
\hline Brazil & & & & & & & & & & & 0 \\
\hline Colombia & & & & & & & & & & & 9 \\
\hline \multicolumn{12}{|l|}{ Paraguay } \\
\hline Peru & & & & & & & & & & & 0 \\
\hline Venezuela & & & & & 1 & & & & 0 & 662 & 662 \\
\hline Algeria & & & & 0 & 0 & & & 0 & 46 & 543 & 543 \\
\hline SouthAfrica & & & & & & & & & & 133 & 480 \\
\hline UnitedArabEmirates & & & & 165 & & & 228 & 214 & 428 & 896 & 896 \\
\hline Bangladesh & & & & & & & & & & & 44 \\
\hline HongKong & & & & & & & & & & & 454 \\
\hline Singapore & & & & & & & & & & & 77 \\
\hline Thailand & & & & & & & & & & & 3 \\
\hline OtherOceania & & & & & & & & & & & 0 \\
\hline World & 476504 & 471485 & 443552 & 510783 & 506715 & 531296 & 583021 & 669897 & 752486 & 803008 & 861786 \\
\hline
\end{tabular}


Tabela 10 - Importação mundial de minério de ferro entre 1997 e 2007 (em 1000 t)

Continuação

\begin{tabular}{|c|c|c|c|c|c|c|c|c|c|c|c|}
\hline Paises & 1997 & 1998 & 1999 & 2000 & 2001 & 2002 & 2003 & 2004 & 2005 & 2006 & 2007 \\
\hline SUM & 480498 & 475124 & 447647 & 514767 & 510304 & 537299 & 590432 & 677047 & 760532 & 812002 & 871053 \\
\hline DIF & -586 & -802 & -626 & -616 & -172 & -99 & -45 & -13 & 18 & 191 & -1 \\
\hline $\mathrm{DIF}(\%)$ & $-0,12 \%$ & $-0,17 \%$ & $-0,14 \%$ & $-0,12 \%$ & $-0,03 \%$ & $-0,02 \%$ & $-0,01 \%$ & $0,00 \%$ & $0,00 \%$ & $0,02 \%$ & $0,00 \%$ \\
\hline
\end{tabular}


Tabela 11 - Importação mundial de minério de ferro entre 2007 e 2016 (em 1000 t)

Continua

\begin{tabular}{|c|c|c|c|c|c|c|c|c|c|c|}
\hline Paises_Anos & 2007 & 2008 & 2009 & 2010 & 2011 & 2012 & 2013 & 2014 & 2015 & 2016 \\
\hline Austria & 9006 & 5017 & 3471 & 5955 & 6732 & 6056 & 5864 & 5100 & 5137 & 4152 \\
\hline Belgium-Luxembourg & 9662 & 12726 & 3255 & 7527 & 7430 & 6311 & 6351 & 6812 & 6631 & 6998 \\
\hline Bulgaria & 923 & 526 & 139 & 0 & 1 & 2 & 10 & 14 & 1 & 1 \\
\hline CzechRepublic & 5046 & 6800 & 4803 & 3853 & 7366 & 5871 & 6237 & 6305 & 6370 & 6345 \\
\hline Denmark & 43 & 99 & 49 & 51 & 100 & 78 & 40 & 29 & 53 & 85 \\
\hline Germany & 46194 & 44339 & 51922 & 43082 & 39672 & 40724 & 40930 & 43030 & 40964 & 40031 \\
\hline Finland & 3156 & 3121 & 2204 & 2984 & 3045 & 3221 & 2903 & 3078 & 3423 & 3516 \\
\hline France & 19364 & 18290 & 10015 & 15245 & 13512 & 13604 & 15285 & 17106 & 15655 & 13947 \\
\hline Hungary & 967 & 1900 & 1493 & 1888 & 1781 & 1632 & 845 & 1265 & 1641 & 1208 \\
\hline Italy & 17013 & 16313 & 8160 & 10863 & 14675 & 13434 & 11522 & 9511 & 8076 & 9151 \\
\hline Netherlands & 31501 & 32639 & 21638 & 33944 & 33432 & 28269 & 31883 & 29675 & 30911 & 30574 \\
\hline Poland & 8747 & 7785 & 3752 & 5563 & 5968 & 6583 & 6640 & 7433 & 7247 & 7061 \\
\hline Romania & 6260 & 4446 & 806 & 2462 & 2187 & 2023 & 2546 & 2226 & 2964 & 2720 \\
\hline SlovakRepublic & 5854 & 5536 & 4186 & 5174 & 5103 & 5404 & 5647 & 6012 & 5536 & 6031 \\
\hline Spain & 5719 & 6328 & 3951 & 5877 & 5144 & 4506 & 6259 & 5699 & 6377 & 6010 \\
\hline Sweden & 70 & 71 & 41 & 55 & 51 & 44 & 26 & 26 & 70 & 175 \\
\hline UnitedKingdom & 17365 & 15283 & 9186 & 10597 & 9175 & 10062 & 14137 & 14469 & 12047 & 9292 \\
\hline OtherE.U. & 5 & 0 & 18 & 1 & 4 & 5 & 4 & 11 & 28 & 22 \\
\hline EuropeanUnion(28) & 186895 & 181219 & 129089 & 155124 & 155378 & 147830 & 157129 & 157800 & 153130 & 147318 \\
\hline Norway & 180 & 152 & 134 & 149 & 128 & 93 & 74 & 49 & 27 & 75 \\
\hline Serbia & 3000 & 3100 & 3100 & 3422 & 1621 & 241 & 338 & 293 & 1287 & 1771 \\
\hline Turkey & 6088 & 6900 & 5685 & 6382 & 6644 & 7842 & 8114 & 8544 & 10011 & 10418 \\
\hline OtherEurope & 4030 & 6 & 0 & 5 & 149 & 12 & 9 & 13 & 12 & 14 \\
\hline OtherEurope & 13298 & 10158 & 8919 & 9959 & 8542 & 8188 & 8536 & 8900 & 11338 & 12277 \\
\hline Kazakhstan & 1229 & 1936 & 504 & 624 & $\ldots$ & 0 & $\ldots$ & 0 & $\ldots$ & $\ldots$ \\
\hline Russia & 10682 & 11752 & 8404 & 4524 & 146 & 225 & 86 & 10341 & 8103 & 7204 \\
\hline Ukraine & 3482 & 2869 & 3339 & 2738 & 1838 & 2882 & 3110 & 3212 & 2255 & 1765 \\
\hline OtherCIS & & & & & 7 & 45 & 22 & 48 & 52 & 186 \\
\hline C.I.S. & 15393 & 16556 & 12247 & 7886 & 1991 & 3153 & 3219 & 13601 & 10410 & 9154 \\
\hline Canada & 7269 & 9073 & 3103 & 8126 & 7129 & 6500 & 6112 & 8955 & 6596 & 7100 \\
\hline Mexico & 3127 & 3875 & 557 & 1426 & 1460 & 1368 & 1142 & 1551 & 1460 & 3699 \\
\hline TrinidadandTobago & 2894 & 4252 & 2340 & 4347 & 4381 & 4691 & 4659 & 5445 & 7779 & 5890 \\
\hline UnitedStates & 9389 & 9236 & $\ldots$ & 6417 & 5268 & 5132 & 3172 & 5097 & 4550 & 3079 \\
\hline
\end{tabular}


Tabela 11 - Importação mundial de minério de ferro entre 2007 e 2016 (em 1000 t)

\begin{tabular}{|c|c|c|c|c|c|c|c|c|c|c|}
\hline Paises_Anos & 2007 & 2008 & 2009 & 2010 & 2011 & 2012 & 2013 & 2014 & 2015 & 2016 \\
\hline OtherNorthAmerica & 0 & 0 & 1 & 0 & 257 & 5 & 1 & 0 & 0 & 1 \\
\hline NorthAmerica & 22679 & 26435 & 6001 & 20316 & 18494 & 17696 & 15086 & 21049 & 20385 & 19768 \\
\hline Argentina & 6586 & 7176 & 3229 & 6400 & 6891 & 5328 & 5828 & 6385 & 5189 & 4298 \\
\hline Brazil & 0 & 66 & $\ldots$ & 126 & 0 & 0 & 0 & 5 & 0 & 0 \\
\hline Colombia & 9 & 150 & 20 & 9 & 4 & 3 & 3 & 0 & 1 & 1 \\
\hline Paraguay & $\ldots$ & $\ldots$ & $\ldots$ & $\ldots$ & 135 & 48 & 49 & 81 & 108 & 100 \\
\hline Peru & 0 & 170 & 0 & 30 & 30 & 0 & 0 & 0 & 0 & 0 \\
\hline Venezuela & 662 & 387 & $\ldots$ & $\ldots$ & 182 & 0 & 0 & $\ldots$ & $\ldots$ & $\ldots$ \\
\hline OtherSouthAmerica & 0 & $\ldots$ & 0 & 1 & 0 & 1 & 0 & 0 & 0 & 1 \\
\hline SouthAmerica & 7258 & 7948 & 3249 & 6565 & 7241 & 5382 & 5879 & 6471 & 5297 & 4400 \\
\hline Algeria & 543 & 213 & 0 & 117 & 11 & 26 & 0 & 0 & 0 & 2 \\
\hline Egypt & 4435 & 3562 & 4583 & 4178 & 4343 & 4235 & 3824 & 3249 & 2209 & 4062 \\
\hline Libya & 2309 & 2539 & 1304 & 2257 & 63 & 844 & 1819 & 1377 & 306 & 888 \\
\hline SouthAfrica & 480 & 485 & 352 & 401 & 417 & 558 & 476 & 479 & 429 & 341 \\
\hline OtherAfrica & 333 & 86 & 0 & 1 & 85 & 12 & 167 & 371 & 2 & 51 \\
\hline Africa & 8100 & 6884 & 6239 & 6953 & 4918 & 5675 & 6287 & 5476 & 2946 & 5344 \\
\hline Bahrain & 2910 & 7964 & 4144 & 6330 & 7217 & 5103 & 2969 & 5460 & 6059 & 4853 \\
\hline Iran & 1038 & 929 & 216 & $\ldots$ & $\ldots$ & 39 & 0 & 500 & 492 & 390 \\
\hline Qatar & 471 & 1616 & 1680 & 1777 & 3797 & 2714 & 2431 & 2268 & 2451 & 1630 \\
\hline SaudiArabia & 4931 & 7638 & 6039 & 9019 & 7516 & 4161 & 3575 & 5111 & 4031 & 3627 \\
\hline UnitedArabEmirates & 896 & 300 & 199 & 3130 & 2807 & 3050 & 3051 & 2703 & 3850 & 2282 \\
\hline OtherMiddleEast & 382 & 0 & 47 & 154 & 6466 & 10254 & 10137 & 10506 & 10943 & 9202 \\
\hline MiddleEast & 10628 & 18447 & 12324 & 20411 & 27803 & 25321 & 22163 & 26549 & 27825 & 21985 \\
\hline Bangladesh & 44 & 102 & 101 & 0 & 158 & $\ldots$ & $\ldots$ & $\ldots$ & 0 & $\ldots$ \\
\hline China & 383618 & 444028 & 628175 & 618915 & 686747 & 745434 & 820175 & 933108 & 953370 & 1024709 \\
\hline HongKong & 454 & 835 & 1281 & 786 & 811 & 242 & 724 & 4754 & 3655 & 3647 \\
\hline India & 1122 & 600 & 623 & 450 & 1316 & 2822 & 1115 & 7413 & 9515 & 3597 \\
\hline Indonesia & 1737 & 2300 & 1488 & 2029 & 1804 & 973 & 1932 & 3869 & 5424 & 5110 \\
\hline Japan & 138928 & 140351 & 105471 & 134335 & 128489 & 131114 & 135886 & 136436 & 131010 & 130035 \\
\hline SouthKorea & 43668 & 49441 & 41601 & 56298 & 64857 & 65998 & 63372 & 73507 & 73282 & 71741 \\
\hline Malaysia & 2677 & 3043 & 2523 & 3199 & 2852 & 3291 & 1711 & 3814 & 14742 & 22966 \\
\hline Pakistan & 1078 & 489 & 37 & 2 & 116 & $\ldots$ & 0 & 80 & $\ldots$ & $\ldots$ \\
\hline Philippines & 2627 & 2700 & 1066 & 2334 & 3045 & 6746 & 6891 & 6352 & 15836 & 4230 \\
\hline
\end{tabular}


Tabela 11 - Importação mundial de minério de ferro entre 2007 e 2016 (em 1000 t)

Continuação

\begin{tabular}{|c|c|c|c|c|c|c|c|c|c|c|}
\hline Paises_Anos & 2007 & 2008 & 2009 & 2010 & 2011 & 2012 & 2013 & 2014 & 2015 & 2016 \\
\hline Singapore & 77 & $\ldots$ & $\ldots$ & $\ldots$ & $\ldots$ & 1 & 0 & 1 & 1 & 1 \\
\hline Taiwan,China & 16035 & 15571 & 11912 & 18930 & 20507 & 18396 & 21773 & 23039 & 23814 & 23462 \\
\hline Thailand & 3 & 40 & $\ldots$ & $\ldots$ & 82 & 11 & 11 & 4 & $\ldots$ & $\ldots$ \\
\hline OtherAsia & 1250 & 1604 & 1940 & 1807 & 245 & 14110 & 234 & 114 & 298 & 14640 \\
\hline Asia & 593319 & 661105 & 796219 & 839084 & 911030 & 989138 & 1053825 & 1192491 & 1230947 & 1304138 \\
\hline Australia & 4217 & 4649 & 3852 & 5503 & 4987 & 3951 & 4070 & 3003 & 2792 & 815 \\
\hline OtherOceania & 0 & 0 & 0 & 0 & 1 & 1 & 1 & 1 & 1 & 0 \\
\hline Oceania & 4218 & 4649 & 3852 & 5503 & 4988 & 3952 & 4071 & 3004 & 2793 & 815 \\
\hline World & 861786 & 933401 & 978139 & 1071802 & 1140385 & 1206334 & 1276195 & 1435340 & 1465071 & 1525200 \\
\hline
\end{tabular}

Fonte: compilado pelo autor com dados da WorldSteel (2017), WorldSteel (2007). 


\section{A.2.3 Exportação mundial de minério de ferro}

A tabela 12 mostra a Exportaçao mundial anual de minério de ferro por países entre os anos de 1997 a 2007, enquanto a tabela 13 apresenta os dados entre os anos de 2008 e 2016. 
Tabela 12 - Importação mundial de minério de ferro entre 1997 e 2007 (em 1000 t)

Continua

\begin{tabular}{|c|c|c|c|c|c|c|c|c|c|c|c|}
\hline Paises & 1997 & 1998 & 1999 & 2000 & 2001 & 2002 & 2003 & 2004 & 2005 & 2006 & 2007 \\
\hline Japan & 126601 & 120782 & 120107 & 131733 & 126297 & 129088 & 132081 & 134884 & 132285 & 134287 & 138928 \\
\hline China & 55106 & 51771 & 55274 & 69971 & 92393 & 111423 & 148128 & 208089 & 275260 & 326303 & 383618 \\
\hline Germany & 41687 & 52530 & 38802 & 47503 & 40095 & 44298 & 33876 & 38861 & 39061 & 44850 & 46194 \\
\hline SouthKorea & 38592 & 33612 & 35400 & 38980 & 45875 & 43311 & 43069 & 44225 & 42250 & 42807 & 43668 \\
\hline UnitedKingdom & 21033 & 20765 & 17030 & 16779 & 15352 & 13316 & 16118 & 15299 & 16205 & 16441 & 17365 \\
\hline France & 20176 & 19735 & 20304 & 19690 & 16707 & 19015 & 19040 & 20773 & 19498 & 19892 & 19364 \\
\hline UnitedStates & 18599 & 17009 & 14244 & 15677 & 10645 & 12453 & 12497 & 11757 & 12992 & 11470 & 9389 \\
\hline Italy & 16663 & 14165 & 15615 & 17619 & 15814 & 14898 & 15232 & 16715 & 17552 & 17845 & 17013 \\
\hline Taiwan,China & 14043 & 14042 & 13237 & 14900 & 15571 & 15242 & 15608 & 15667 & 14579 & 15459 & 16035 \\
\hline Belgium-Luxembourg & 11159 & 13494 & 12165 & 11830 & 11223 & 12192 & 11578 & 10438 & 9390 & 11370 & 9662 \\
\hline Poland & 10337 & 9982 & 7327 & 9739 & 8261 & 6946 & 8744 & 9990 & 6782 & 8576 & 8747 \\
\hline Netherlands & 8596 & 8831 & 7911 & 7334 & 7703 & 7370 & 14705 & 30279 & 37637 & 33562 & 31501 \\
\hline CzechRepublic & 7383 & 7395 & 5357 & 6637 & 6887 & 6807 & 8221 & 9387 & 6802 & 7985 & 5046 \\
\hline Canada & 7081 & 7201 & 7311 & 6566 & 5906 & 6845 & 6648 & 7979 & 9562 & 7551 & 7269 \\
\hline Romania & 6625 & 6569 & 4171 & 5049 & 3900 & 6200 & 6978 & 6609 & 6601 & 5166 & 6260 \\
\hline Spain & 5858 & 6584 & 6283 & 6265 & 6641 & 6158 & 5766 & 6107 & 6248 & 5511 & 5719 \\
\hline Russia & 5396 & 6751 & 3327 & 9189 & 8799 & 9326 & 10489 & 10536 & 19208 & 10116 & 10682 \\
\hline Austria & 5103 & 4910 & 4349 & 5426 & 5345 & 5775 & 5668 & 5783 & 4488 & 8413 & 9006 \\
\hline Argentina & 5054 & 5470 & 4143 & 5074 & 4477 & 5219 & 6322 & 5407 & 6671 & 6686 & 6586 \\
\hline Philippines & 4800 & 4800 & 4000 & 4300 & 4300 & 4676 & 4320 & 3573 & 4000 & 3818 & 2627 \\
\hline OtherEurope & 4580 & 4441 & 4721 & 4600 & 3761 & 6102 & 7456 & 7163 & 8028 & 8803 & 13298 \\
\hline SlovakRepublic & 4505 & 3975 & 4270 & 4742 & 4629 & 5130 & 5665 & 5279 & 5510 & 6692 & 5854 \\
\hline Finland & 3732 & 3993 & 3819 & 3865 & 3916 & 3779 & 4212 & 3793 & 4216 & 3481 & 3156 \\
\hline Australia & 3250 & 2600 & 2004 & 1857 & 1804 & 1990 & 1282 & 2284 & 1547 & 3144 & 4217 \\
\hline Bahrain & 3163 & 2020 & 1755 & 3291 & 1836 & 2931 & 3290 & 3723 & 4146 & 3363 & 2910 \\
\hline Iran & 3000 & 1700 & 1800 & 2400 & 3000 & 1845 & 538 & 597 & 657 & 1421 & 1038 \\
\hline Turkey & 2951 & 3858 & 2973 & 4110 & 3550 & 5776 & 5474 & 4574 & 4621 & 5587 & 6088 \\
\hline Mexico & 2800 & 4000 & 3900 & 3065 & 2292 & 2709 & 3645 & 4354 & 4181 & 3864 & 3127 \\
\hline SaudiArabia & 2700 & 3300 & 3500 & 4550 & 4430 & 4676 & 4320 & 4100 & 9722 & 5546 & 4931 \\
\hline Malaysia & 2618 & 1072 & 1356 & 1736 & 1568 & 1257 & 2436 & 2185 & 1891 & 2145 & 2677 \\
\hline Ukraine & 2124 & 3430 & 4683 & 7417 & 6341 & 4986 & 7618 & 3338 & 2950 & 2097 & 3482 \\
\hline Indonesia & 1871 & 1311 & 2070 & 2159 & 1292 & 1319 & 1622 & 1996 & 1548 & 1761 & 1737 \\
\hline Egypt & 1804 & 2200 & 2200 & 3400 & 3255 & 3529 & 4393 & 4347 & 4516 & 4435 & 4435 \\
\hline
\end{tabular}


Tabela 12 - Importação mundial de minério de ferro entre 1997 e 2007 (em 1000 t)

Continuação

\begin{tabular}{|c|c|c|c|c|c|c|c|c|c|c|c|}
\hline Paises & 1997 & 1998 & 1999 & 2000 & 2001 & 2002 & 2003 & 2004 & 2005 & 2006 & 2007 \\
\hline TrinidadandTobago & 1689 & 1700 & 2300 & 2460 & 3338 & 3177 & 3248 & 3779 & 3900 & 4284 & 2894 \\
\hline Pakistan & 1650 & 1378 & 1645 & 1477 & 1442 & 1500 & 1452 & 1041 & 2111 & 1309 & 1078 \\
\hline Bulgaria & 1638 & 1706 & 1700 & 1800 & 1300 & 1500 & 1725 & 1725 & 1426 & 1785 & 923 \\
\hline Hungary & 1453 & 2048 & 1744 & 2098 & 2184 & 1690 & 1777 & 1749 & 1211 & 988 & 967 \\
\hline Libya & 1348 & 1700 & 1600 & 2100 & 1532 & 1652 & 1884 & 2312 & 3100 & 2309 & 2309 \\
\hline Serbia & 1067 & 53 & 1259 & 302 & 23 & 119 & 1804 & 2057 & 2880 & 3000 & 3000 \\
\hline India & 800 & 600 & 700 & 510 & 300 & 282 & 457 & 1019 & 1266 & 806 & 1122 \\
\hline Qatar & 600 & 600 & 500 & 500 & 400 & 309 & 368 & 431 & 1300 & 1399 & 471 \\
\hline Norway & 562 & 530 & 489 & 188 & 188 & 207 & 178 & 532 & 527 & 216 & 180 \\
\hline OtherMiddleEast & 155 & & & 510 & 2 & & & 622 & 619 & 382 & 382 \\
\hline OtherSouthAmerica & 150 & 150 & 150 & 261 & 300 & 160 & 160 & 252 & 193 & 210 & 0 \\
\hline OtherAfrica & 143 & 80 & 80 & 200 & 197 & 0 & 0 & 135 & 46 & 617 & 333 \\
\hline Sweden & 103 & 69 & 69 & 94 & 109 & 116 & 111 & 100 & 98 & 82 & 70 \\
\hline OtherAsia & 96 & & & 4646 & 5118 & 0 & 0 & 986 & 773 & 1748 & 1250 \\
\hline Kazakhstan & 48 & 209 & & & & & & & & 183 & 1229 \\
\hline Denmark & 6 & 3 & 3 & 3 & 5 & & 1 & 2 & 4 & 3 & 43 \\
\hline OtherE.U. & & & & & & & & & & & 5 \\
\hline OtherCIS & & & & & & & & & & & 0 \\
\hline OtherNorthAmerica & & & & & & & & & & & 0 \\
\hline Brazil & & & & & & & & & & & 0 \\
\hline Colombia & & & & & & & & & & & 9 \\
\hline \multicolumn{12}{|l|}{ Paraguay } \\
\hline Peru & & & & & & & & & & & 0 \\
\hline Venezuela & & & & & 1 & & & & 0 & 662 & 662 \\
\hline Algeria & & & & 0 & 0 & & & 0 & 46 & 543 & 543 \\
\hline SouthAfrica & & & & & & & & & & 133 & 480 \\
\hline UnitedArabEmirates & & & & 165 & & & 228 & 214 & 428 & 896 & 896 \\
\hline Bangladesh & & & & & & & & & & & 44 \\
\hline HongKong & & & & & & & & & & & 454 \\
\hline Singapore & & & & & & & & & & & 77 \\
\hline Thailand & & & & & & & & & & & 3 \\
\hline OtherOceania & & & & & & & & & & & 0 \\
\hline World & 476504 & 471485 & 443552 & 510783 & 506715 & 531296 & 583021 & 669897 & 752486 & 803008 & 861786 \\
\hline
\end{tabular}


Tabela 12 - Importação mundial de minério de ferro entre 1997 e 2007 (em 1000 t)

Continuação

\begin{tabular}{|c|c|c|c|c|c|c|c|c|c|c|c|}
\hline Paises & 1997 & 1998 & 1999 & 2000 & 2001 & 2002 & 2003 & 2004 & 2005 & 2006 & 2007 \\
\hline SUM & 480498 & 475124 & 447647 & 514767 & 510304 & 537299 & 590432 & 677047 & 760532 & 812002 & 871053 \\
\hline DIF & -586 & -802 & -626 & -616 & -172 & -99 & -45 & -13 & 18 & 191 & -1 \\
\hline $\mathrm{DIF}(\%)$ & $-0,12 \%$ & $-0,17 \%$ & $-0,14 \%$ & $-0,12 \%$ & $-0,03 \%$ & $-0,02 \%$ & $-0,01 \%$ & $0,00 \%$ & $0,00 \%$ & $0,02 \%$ & $0,00 \%$ \\
\hline
\end{tabular}


Tabela 13 - Importação mundial de minério de ferro entre 2007 e 2016 (em 1000 t)

Continua

\begin{tabular}{|c|c|c|c|c|c|c|c|c|c|c|}
\hline Paises_Anos & 2007 & 2008 & 2009 & 2010 & 2011 & 2012 & 2013 & 2014 & 2015 & 2016 \\
\hline Austria & 9006 & 5017 & 3471 & 5955 & 6732 & 6056 & 5864 & 5100 & 5137 & 4152 \\
\hline Belgium-Luxembourg & 9662 & 12726 & 3255 & 7527 & 7430 & 6311 & 6351 & 6812 & 6631 & 6998 \\
\hline Bulgaria & 923 & 526 & 139 & 0 & 1 & 2 & 10 & 14 & 1 & 1 \\
\hline CzechRepublic & 5046 & 6800 & 4803 & 3853 & 7366 & 5871 & 6237 & 6305 & 6370 & 6345 \\
\hline Denmark & 43 & 99 & 49 & 51 & 100 & 78 & 40 & 29 & 53 & 85 \\
\hline Germany & 46194 & 44339 & 51922 & 43082 & 39672 & 40724 & 40930 & 43030 & 40964 & 40031 \\
\hline Finland & 3156 & 3121 & 2204 & 2984 & 3045 & 3221 & 2903 & 3078 & 3423 & 3516 \\
\hline France & 19364 & 18290 & 10015 & 15245 & 13512 & 13604 & 15285 & 17106 & 15655 & 13947 \\
\hline Hungary & 967 & 1900 & 1493 & 1888 & 1781 & 1632 & 845 & 1265 & 1641 & 1208 \\
\hline Italy & 17013 & 16313 & 8160 & 10863 & 14675 & 13434 & 11522 & 9511 & 8076 & 9151 \\
\hline Netherlands & 31501 & 32639 & 21638 & 33944 & 33432 & 28269 & 31883 & 29675 & 30911 & 30574 \\
\hline Poland & 8747 & 7785 & 3752 & 5563 & 5968 & 6583 & 6640 & 7433 & 7247 & 7061 \\
\hline Romania & 6260 & 4446 & 806 & 2462 & 2187 & 2023 & 2546 & 2226 & 2964 & 2720 \\
\hline SlovakRepublic & 5854 & 5536 & 4186 & 5174 & 5103 & 5404 & 5647 & 6012 & 5536 & 6031 \\
\hline Spain & 5719 & 6328 & 3951 & 5877 & 5144 & 4506 & 6259 & 5699 & 6377 & 6010 \\
\hline Sweden & 70 & 71 & 41 & 55 & 51 & 44 & 26 & 26 & 70 & 175 \\
\hline UnitedKingdom & 17365 & 15283 & 9186 & 10597 & 9175 & 10062 & 14137 & 14469 & 12047 & 9292 \\
\hline OtherE.U. & 5 & 0 & 18 & 1 & 4 & 5 & 4 & 11 & 28 & 22 \\
\hline EuropeanUnion(28) & 186895 & 181219 & 129089 & 155124 & 155378 & 147830 & 157129 & 157800 & 153130 & 147318 \\
\hline Norway & 180 & 152 & 134 & 149 & 128 & 93 & 74 & 49 & 27 & 75 \\
\hline Serbia & 3000 & 3100 & 3100 & 3422 & 1621 & 241 & 338 & 293 & 1287 & 1771 \\
\hline Turkey & 6088 & 6900 & 5685 & 6382 & 6644 & 7842 & 8114 & 8544 & 10011 & 10418 \\
\hline OtherEurope & 4030 & 6 & 0 & 5 & 149 & 12 & 9 & 13 & 12 & 14 \\
\hline OtherEurope & 13298 & 10158 & 8919 & 9959 & 8542 & 8188 & 8536 & 8900 & 11338 & 12277 \\
\hline Kazakhstan & 1229 & 1936 & 504 & 624 & $\ldots$ & 0 & $\ldots$ & 0 & $\ldots$ & $\ldots$ \\
\hline Russia & 10682 & 11752 & 8404 & 4524 & 146 & 225 & 86 & 10341 & 8103 & 7204 \\
\hline Ukraine & 3482 & 2869 & 3339 & 2738 & 1838 & 2882 & 3110 & 3212 & 2255 & 1765 \\
\hline OtherCIS & & & & & 7 & 45 & 22 & 48 & 52 & 186 \\
\hline C.I.S. & 15393 & 16556 & 12247 & 7886 & 1991 & 3153 & 3219 & 13601 & 10410 & 9154 \\
\hline Canada & 7269 & 9073 & 3103 & 8126 & 7129 & 6500 & 6112 & 8955 & 6596 & 7100 \\
\hline Mexico & 3127 & 3875 & 557 & 1426 & 1460 & 1368 & 1142 & 1551 & 1460 & 3699 \\
\hline TrinidadandTobago & 2894 & 4252 & 2340 & 4347 & 4381 & 4691 & 4659 & 5445 & 7779 & 5890 \\
\hline UnitedStates & 9389 & 9236 & $\ldots$ & 6417 & 5268 & 5132 & 3172 & 5097 & 4550 & 3079 \\
\hline
\end{tabular}


Tabela 13 - Importação mundial de minério de ferro entre 2007 e 2016 (em 1000 t)

\begin{tabular}{|c|c|c|c|c|c|c|c|c|c|c|}
\hline Paises_Anos & 2007 & 2008 & 2009 & 2010 & 2011 & 2012 & 2013 & 2014 & 2015 & 2016 \\
\hline OtherNorthAmerica & 0 & 0 & 1 & 0 & 257 & 5 & 1 & 0 & 0 & 1 \\
\hline NorthAmerica & 22679 & 26435 & 6001 & 20316 & 18494 & 17696 & 15086 & 21049 & 20385 & 19768 \\
\hline Argentina & 6586 & 7176 & 3229 & 6400 & 6891 & 5328 & 5828 & 6385 & 5189 & 4298 \\
\hline Brazil & 0 & 66 & $\ldots$ & 126 & 0 & 0 & 0 & 5 & 0 & 0 \\
\hline Colombia & 9 & 150 & 20 & 9 & 4 & 3 & 3 & 0 & 1 & 1 \\
\hline Paraguay & $\ldots$ & $\ldots$ & $\ldots$ & $\ldots$ & 135 & 48 & 49 & 81 & 108 & 100 \\
\hline Peru & 0 & 170 & 0 & 30 & 30 & 0 & 0 & 0 & 0 & 0 \\
\hline Venezuela & 662 & 387 & $\ldots$ & $\ldots$ & 182 & 0 & 0 & $\ldots$ & $\ldots$ & $\ldots$ \\
\hline OtherSouthAmerica & 0 & $\ldots$ & 0 & 1 & 0 & 1 & 0 & 0 & 0 & 1 \\
\hline SouthAmerica & 7258 & 7948 & 3249 & 6565 & 7241 & 5382 & 5879 & 6471 & 5297 & 4400 \\
\hline Algeria & 543 & 213 & 0 & 117 & 11 & 26 & 0 & 0 & 0 & 2 \\
\hline Egypt & 4435 & 3562 & 4583 & 4178 & 4343 & 4235 & 3824 & 3249 & 2209 & 4062 \\
\hline Libya & 2309 & 2539 & 1304 & 2257 & 63 & 844 & 1819 & 1377 & 306 & 888 \\
\hline SouthAfrica & 480 & 485 & 352 & 401 & 417 & 558 & 476 & 479 & 429 & 341 \\
\hline OtherAfrica & 333 & 86 & 0 & 1 & 85 & 12 & 167 & 371 & 2 & 51 \\
\hline Africa & 8100 & 6884 & 6239 & 6953 & 4918 & 5675 & 6287 & 5476 & 2946 & 5344 \\
\hline Bahrain & 2910 & 7964 & 4144 & 6330 & 7217 & 5103 & 2969 & 5460 & 6059 & 4853 \\
\hline Iran & 1038 & 929 & 216 & $\ldots$ & $\ldots$ & 39 & 0 & 500 & 492 & 390 \\
\hline Qatar & 471 & 1616 & 1680 & 1777 & 3797 & 2714 & 2431 & 2268 & 2451 & 1630 \\
\hline SaudiArabia & 4931 & 7638 & 6039 & 9019 & 7516 & 4161 & 3575 & 5111 & 4031 & 3627 \\
\hline UnitedArabEmirates & 896 & 300 & 199 & 3130 & 2807 & 3050 & 3051 & 2703 & 3850 & 2282 \\
\hline OtherMiddleEast & 382 & 0 & 47 & 154 & 6466 & 10254 & 10137 & 10506 & 10943 & 9202 \\
\hline MiddleEast & 10628 & 18447 & 12324 & 20411 & 27803 & 25321 & 22163 & 26549 & 27825 & 21985 \\
\hline Bangladesh & 44 & 102 & 101 & 0 & 158 & $\ldots$ & $\ldots$ & $\ldots$ & 0 & $\ldots$ \\
\hline China & 383618 & 444028 & 628175 & 618915 & 686747 & 745434 & 820175 & 933108 & 953370 & 1024709 \\
\hline HongKong & 454 & 835 & 1281 & 786 & 811 & 242 & 724 & 4754 & 3655 & 3647 \\
\hline India & 1122 & 600 & 623 & 450 & 1316 & 2822 & 1115 & 7413 & 9515 & 3597 \\
\hline Indonesia & 1737 & 2300 & 1488 & 2029 & 1804 & 973 & 1932 & 3869 & 5424 & 5110 \\
\hline Japan & 138928 & 140351 & 105471 & 134335 & 128489 & 131114 & 135886 & 136436 & 131010 & 130035 \\
\hline SouthKorea & 43668 & 49441 & 41601 & 56298 & 64857 & 65998 & 63372 & 73507 & 73282 & 71741 \\
\hline Malaysia & 2677 & 3043 & 2523 & 3199 & 2852 & 3291 & 1711 & 3814 & 14742 & 22966 \\
\hline Pakistan & 1078 & 489 & 37 & 2 & 116 & $\ldots$ & 0 & 80 & $\ldots$ & $\ldots$ \\
\hline Philippines & 2627 & 2700 & 1066 & 2334 & 3045 & 6746 & 6891 & 6352 & 15836 & 4230 \\
\hline
\end{tabular}


Tabela 13 - Importação mundial de minério de ferro entre 2007 e 2016 (em 1000 t)

Continuação

\begin{tabular}{|c|c|c|c|c|c|c|c|c|c|c|}
\hline Paises_Anos & 2007 & 2008 & 2009 & 2010 & 2011 & 2012 & 2013 & 2014 & 2015 & 2016 \\
\hline Singapore & 77 & $\ldots$ & $\ldots$ & $\ldots$ & $\ldots$ & 1 & 0 & 1 & 1 & 1 \\
\hline Taiwan,China & 16035 & 15571 & 11912 & 18930 & 20507 & 18396 & 21773 & 23039 & 23814 & 23462 \\
\hline Thailand & 3 & 40 & $\ldots$ & $\ldots$ & 82 & 11 & 11 & 4 & $\ldots$ & $\ldots$ \\
\hline OtherAsia & 1250 & 1604 & 1940 & 1807 & 245 & 14110 & 234 & 114 & 298 & 14640 \\
\hline Asia & 593319 & 661105 & 796219 & 839084 & 911030 & 989138 & 1053825 & 1192491 & 1230947 & 1304138 \\
\hline Australia & 4217 & 4649 & 3852 & 5503 & 4987 & 3951 & 4070 & 3003 & 2792 & 815 \\
\hline OtherOceania & 0 & 0 & 0 & 0 & 1 & 1 & 1 & 1 & 1 & 0 \\
\hline Oceania & 4218 & 4649 & 3852 & 5503 & 4988 & 3952 & 4071 & 3004 & 2793 & 815 \\
\hline World & 861786 & 933401 & 978139 & 1071802 & 1140385 & 1206334 & 1276195 & 1435340 & 1465071 & 1525200 \\
\hline
\end{tabular}

Fonte: compilado pelo autor com dados da WorldSteel (2017), WorldSteel (2007). 
A.2.4 Produção mundial de aço em pelotas

A tabela 14 mostra a produção mundial anual de aço em pelotas por países entre os anos de 1996 a 2007, enquanto a tabela 15 apresenta os dados entre os anos de 2008 e 2016. 
Tabela 14 - Produção mundial de pelotas de aço entre 1997 e 2007 (em 1000 t)

Continua

\begin{tabular}{|c|c|c|c|c|c|c|c|c|c|c|c|}
\hline Países & 1997 & 1998 & 1999 & 2000 & 2001 & 2002 & 2003 & 2004 & 2005 & 2006 & 2007 \\
\hline Austria & 3966 & 4021 & 3913 & 4318 & 4375 & 4669 & 4677 & 4847 & 5444 & 5547 & 5908 \\
\hline Belgium & 8076 & 8618 & 8430 & 8471 & 7732 & 7988 & 7813 & 8224 & 7254 & 7516 & 6577 \\
\hline CzechRepublic & 5195 & 4982 & 4023 & 4621 & 4671 & 4840 & 5207 & 5384 & 4627 & 5192 & 5287 \\
\hline Germany & 30940 & 30162 & 27934 & 30845 & 29184 & 29427 & 29481 & 30018 & 28854 & 30360 & 30562 \\
\hline Finland & 2786 & 2920 & 2954 & 2983 & 2852 & 2828 & 3092 & 3037 & 3056 & 3158 & 2915 \\
\hline France & 13316 & 13458 & 13852 & 13916 & 12298 & 13510 & 12972 & 13198 & 12705 & 13013 & 12426 \\
\hline Hungary & 1140 & 1259 & 1310 & 1340 & 1226 & 1335 & 1333 & 1351 & 1338 & 1336 & 1393 \\
\hline Italy & 11305 & 10771 & 10621 & 11220 & 11220 & 9775 & 10148 & 10604 & 11423 & 11497 & 11110 \\
\hline Netherlands & 5805 & 5562 & 5307 & 4970 & 5305 & 5367 & 5846 & 6011 & 6031 & 5417 & 6412 \\
\hline Poland & 7295 & 6179 & 5233 & 6492 & 5440 & 5294 & 5632 & 6400 & 4477 & 5333 & 5804 \\
\hline Romania & 4538 & 4525 & 3006 & 2985 & 3085 & 3976 & 4101 & 4244 & 4098 & 3975 & 3923 \\
\hline SlovakRepublic & 3072 & 2756 & 2987 & 3166 & 3255 & 3533 & 3892 & 3765 & 3681 & 4145 & 4012 \\
\hline Spain & 3927 & 4236 & 4058 & 4059 & 4219 & 4021 & 3645 & 4036 & 4160 & 3432 & 3976 \\
\hline Sweden & 3060 & 3149 & 3212 & 3145 & 3614 & 3703 & 3710 & 3871 & 3730 & 3577 & 3816 \\
\hline UnitedKingdom & 13054 & 12746 & 12139 & 10890 & 9870 & 8561 & 10228 & 10180 & 10189 & 10696 & 10960 \\
\hline EuropeanUnion(15) & 117475 & 115344 & 108979 & 113421 & 108346 & 108827 & 111777 & 115170 & 111067 & 114194 & 115081 \\
\hline Norway & 70 & 70 & 70 & 70 & 70 & 108 & 110 & 100 & 100 & 100 & 111 \\
\hline Serbia & 907 & 850 & 139 & 598 & 456 & 485 & 635 & 1003 & 1208 & 1762 & 1485 \\
\hline Turkey & 5565 & 5286 & 5181 & 5333 & 5289 & 5003 & 5706 & 5836 & 5970 & 5952 & 6235 \\
\hline OtherEurope & 12823 & 12201 & 9628 & 10285 & 10191 & 10724 & 12019 & 12420 & 12536 & 13017 & 7832 \\
\hline Europe & 130298 & 127545 & 118607 & 123706 & 118537 & 119551 & 123796 & 127590 & 123603 & 127211 & 122913 \\
\hline Kazakhstan & 3089 & 2594 & 3468 & 4010 & 3906 & 4008 & 4123 & 4312 & 3624 & 3393 & 3240 \\
\hline Russia & 37207 & 34736 & 40033 & 44536 & 44947 & 46251 & 48325 & 50321 & 48410 & 51742 & 51043 \\
\hline Ukraine & 20496 & 20777 & 21937 & 25697 & 26364 & 27634 & 29528 & 31056 & 30782 & 32937 & 35647 \\
\hline C.I.S. & 60792 & 58107 & 65438 & 74243 & 75217 & 77893 & 81976 & 85689 & 82816 & 88072 & 89930 \\
\hline Canada & 9567 & 8937 & 8857 & 8904 & 8302 & 8670 & 8554 & 8828 & 8274 & 8305 & 8579 \\
\hline Mexico & 4450 & 4532 & 4822 & 4856 & 4373 & 3996 & 4183 & 4278 & 4047 & 3790 & 4078 \\
\hline UnitedStates & 49604 & 48230 & 46268 & 47878 & 42107 & 40225 & 40644 & 42291 & 37222 & 37903 & 36337 \\
\hline NorthAmerica & 63621 & 61699 & 59947 & 61638 & 54782 & 52891 & 53381 & 55397 & 49543 & 49998 & 48994 \\
\hline Argentina & 2080 & 2122 & 1984 & 2186 & 1917 & 2180 & 2402 & 2392 & 2646 & 2481 & 2593 \\
\hline Brazil & 25013 & 25111 & 24549 & 27723 & 27391 & 29694 & 32038 & 34558 & 33884 & 32452 & 35571 \\
\hline Chile & 941 & 993 & 1030 & 1024 & 897 & 964 & 988 & 1137 & 1074 & 1115 & 1147 \\
\hline Colombia & 324 & 256 & 264 & 285 & 319 & 311 & 283 & 312 & 325 & 360 & 341 \\
\hline
\end{tabular}


Tabela 14 - Produção mundial de pelotas de aço entre 1997 e 2007 (em 1000 t)

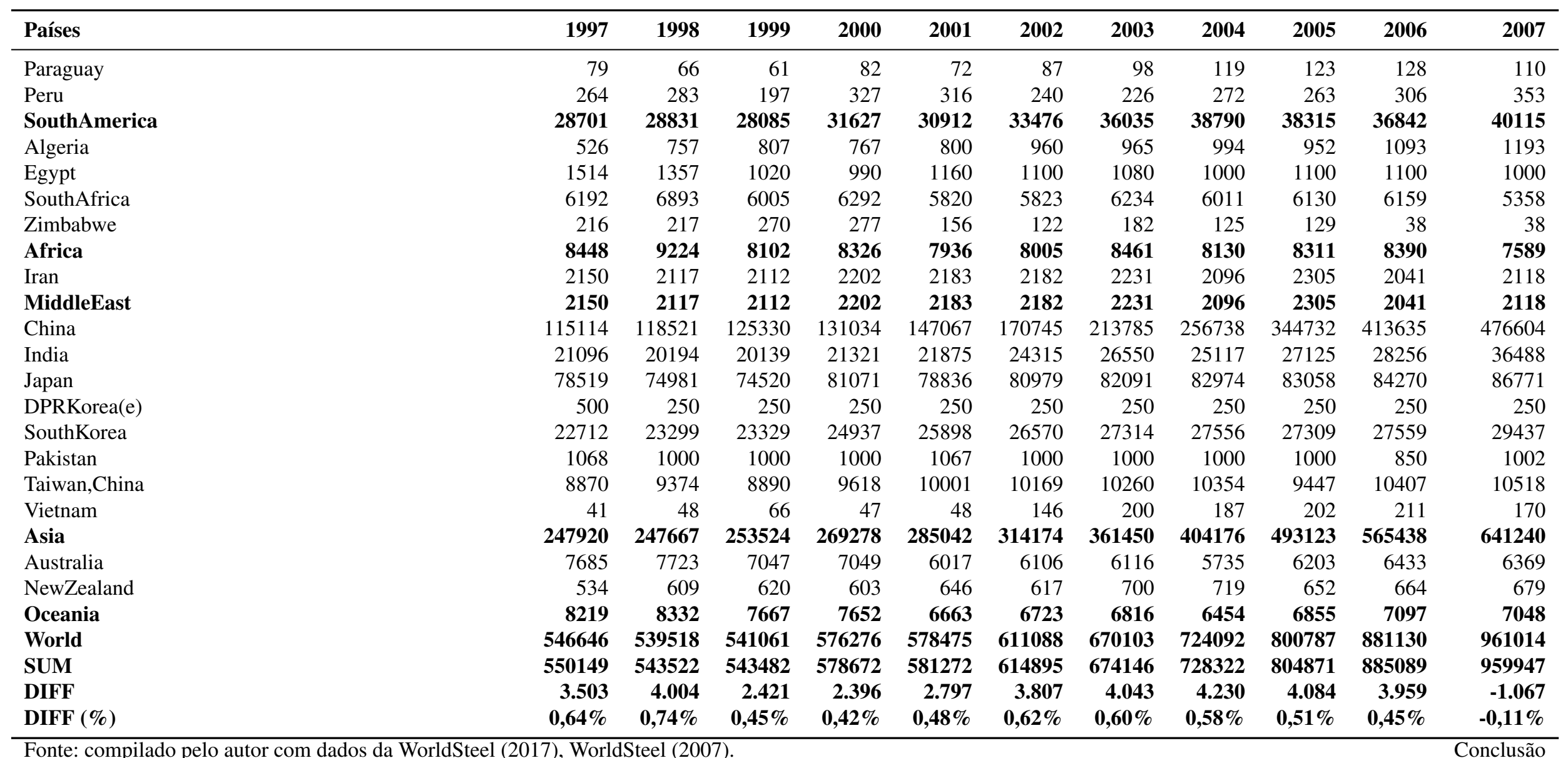


Tabela 15 - Produção mundial de pelotas de aço entre 2008 e 2016 (em 1000 t)

\begin{tabular}{|c|c|c|c|c|c|c|c|c|c|}
\hline Países & 2008 & 2009 & 2010 & 2011 & 2012 & 2013 & 2014 & 2015 & 2016 Continua \\
\hline Austria & 5795 & 4353 & 5621 & 5815 & 5751 & 6152 & 6029 & 5805 & 5642 \\
\hline Belgium & 6977 & 3087 & 4688 & 4725 & 4073 & 4343 & 4388 & 4248 & 4869 \\
\hline CzechRepublic & 4737 & 3483 & 3987 & 4137 & 3935 & 4040 & 4152 & 4031 & 4165 \\
\hline Germany & 28592 & 19715 & 28112 & 27563 & 26493 & 26678 & 27379 & 27842 & 27270 \\
\hline Finland & 2943 & 2042 & 2564 & 2500 & 2130 & 2050 & 2475 & 2594 & 2670 \\
\hline France & 11372 & 8104 & 10137 & 9698 & 9532 & 10276 & 10866 & 10097 & 9724 \\
\hline Hungary & 1289 & 1050 & 1325 & 1317 & 1229 & 628 & 801 & 1247 & 863 \\
\hline Italy & 10377 & 5692 & 8555 & 9838 & 9424 & 6933 & 6371 & 5051 & 6044 \\
\hline Netherlands & 5998 & 4601 & 5799 & 5943 & 5917 & 5681 & 5868 & 6050 & 6092 \\
\hline Poland & 4934 & 2984 & 3638 & 3975 & 3952 & 4011 & 4637 & 4821 & 4674 \\
\hline Romania & 2958 & 1575 & 1726 & 1593 & 1467 & 1604 & 1631 & 1983 & 1972 \\
\hline SlovakRepublic & 3529 & 3019 & 3649 & 3346 & 3520 & 3617 & 3838 & 3738 & 3987 \\
\hline Spain & 3784 & 2920 & 3572 & 3540 & 3081 & 3949 & 3958 & 4450 & 4116 \\
\hline Sweden & 3583 & 1966 & 3447 & 3240 & 2805 & 2896 & 3078 & 2865 & 3079 \\
\hline UnitedKingdom & 10137 & 7671 & 7233 & 6625 & 7183 & 9471 & 9705 & 8774 & 6142 \\
\hline EuropeanUnion(15) & 107005 & 72262 & 94053 & 93855 & 90492 & 92329 & 95176 & 93596 & 91309 \\
\hline Norway & 108 & 83 & 108 & 101 & 100 & 106 & 102 & 100 & 100 \\
\hline Serbia & 1582 & 1008 & 1235 & 1226 & 312 & 365 & 550 & 904 & 1154 \\
\hline Turkey & 6704 & 7004 & 7679 & 8173 & 8613 & 9180 & 9364 & 10184 & 10304 \\
\hline OtherEurope & 8637 & 8577 & 9643 & 10184 & 9774 & 10411 & 10876 & 12033 & 12336 \\
\hline Europe & 115642 & 80839 & 103696 & 104039 & 100266 & 102740 & 106052 & 105629 & 103645 \\
\hline Kazakhstan & 2761 & 2409 & 2640 & 3190 & 2831 & 2756 & 3185 & 3235 & 3302 \\
\hline Russia & 48295 & 43945 & 47934 & 48117 & 50529 & 50111 & 51479 & 52553 & 51820 \\
\hline Ukraine & 30981 & 25676 & 27349 & 28867 & 28500 & 29094 & 24788 & 21797 & 23618 \\
\hline C.I.S. & 82037 & 72030 & 77923 & 80174 & 81860 & 81961 & 79452 & 77585 & 78740 \\
\hline Canada & 8770 & 5273 & 7666 & 7323 & 7654 & 6100 & 6728 & 5851 & 6240 \\
\hline Mexico & 4450 & 3919 & 4707 & 4609 & 4611 & 4911 & 5115 & 4573 & 4476 \\
\hline UnitedStates & 33729 & 19018 & 26843 & 30227 & 32062 & 30308 & 29374 & 25435 & 22293 \\
\hline NorthAmerica & 46949 & 28210 & 39216 & 42159 & 44327 & 41319 & 41217 & 35859 & 33009 \\
\hline Argentina & 2581 & 2042 & 2532 & 2801 & 2073 & 2650 & 2766 & 2685 & 2141 \\
\hline Brazil & 34925 & 25135 & 30955 & 33319 & 26900 & 26200 & 27016 & 27803 & 26036 \\
\hline Chile & 1109 & 923 & 635 & 1072 & 1068 & 766 & 584 & 644 & 677 \\
\hline Colombia & 308 & 342 & 327 & 302 & 345 & 307 & 234 & 240 & 225 \\
\hline
\end{tabular}


Tabela 15 - Produção mundial de pelotas de aço entre 2008 e 2016 (em 1000 t)

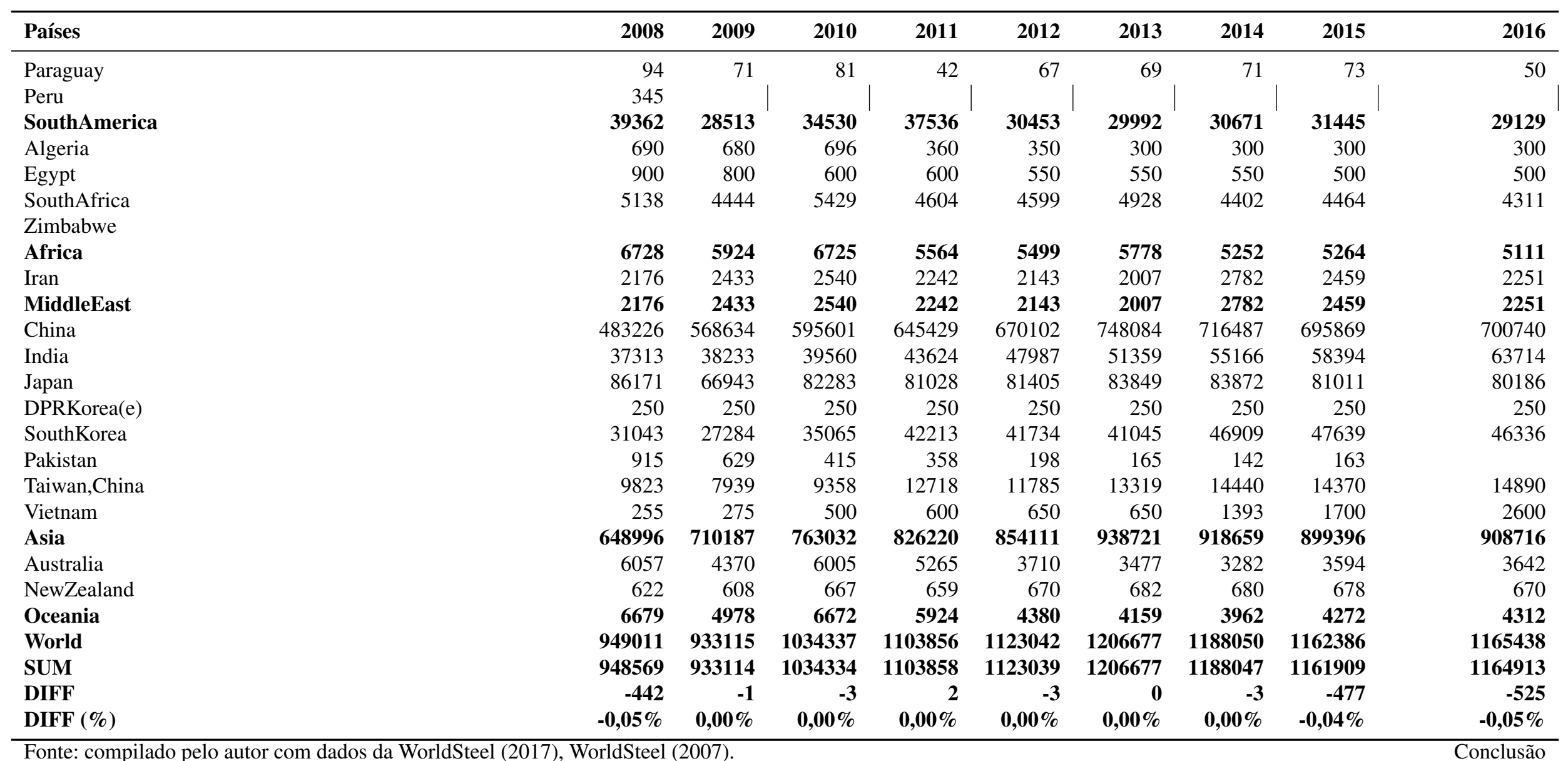




\section{A.2.5 Produção mundial de aço bruto}

A tabela 16 mostra a produção mundial anual de aço bruto entre os anos de 1997 a 2006. A tabela 17 mostra a produção mundial anual de aço bruto entre os anos de 2007 a 2016. 
Tabela 16 - Produção mundial de aço bruto entre 1997 e 2006 (em 1000t)

\begin{tabular}{|c|c|c|c|c|c|c|c|c|c|c|}
\hline Paises_Anos & 1997 & 1998 & 1999 & 2000 & 2001 & 2002 & 2003 & 2004 & 2005 & 2006 \\
\hline China & 108911 & 114588 & 123954 & 127236 & 150906 & 182249 & 222413 & 280486 & 355790 & 422660 \\
\hline Japan & 104545 & 93548 & 94192 & 106444 & 102866 & 107745 & 110511 & 112718 & 112471 & 116226 \\
\hline UnitedStates & 98485 & 98658 & 97427 & 101803 & 90104 & 91587 & 93677 & 99681 & 94897 & 98557 \\
\hline Russia & 48502 & 43822 & 51510 & 59136 & 58970 & 59777 & 61450 & 65583 & 66146 & 70830 \\
\hline Germany & 45007 & 44046 & 42062 & 46376 & 44803 & 45015 & 44809 & 46374 & 44524 & 47224 \\
\hline SouthKorea & 42554 & 39896 & 41042 & 43107 & 43852 & 45390 & 46310 & 47521 & 47820 & 48455 \\
\hline Brazil & 26153 & 25760 & 24996 & 27865 & 26717 & 29604 & 31147 & 32909 & 31610 & 30901 \\
\hline Italy & 25842 & 25714 & 24878 & 26759 & 26545 & 26066 & 27058 & 28604 & 29350 & 31624 \\
\hline Ukraine & 25629 & 24445 & 27453 & 31767 & 33108 & 34050 & 36932 & 38738 & 38641 & 40899 \\
\hline India & 24415 & 23480 & 24296 & 26924 & 27291 & 28814 & 31779 & 32626 & 45780 & 49450 \\
\hline France & 19767 & 20126 & 20200 & 20954 & 19343 & 20258 & 19758 & 20770 & 19481 & 19852 \\
\hline UnitedKingdom & 18501 & 17315 & 16298 & 15155 & 13543 & 11667 & 13268 & 13766 & 13239 & 13871 \\
\hline Taiwan,China & 16056 & 16965 & 15438 & 16896 & 17261 & 18230 & 18832 & 19599 & 18942 & 20000 \\
\hline Canada & 15553 & 15930 & 16235 & 16595 & 15276 & 16002 & 15929 & 16305 & 15327 & 15493 \\
\hline Turkey & 14475 & 14144 & 14313 & 14325 & 14981 & 16467 & 18298 & 20478 & 20965 & 23308 \\
\hline Mexico & 14246 & 14218 & 15274 & 15631 & 13300 & 14010 & 15159 & 16737 & 16195 & 16313 \\
\hline Spain & 13683 & 14827 & 14882 & 15874 & 16504 & 16408 & 16286 & 17621 & 17826 & 18391 \\
\hline Poland & 11585 & 9915 & 8848 & 10498 & 8809 & 8368 & 9107 & 10593 & 8336 & 10008 \\
\hline Belgium & 10739 & 11425 & 10931 & 11636 & 10762 & 11343 & 11114 & 11698 & 10420 & 11631 \\
\hline SouthAfrica & 8311 & 7956 & 7857 & 8481 & 8821 & 9095 & 9481 & 9500 & 9494 & 9718 \\
\hline Netherlands & 6641 & 6377 & 6075 & 5666 & 6037 & 6117 & 6571 & 6848 & 6919 & 6372 \\
\hline Iran & 6322 & 5602 & 6070 & 6600 & 6916 & 7321 & 7869 & 8682 & 9404 & 9789 \\
\hline Austria & 5181 & 5282 & 5202 & 5707 & 5869 & 6189 & 6261 & 6530 & 7031 & 7129 \\
\hline SaudiArabia & 2539 & 2356 & 2610 & 2981 & 3413 & 3570 & 3944 & 3902 & 4186 & 3974 \\
\hline VietNam & 314 & 306 & 308 & 306 & 319 & 409 & 544 & 689 & 890 & 1400 \\
\hline World & 798954 & 777330 & 788970 & 847671 & 850266 & 903929 & 969743 & 1068691 & 1146203 & 1249997 \\
\hline TOTSEL & 713956 & 696701 & 712351 & 764722 & 766316 & 815751 & 878507 & 968958 & 1045684 & 1144075 \\
\hline TOTSEL (\%) & $89 \%$ & $90 \%$ & $90 \%$ & $90 \%$ & $90 \%$ & $90 \%$ & $91 \%$ & $91 \%$ & $91 \%$ & $92 \%$ \\
\hline ROW & 84998 & 80629 & 76619 & 82949 & 83950 & 88178 & 91236 & 99733 & 100519 & 105922 \\
\hline
\end{tabular}

Fonte: compilado pelo autor com dados da WorldSteel (2017), WorldSteel (2007). 
Tabela 17 - Produção mundial de aço bruto entre 2007 e 2016 (em 1000t)

\begin{tabular}{|c|c|c|c|c|c|c|c|c|c|c|}
\hline Paises_Anos & 2007 & 2008 & 2009 & 2010 & 2011 & 2012 & 2013 & 2014 & 2015 & 2016 \\
\hline China & 489712 & 512339 & 577070 & 638743 & 701968 & 731040 & 822000 & 822306 & 803825 & 808366 \\
\hline Japan & 120203 & 118739 & 87534 & 109599 & 107601 & 107232 & 110595 & 110666 & 105134 & 104775 \\
\hline UnitedStates & 98101 & 91895 & 59384 & 80495 & 86398 & 88695 & 86878 & 88174 & 78845 & 78475 \\
\hline Russia & 72387 & 68510 & 60011 & 66942 & 68852 & 70209 & 69008 & 71461 & 70898 & 70808 \\
\hline Germany & 48550 & 45833 & 32670 & 43830 & 44284 & 42661 & 42645 & 42943 & 42676 & 42080 \\
\hline SouthKorea & 51517 & 53625 & 48572 & 58914 & 68519 & 69073 & 66061 & 71543 & 69670 & 68576 \\
\hline Brazil & 33782 & 33716 & 26506 & 32948 & 35220 & 34524 & 34163 & 33897 & 33256 & 31275 \\
\hline Italy & 31553 & 30590 & 19848 & 25750 & 28735 & 27252 & 24093 & 23714 & 22018 & 23373 \\
\hline Ukraine & 42830 & 37279 & 29855 & 33432 & 35332 & 32975 & 32771 & 27170 & 22968 & 24218 \\
\hline India & 53468 & 57791 & 63527 & 68976 & 73471 & 77264 & 81299 & 87292 & 89026 & 95477 \\
\hline France & 19250 & 17879 & 12840 & 15414 & 15780 & 15609 & 15685 & 16143 & 14984 & 14413 \\
\hline UnitedKingdom & 14317 & 13521 & 10079 & 9709 & 9478 & 9579 & 11858 & 12120 & 10907 & 7635 \\
\hline Taiwan,China & 20903 & 19882 & 15814 & 19755 & 20178 & 20664 & 22282 & 23121 & 21392 & 21751 \\
\hline Canada & 15572 & 14945 & 9292 & 13009 & 12891 & 13507 & 12417 & 12730 & 12473 & 12646 \\
\hline Turkey & 25754 & 26806 & 25304 & 29143 & 34107 & 35885 & 34654 & 34035 & 31517 & 33163 \\
\hline Mexico & 17573 & 17209 & 14132 & 16870 & 18110 & 18073 & 18242 & 18930 & 18218 & 18809 \\
\hline Spain & 18999 & 18640 & 14358 & 16343 & 15504 & 13639 & 14252 & 14249 & 14845 & 13616 \\
\hline Poland & 10632 & 9728 & 7128 & 7993 & 8779 & 8366 & 7950 & 8558 & 9198 & 9001 \\
\hline Belgium & 10692 & 10673 & 5635 & 7973 & 8026 & 7301 & 7093 & 7331 & 7257 & 7687 \\
\hline SouthAfrica & 9098 & 8246 & 7484 & 7617 & 7546 & 6938 & 7162 & 6412 & 6417 & 6141 \\
\hline Netherlands & 7368 & 6853 & 5194 & 6651 & 6937 & 6879 & 6713 & 6964 & 6995 & 6917 \\
\hline Iran & 10051 & 9964 & 10908 & 11995 & 13197 & 14463 & 15422 & 16331 & 16146 & 17895 \\
\hline Austria & 7578 & 7594 & 5662 & 7206 & 7474 & 7421 & 7953 & 7876 & 7687 & 7438 \\
\hline SaudiArabia & 4644 & 4667 & 4690 & 5015 & 5275 & 5203 & 5471 & 6291 & 5229 & 5461 \\
\hline VietNam & 2024 & 2250 & 2700 & 4314 & 4900 & 5298 & 5474 & 5847 & 5647 & 7811 \\
\hline World & 1348108 & 1343429 & 1238755 & 1433433 & 1538003 & 1560131 & 1650354 & 1669450 & 1620001 & 1628049 \\
\hline TOTSEL & 1236558 & 1239174 & 1156197 & 1338636 & 1438562 & 1469750 & 1562141 & 1576104 & 1527228 & 1537807 \\
\hline TOTSEL (\%) & $92 \%$ & $92 \%$ & $93 \%$ & $93 \%$ & $94 \%$ & $94 \%$ & $95 \%$ & $94 \%$ & $94 \%$ & $94 \%$ \\
\hline ROW & 111550 & 104255 & 82558 & 94797 & 99441 & 90381 & 88213 & 93346 & 92773 & 90242 \\
\hline
\end{tabular}

Fonte: compilado pelo autor com dados da WorldSteel (2017), WorldSteel (2007). 
A.2.6 Consumo aparente de aço (em aço bruto equivalente)

A tabela 18 mostra a consumo aparente de aço bruto entre os anos de 1996 a 2006 . A tabela 19 mostra a produção mundial anual de aço bruto entre os anos de 2007 a 2016. 
Tabela 18 - Consumo aparente de aço (equivalente em aço bruto) entre 1996 e 2006 (em 1000t)

Continua

\begin{tabular}{|c|c|c|c|c|c|c|c|c|c|c|}
\hline Paises & 1997 & 1998 & 1999 & 2000 & 2001 & 2002 & 2003 & 2004 & 2005 & 2006 \\
\hline United States & 124114 & 135280 & 127949 & 133353 & 114397 & 118268 & 105776 & 123835 & 113326 & 128545 \\
\hline China & 114721 & 122939 & 136181 & 138086 & 170648 & 205720 & 258580 & 296580 & 353020 & 384320 \\
\hline Japan & 85500 & 72500 & 71000 & 79600 & 75200 & 73600 & 76400 & 80500 & 82900 & 83300 \\
\hline South Korea & 39900 & 25800 & 35200 & 40000 & 39700 & 45400 & 47500 & 49100 & 49000 & 51600 \\
\hline Germany & 38921 & 40464 & 38974 & 42087 & 39938 & 37914 & 38046 & 38736 & 38612 & 42186 \\
\hline Italy & 29308 & 31869 & 31469 & 32479 & 32473 & 31722 & 33619 & 34810 & 33360 & 38752 \\
\hline India & 27300 & 27100 & 29900 & 30200 & 31200 & 30200 & 34179 & 36894 & 43660 & 48572 \\
\hline Taiwan & 25240 & 24220 & 24470 & 25300 & 20910 & 24470 & 23830 & 26460 & 23890 & 23790 \\
\hline Russia & 18600 & 18400 & 21589 & 29412 & 31861 & 29260 & 29062 & 32509 & 36128 & 42781 \\
\hline Canada & 17700 & 18200 & 18200 & 19800 & 16900 & 17671 & 17233 & 19314 & 18014 & 19252 \\
\hline France & 17695 & 19757 & 19623 & 21041 & 18745 & 18571 & 17126 & 18738 & 16954 & 18084 \\
\hline Brazil & 17000 & 16100 & 15700 & 17500 & 18500 & 19673 & 17730 & 20350 & 18680 & 20590 \\
\hline United Kingdom & 15420 & 16390 & 15480 & 15170 & 15110 & 14080 & 14200 & 14990 & 13090 & 14710 \\
\hline Mexico & 14438 & 16832 & 17623 & 19800 & 18790 & 19673 & 20608 & 22298 & 22403 & 25449 \\
\hline Spain & 14400 & 16500 & 18500 & 18600 & 19900 & 20600 & 27255 & 27239 & 26771 & 30437 \\
\hline Turkey & 12440 & 13490 & 11530 & 13370 & 14346 & 14966 & 16798 & 18581 & 20582 & 24299 \\
\hline Malaysia & 9036 & 4620 & 6354 & 6997 & 8246 & 7879 & 6693 & 7707 & 7371 & 7320 \\
\hline Thailand & 8544 & 4326 & 7129 & 7428 & 8403 & 11145 & 11896 & 14141 & 15265 & 14488 \\
\hline Poland & 8423 & 8401 & 7867 & 8413 & 7426 & 8443 & 8911 & 9824 & 9346 & 12437 \\
\hline Ukraine & 7691 & 6566 & 4502 & 5540 & 6488 & 6211 & 7059 & 6205 & 8635 & 10142 \\
\hline Iran & 7665 & 7057 & 7577 & 10296 & 11412 & 12068 & 15773 & 15540 & 16736 & 15663 \\
\hline Indonesia & 7645 & 3746 & 3659 & 5471 & 5608 & 5422 & 5064 & 6177 & 6372 & 6631 \\
\hline Australia & 6500 & 6600 & 6600 & 6100 & 6000 & 6800 & 7000 & 7500 & 7400 & 7400 \\
\hline Netherlands & 5410 & 6070 & 5850 & 5300 & 4980 & 4540 & 3860 & 4400 & 4390 & 4267 \\
\hline Egypt & 5162 & 4463 & 4657 & 4775 & 5734 & 5948 & 5075 & 4583 & 7071 & 6662 \\
\hline South Africa & 4964 & 4519 & 4266 & 4488 & 4673 & 5396 & 4547 & 5472 & 5175 & 6680 \\
\hline Philippines & 4699 & 3365 & 3703 & 3425 & 3479 & 4168 & 4521 & 3835 & 3907 & 3969 \\
\hline SaudiArabia & 4419 & 4765 & 4248 & 4165 & 5417 & 5551 & 6160 & 6230 & 7057 & 7940 \\
\hline Czech Republic & 4340 & 4390 & 3880 & 4460 & 4550 & 4470 & 5035 & 5788 & 5854 & 6632 \\
\hline Argentina & 4250 & 4340 & 3568 & 3379 & 2920 & 1970 & 3220 & 4114 & 4214 & 5089 \\
\hline VietNam & 1720 & 2123 & 2538 & 2934 & 4036 & 5234 & 5181 & 5793 & 5569 & 5627 \\
\hline Pakistan & 1474 & 1557 & 1612 & 1675 & 1759 & 1923 & 2260 & 2526 & 3001 & 2996 \\
\hline United Arab Emirates & 1213 & 1570 & 2090 & 1967 & 2485 & 3167 & 4039 & 4961 & 5902 & 7331 \\
\hline
\end{tabular}


Tabela 18 - Consumo aparente de aço (equivalente em aço bruto) entre 1996 e 2006 (em 1000t)

Continuação

\begin{tabular}{|c|c|c|c|c|c|c|c|c|c|c|}
\hline Paises & 1997 & 1998 & 1999 & 2000 & 2001 & 2002 & 2003 & 2004 & 2005 & 2006 \\
\hline Algeria & 989 & 1714 & 1500 & 2041 & 2107 & 2418 & 2993 & 3221 & 3169 & 4184 \\
\hline World & 783277 & 775921 & 785691 & 845856 & 855895 & 908013 & 972969 & 1072350 & 1131214 & 1239083 \\
\hline SUM & 706841 & 696033 & 714988 & 764652 & 774341 & 824541 & 887229 & 978951 & 1036824 & 1132125 \\
\hline ROW (\%) & $9,76 \%$ & $10,30 \%$ & $9,00 \%$ & $9,60 \%$ & $9,53 \%$ & $9,19 \%$ & $8,81 \%$ & $8,71 \%$ & $8,34 \%$ & $8,63 \%$ \\
\hline
\end{tabular}


Tabela 19 - Consumo aparente de aço (equivalente em aço bruto) entre 2007 e 2016 (em 1000t)

\begin{tabular}{|c|c|c|c|c|c|c|c|c|c|c|}
\hline Paises & 2007 & 2008 & 2009 & 2010 & 2011 & 2012 & 2013 & 2014 & 2015 & 2016 \\
\hline United States & 120381 & 110500 & 69400 & 92400 & 101000 & 108300 & 106300 & 121600 & 108333 & 102570 \\
\hline China & 435860 & 465480 & 574420 & 612063 & 667941 & 687609 & 772340 & 739980 & 700351 & 708637 \\
\hline Japan & 85900 & 83200 & 56000 & 67400 & 69600 & 68800 & 70800 & 72900 & 67800 & 67500 \\
\hline South Korea & 57404 & 61011 & 47303 & 54573 & 58741 & 56322 & 53919 & 57834 & 58125 & 59520 \\
\hline Germany & 45992 & 44900 & 29100 & 40479 & 45141 & 40829 & 41700 & 42800 & 42400 & 42800 \\
\hline Italy & 38102 & 35286 & 21280 & 27212 & 28143 & 22810 & 23218 & 23222 & 25957 & 25535 \\
\hline India & 55491 & 56209 & 64360 & 69082 & 73154 & 77436 & 80656 & 86537 & 89466 & 95779 \\
\hline Taiwan & 21700 & 20290 & 13530 & 21350 & 21715 & 21332 & 22285 & 23469 & 21032 & 21932 \\
\hline Russia & 46959 & 40896 & 28477 & 41444 & 47981 & 49488 & 49671 & 49423 & 44746 & 43424 \\
\hline Canada & 18248 & 16799 & 10591 & 15656 & 15746 & 17305 & 16445 & 17527 & 14827 & 16717 \\
\hline France & 19147 & 17775 & 12290 & 15454 & 16304 & 14130 & 14566 & 14472 & 14520 & 15251 \\
\hline Brazil & 24511 & 26720 & 20640 & 29004 & 28993 & 29526 & 31131 & 28451 & 23657 & 20241 \\
\hline United Kingdom & 16245 & 14389 & 8808 & 11358 & 11489 & 10839 & 10955 & 11768 & 11811 & 12058 \\
\hline Mexico & 25537 & 24505 & 17565 & 20648 & 23140 & 23714 & 22904 & 26073 & 27707 & 28421 \\
\hline Spain & 27500 & 24200 & 12500 & 14100 & 14000 & 11510 & 11873 & 12449 & 13467 & 13517 \\
\hline Turkey & 25309 & 22862 & 19198 & 25131 & 28665 & 30286 & 33305 & 32750 & 36570 & 36250 \\
\hline Malaysia & 8947 & 9873 & 7727 & 9668 & 9578 & 10374 & 11685 & 11720 & 11629 & 11925 \\
\hline Thailand & 14160 & 15655 & 12501 & 16378 & 16881 & 19047 & 20732 & 20544 & 19403 & 22340 \\
\hline Poland & 14002 & 12450 & 8414 & 10309 & 11635 & 10986 & 11241 & 12955 & 13632 & 14049 \\
\hline Ukraine & 9713 & 7806 & 4474 & 6305 & 7307 & 7057 & 6331 & 4810 & 3799 & 4900 \\
\hline Iran & 20343 & 16717 & 19496 & 21878 & 23467 & 21081 & 21998 & 22089 & 21911 & 21228 \\
\hline Indonesia & 8694 & 10587 & 8908 & 10744 & 13148 & 15006 & 15237 & 15483 & 13656 & 15214 \\
\hline Australia & 8126 & 8224 & 5916 & 7716 & 6672 & 7152 & 6376 & 7142 & 6968 & 6478 \\
\hline Netherlands & 6100 & 5492 & 3662 & 4285 & 4869 & 4996 & 4707 & 4012 & 4144 & 4700 \\
\hline Egypt & 5793 & 6864 & 9829 & 9306 & 8370 & 10182 & 9900 & 10930 & 11622 & 12501 \\
\hline South Africa & 6629 & 6779 & 4931 & 5534 & 5900 & 5827 & 6295 & 5663 & 5858 & 5500 \\
\hline Philippines & 3950 & 4134 & 3993 & 4650 & 5940 & 6986 & 7796 & 8517 & 10186 & 11253 \\
\hline SaudiArabia & 9328 & 12246 & 10158 & 10800 & 12600 & 13500 & 14000 & 14600 & 14000 & 12650 \\
\hline Czech Republic & 7599 & 7555 & 5207 & 6379 & 6985 & 6747 & 6765 & 7145 & 7630 & 7720 \\
\hline Argentina & 5290 & 5457 & 3652 & 5268 & 6087 & 5582 & 5775 & 5712 & 5991 & 4796 \\
\hline VietNam & 10833 & 9516 & 12700 & 12293 & 11276 & 12740 & 13685 & 16226 & 20510 & 25088 \\
\hline Pakistan & 3249 & 2396 & 2621 & 2173 & 3189 & 3788 & 4210 & 4820 & 6464 & 8121 \\
\hline United Arab Emirates & 8569 & 13435 & 6934 & 7364 & 7592 & 7656 & 7413 & 7771 & 7756 & 8514 \\
\hline
\end{tabular}


Tabela 19 - Consumo aparente de aço (equivalente em aço bruto) entre 2007 e 2016 (em 1000t)

Continuação

\begin{tabular}{|c|c|c|c|c|c|c|c|c|c|c|}
\hline Paises & 2007 & 2008 & 2009 & 2010 & 2011 & 2012 & 2013 & 2014 & 2015 & 2016 \\
\hline Algeria & 3232 & 4108 & 4752 & 3403 & 4208 & 5160 & 6268 & 6858 & 6656 & 6320 \\
\hline World & 1330937 & 1336598 & 1233734 & 1409997 & 1523028 & 1552549 & 1658980 & 1667523 & 1615941 & 1633717 \\
\hline SUM & 1218843 & 1224316 & 1141337 & 1311807 & 1417457 & 1444103 & 1542482 & 1548252 & 1492584 & 1513449 \\
\hline ROW & 112094 & 112282 & 92397 & 98190 & 105571 & 108446 & 116498 & 119271 & 123357 & 120268 \\
\hline ROW (\%) & $8,42 \%$ & $8,40 \%$ & $7,49 \%$ & $6,96 \%$ & $6,93 \%$ & $6,99 \%$ & $7,02 \%$ & $7,15 \%$ & $7,63 \%$ & $7,36 \%$ \\
\hline
\end{tabular}


A.2.7 Produção mundial de aço bruto por regiões e China

A tabela 20 mostra a produção mundial anual de aço bruto por regiões e da China entre os anos de 1996 e 2016: 
Tabela 20 - Produção mundial de aço bruto (em Mt) por país / grupo / região de 1996 a 2016

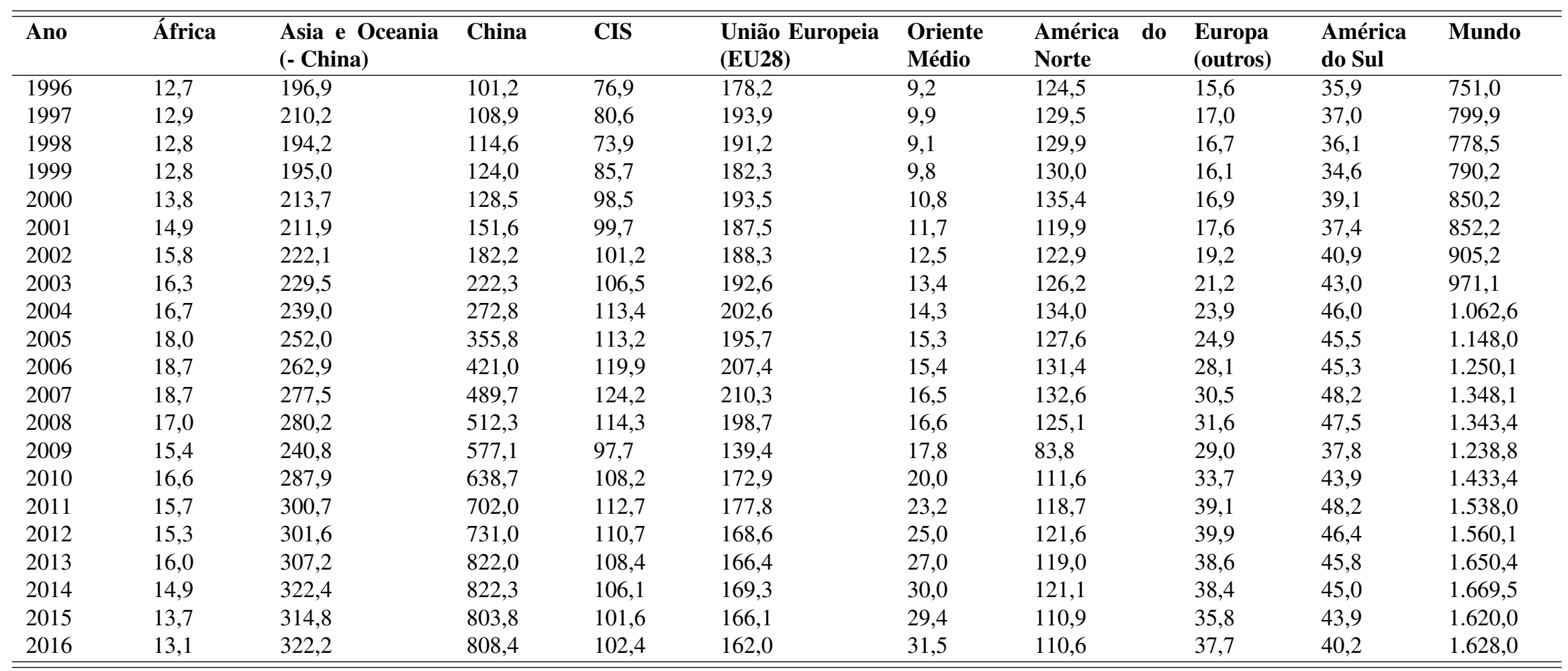

Fonte: Produzido pelo autor pela compilação de dados da WorldSteel (2007), WorldSteel (2017). 


\section{A.3 Tabelas da base de dados WBIG / IEA}

\section{A.3.1 Tabela de variáveis de fluxo}

Tabela 21 - Conteúdo da tabela WBIG_tab_flow

\begin{tabular}{|c|c|c|}
\hline \# & Código fluxo & Variável de fluxo \\
\hline 1 & MARBUNK & International marine bunkers \\
\hline 2 & AVBUNK & International aviation bunkers \\
\hline 3 & STOCKCHA & Stock changes \\
\hline 4 & TPES & Total primary energy supply \\
\hline 5 & TRANSFER & Transfers \\
\hline 6 & STATDIFF & Statistical differences \\
\hline 7 & TOTTRANF & Transformation processes \\
\hline 8 & MAINELEC & Main activity producer electricity plants (transf.) \\
\hline 9 & AUTOELEC & Autoproducer electricity plants (transf.) \\
\hline 10 & MAINCHP & Main activity producer CHP plants (transf.) \\
\hline 11 & AUTOCHP & Autoproducer CHP plants (transf.) \\
\hline 12 & MAINHEAT & Main activity producer heat plants (transf.) \\
\hline 13 & AUTOHEAT & Autoproducer heat plants (transf.) \\
\hline 14 & THEAT & Heat pumps (transf.) \\
\hline 15 & TBOILER & Electric boilers (transf.) \\
\hline 16 & TELE & Chemical heat for electricity production (transf.) \\
\hline 17 & TBLASTFUR & Blast furnaces (transf.) \\
\hline 18 & TGASWKS & Gas works (transf.) \\
\hline 19 & TCOKEOVS & Coke ovens (transf.) \\
\hline 20 & TPATFUEL & Patent fuel plants (transf.) \\
\hline 21 & TBKB & $\mathrm{BKB} /$ peat briquette plants (transf.) \\
\hline 22 & TREFINER & Oil refineries (transf.) \\
\hline 23 & TPETCHEM & Petrochemical plants (transf.) \\
\hline 24 & TCOALLIQ & Coal liquefaction plants (transf.) \\
\hline 25 & TGTL & Gas-to-liquids (GTL) plants (transf.) \\
\hline 26 & TBLENDGAS & For blended natural gas (transf.) \\
\hline 27 & TCHARCOAL & Charcoal production plants (transf.) \\
\hline 28 & TNONSPEC & Non-specified (transformation) \\
\hline 29 & TOTENGY & Energy industry own use \\
\hline 30 & EMINES & Coal mines (energy) \\
\hline 31 & EOILGASEX & Oil and gas extraction (energy) \\
\hline 32 & EBLASTFUR & Blast furnaces (energy) \\
\hline 33 & EGASWKS & Gas works (energy) \\
\hline
\end{tabular}


Conteúdo da tabela WBIG_tab_flow

(continuação)

\begin{tabular}{|c|c|c|}
\hline \# & Código fluxo & Variável de fluxo \\
\hline 34 & EBIOGAS & Gasification plants for biogases (energy) \\
\hline 35 & ECOKEOVS & Coke ovens (energy) \\
\hline 36 & EPATFUEL & Patent fuel plants (energy) \\
\hline 37 & EBKB & BKB/peat briquette plants (energy) \\
\hline 38 & EREFINER & Oil refineries (energy) \\
\hline 39 & ECOALLIQ & Coal liquefaction plants (energy) \\
\hline 40 & ELNG & Liquefaction (LNG) / regasification plants (energy) \\
\hline 41 & EGTL & Gas-to-liquids (GTL) plants (energy) \\
\hline 42 & EPOWERPLT & Own use in electricity, CHP and heat plants (energy) \\
\hline 43 & EPUMPST & Pumped storage plants (energy) \\
\hline 44 & ENUC & Nuclear industry (energy) \\
\hline 45 & ECHARCOAL & Charcoal production plants (energy) \\
\hline 46 & ENONSPEC & Non-specified (energy) \\
\hline 47 & DISTLOSS & Losses \\
\hline 48 & TFC & Total final consumption \\
\hline 49 & TOTIND & Industry \\
\hline 50 & IRONSTL & Iron and steel \\
\hline 51 & CHEMICAL & Chemical and petrochemical \\
\hline 52 & NONFERR & Non-ferrous metals \\
\hline 53 & NONMET & Non-metallic minerals \\
\hline 54 & TRANSEQ & Transport equipment \\
\hline 55 & MACHINE & Machinery \\
\hline 56 & MINING & Mining and quarrying \\
\hline 57 & FOODPRO & Food and tobacco \\
\hline 58 & PAPERPRO & Paper, pulp and print \\
\hline 59 & WOODPRO & Wood and wood products \\
\hline 60 & CONSTRUC & Construction \\
\hline 61 & TEXTILES & Textile and leather \\
\hline 62 & INONSPEC & Non-specified (industry) \\
\hline 63 & TOTTRANS & Transport \\
\hline 64 & WORLDAV & World aviation bunkers \\
\hline 65 & DOMESAIR & Domestic aviation \\
\hline 66 & ROAD & Road \\
\hline 67 & RAIL & Rail \\
\hline 68 & PIPELINE & Pipeline transport \\
\hline 69 & WORLDMAR & World marine bunkers \\
\hline 70 & DOMESNAV & Domestic navigation \\
\hline
\end{tabular}


Conteúdo da tabela WBIG_tab_flow

(continuação)

\begin{tabular}{lll}
\hline$\#$ & Código fluxo & Variável de fluxo \\
\hline 71 & TRNONSPE & Non-specified (transport) \\
72 & TOTOTHER & Other \\
73 & RESIDENT & Residential \\
74 & COMMPUB & Commercial and public services \\
75 & AGRICULT & Agriculture/forestry \\
76 & FISHING & Fishing \\
77 & ONONSPEC & Non-specified (other) \\
78 & NONENUSE & Non-energy use \\
79 & NEINTREN & Non-energy use industry/transformation/energy \\
80 & NECHEM & Memo: Non-energy use chemical/petrochemical \\
81 & NETRANS & Non-energy use in transport \\
82 & NEOTHER & Non-energy use in other \\
83 & ELOUTPUT & Electricity output (GWh) \\
84 & ELMAINE & Electricity output (GWh)-main activity producer electricity plants \\
85 & ELAUTOE & Electricity output (GWh)-autoproducer electricity plants \\
86 & ELMAINC & Electricity output (GWh)-main activity producer CHP plants \\
87 & ELAUTOC & Electricity output (GWh)-autoproducer CHP plants \\
88 & HEATOUT & Heat output \\
89 & HEMAINC & Heat output-main activity producer CHP plants \\
90 & HEAUTOC & Heat output-autoproducer CHP plants \\
91 & HEMAINH & Heat output-main activity producer heat plants \\
92 & HEAUTOH & Heat output-autoproducer heat plants \\
93 & INDPROD & Production \\
94 & IMPORTS & Imports \\
95 & EXPORTS & Exports \\
\hline Fon & \\
\hline
\end{tabular}

Fonte: fornecido pela IAEA (2013)

\section{A.3.2 Tabela de produtos}

Tabela 22 - Conteúdo da tabela WBIG_tab_prod

\begin{tabular}{lll}
\hline CDPROD & COD_PROD & \multicolumn{1}{c}{ DESCR_PROD } \\
\hline 1 & BROWN & Brown coal (if no detail) \\
2 & ANTCOAL & Anthracite \\
3 & COKCOAL & Coking coal \\
4 & BITCOAL & Other bituminous coal \\
5 & SUBCOAL & Sub-bituminous coal
\end{tabular}


Conteúdo da tabela WBIG_tab_prod (continuação)

\begin{tabular}{|c|c|c|}
\hline CDPROD & COD_PROD & DESCR_PROD \\
\hline 6 & LIGNITE & Lignite \\
\hline 7 & PEAT & Peat \\
\hline 8 & PATFUEL & Patent fuel \\
\hline 9 & OVENCOKE & Coke oven coke \\
\hline 10 & GASCOKE & Gas coke \\
\hline 11 & COALTAR & Coal tar \\
\hline 12 & $\mathrm{BKB}$ & $\mathrm{BKB}$ \\
\hline 13 & GASWKSGS & Gas works gas \\
\hline 14 & COKEOVGS & Coke oven gas \\
\hline 15 & BLFURGS & Blast furnace gas \\
\hline 16 & MANGAS & Elec/heat output from non-specified manufactured gases \\
\hline 17 & INDWASTE & Industrial waste \\
\hline 18 & MUNWASTER & Municipal waste (renewable) \\
\hline 19 & MUNWASTEN & Municipal waste (non-renewable) \\
\hline 20 & BIOGASOL & Biogasoline \\
\hline 21 & BIODIESEL & Biodiesels \\
\hline 22 & OBIOLIQ & Other liquid biofuels \\
\hline 23 & RENEWNS & Non-specified primary biofuels and waste \\
\hline 24 & CHARCOAL & Charcoal \\
\hline 25 & NATGAS & Natural gas \\
\hline 26 & CRNGFEED & Crude/NGL/feedstocks (if no detail) \\
\hline 27 & CRUDEOIL & Crude oil \\
\hline 28 & NGL & Natural gas liquids \\
\hline 29 & REFFEEDS & Refinery feedstocks \\
\hline 30 & ADDITIVE & Additives/blending components \\
\hline 31 & NONCRUDE & Other hydrocarbons \\
\hline 32 & REFINGAS & Refinery gas \\
\hline 33 & ETHANE & Ethane \\
\hline 34 & LPG & Liquefied petroleum gases (LPG) \\
\hline 35 & AVGAS & Aviation gasoline \\
\hline 36 & JETGAS & Gasoline type jet fuel \\
\hline 37 & OTHKERO & Other kerosene \\
\hline 38 & RESFUEL & Fuel oil \\
\hline 39 & NAPHTHA & Naphtha \\
\hline 40 & WHITESP & White spirit \& SBP \\
\hline 41 & LUBRIC & Lubricants \\
\hline
\end{tabular}


Conteúdo da tabela WBIG_tab_prod (continuação)

\begin{tabular}{lll}
\hline CDPROD & COD_PROD & \multicolumn{1}{c}{ DESCR_PROD } \\
\hline 42 & BITUMEN & Bitumen \\
43 & PARWAX & Paraffin waxes \\
44 & PETCOKE & Petroleum coke \\
45 & ONONSPEC & Other oil products \\
46 & HEATNS & Heat output from non-specified combustible fuels \\
47 & NUCLEAR & Nuclear \\
48 & HYDRO & Hydro \\
49 & GEOTHERM & Geothermal \\
50 & SOLARPV & Solar photovoltaics \\
51 & SOLARTH & Solar thermal \\
52 & TIDE & Tide, wave and ocean \\
53 & WIND & Wind \\
54 & OTHER & Other sources \\
55 & ELECTR & Electricity \\
56 & HEAT & Heat \\
57 & TOTAL & Total \\
58 & MRENEW & Memo: Renewables \\
59 & HARDCOAL & Hard coal (if no detail) \\
60 & PEATPROD & Peat products \\
61 & PRIMSBIO & Primary solid biofuels \\
62 & NONBIODIES & Gas/diesel oil excl. biofuels \\
63 & BIOGASES & Biogases \\
64 & NONBIOGASO & Motor gasoline excl. biofuels \\
65 & NONBIOJETK & Kerosene type jet fuel excl. biofuels \\
66 & OILSHALE & Oil shale and oil sands \\
67 & OGASES & Other recovered gases \\
\hline & &
\end{tabular}

Fonte: fornecido pela IAEA (2013) 


\section{APÊNDICE B - PROCESSAMENTO E CONSOLIDAÇÃO DAS BASES DE DADOS}

\section{B.1 Base de dados WorldSteel}

Os dados da produção física de ferro e aço foram extraídos a partir de dois anuários estatísticos obtidos através da internet no formato pdf (WORLDSTEEL, 2007; WORLDSTEEL, 2017).

Seguindo o procedimento detalhado na metodologia (seção 3.5.2), depois de terem sido importados para uma planilha no formato ods do openoffice calc, os dados tiveram que ser agrupados e os totais e subtotais foram recalculados de forma a garantir a integridade dos dados importados.

Isso foi particularmente importante nessa bases de dados porque o anuário de 2007 (WORLDSTEEL, 2007) possui os dados de 1997 até 2006 enquanto o de 2017 (WORLDSTEEL, 2017) possui os dados de 2007 a 2016. Nesse período, diversos grupos de países e blocos tiveram modificações, como o ingresso de alguns países à União Europeia, por exemplo.

Como resultado desse processamento, tem-se as tabelas e gráficos produzidos diretamente a partir dessa base, como evidenciado nas seções A.2 $\mathrm{e} 4.1$.

\section{B.2 Base de dados IEA WBIG}

$\mathrm{O}$ arquivo bruto da base de dados WBIG foi baixado pela internet e tem um tamanho de 16,5 GB e 121.189.600 registros. Essa enorme quantidade de dados tornou o tratamento dos dados uma tarefa muito complicada. Mesmo utilizando as ferramentas mais avançadas de tratamento de big data, os softwares raramente são capazes de importar tamanha quantidade de dados para a memória. A filtragem de um conjunto tão grande de dados torna-se quase impossível. Seguindo o procedimento detalhado na metodologia (seção 3.5 .2 ), esse arquivo foi importado e tratado utilizando-se de diversos scripts (em R, SQL e Python), a partir dos quais foi possível obter tabelas auxiliares de normalização, tais como as obtidas na seção A.3.

\section{B.2.1 Scripts}

\section{B.2.1.1 Importação do arquivo bruto em $\mathrm{R}$}

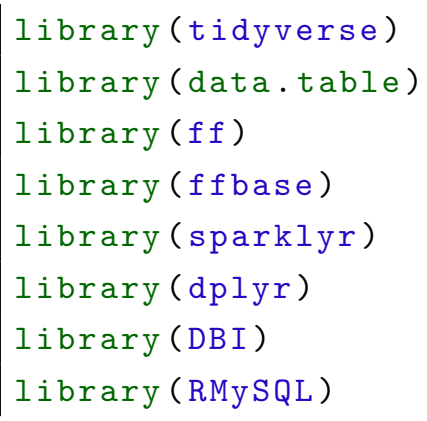




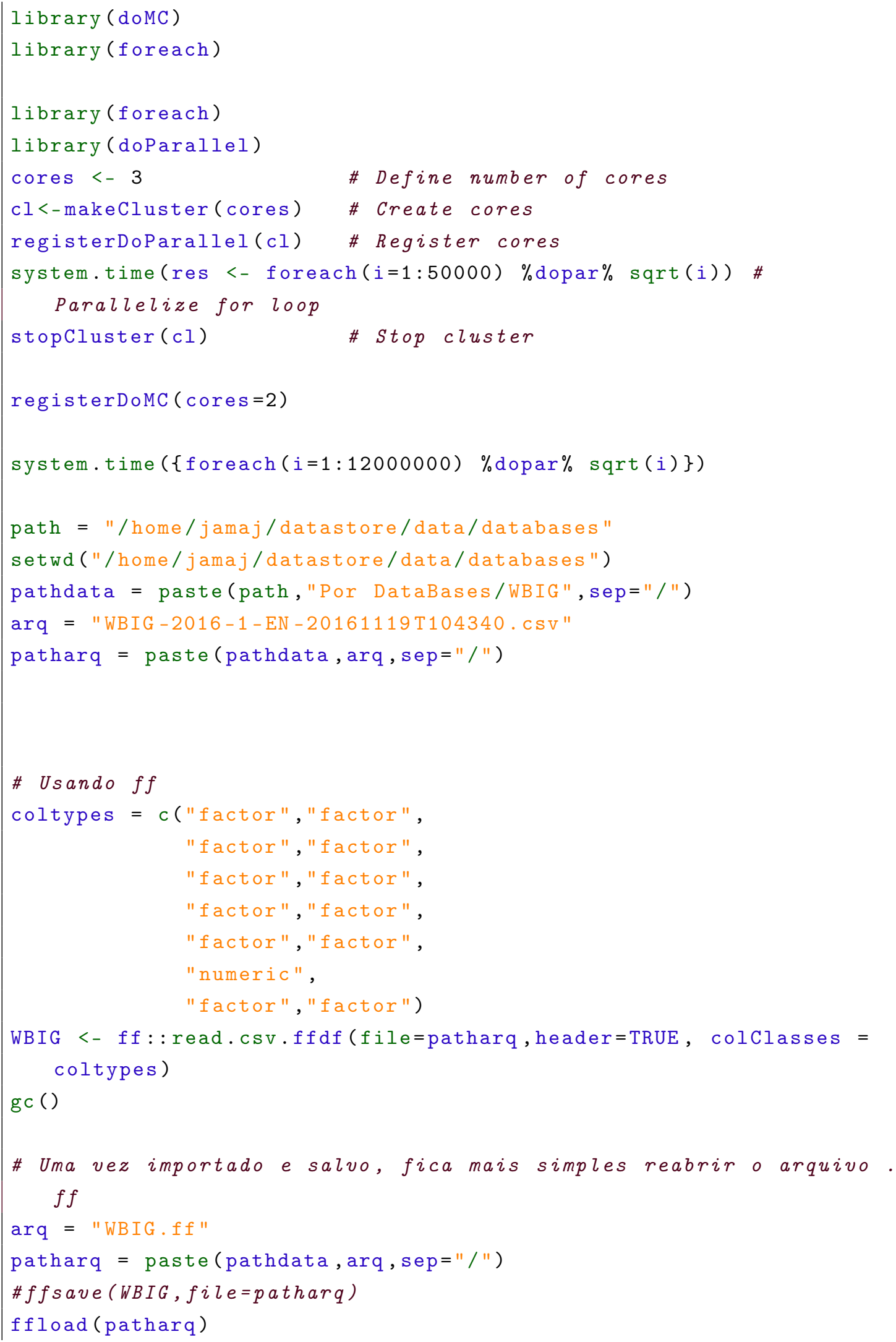

\section{B.2.1.2 Tabelas auxiliares - normalização}

\# Gerando WBIG_FLOW

WBIG_FLOW <- cbind (unique (WBIG\$FLOW[]), unique (WBIG\$Flow [])) 


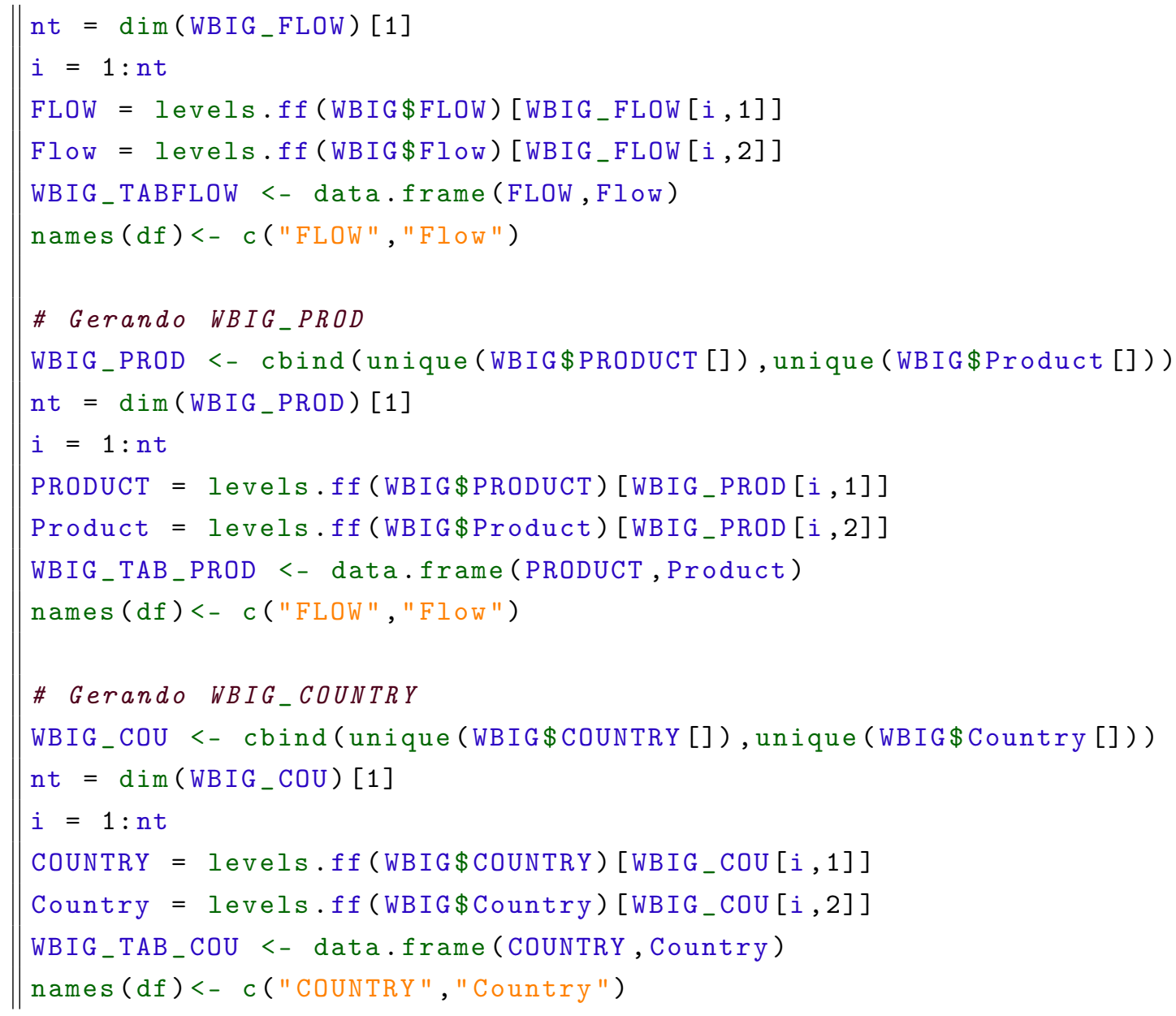

\section{B.2.1.3 Filtragem e exportação}

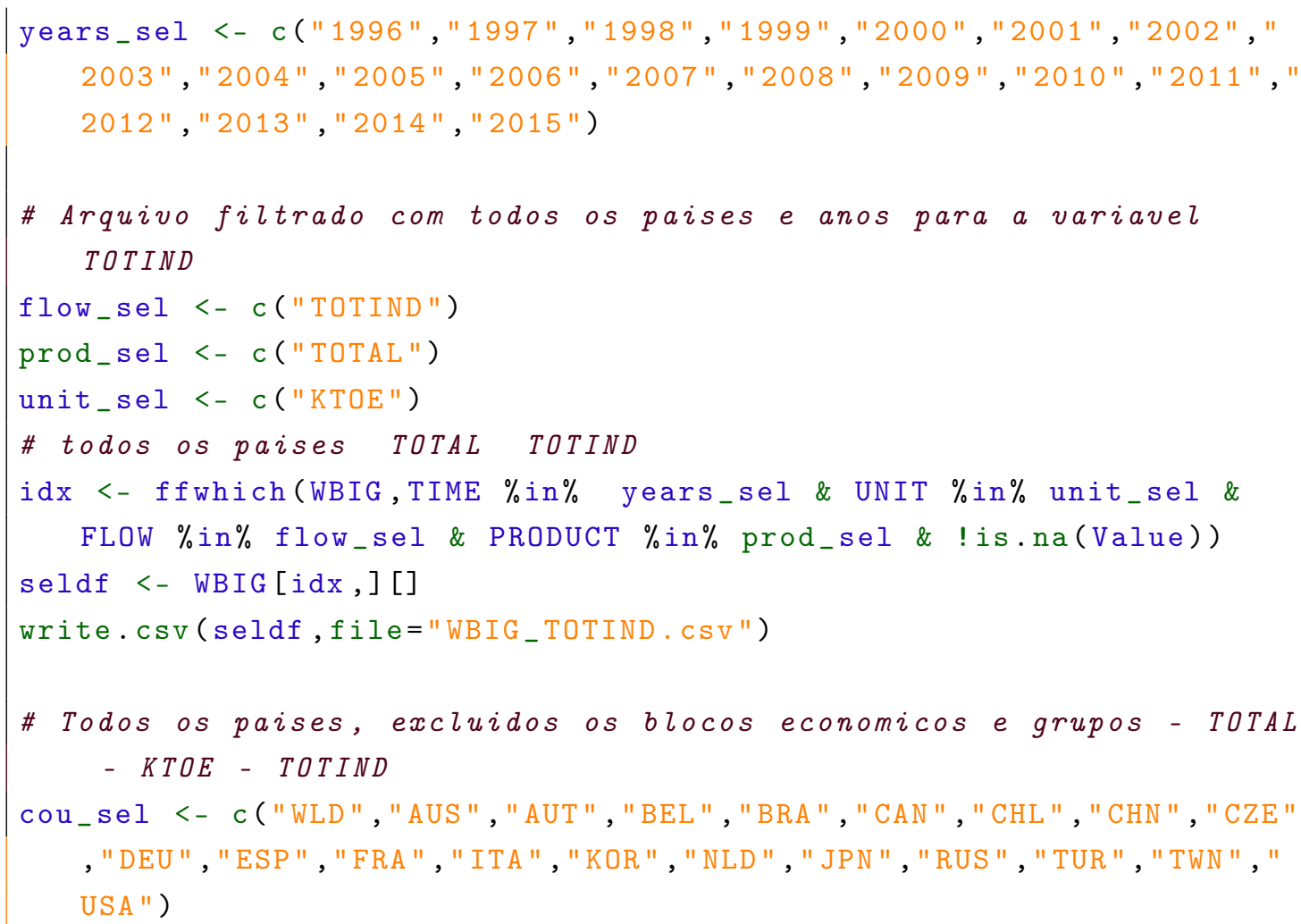




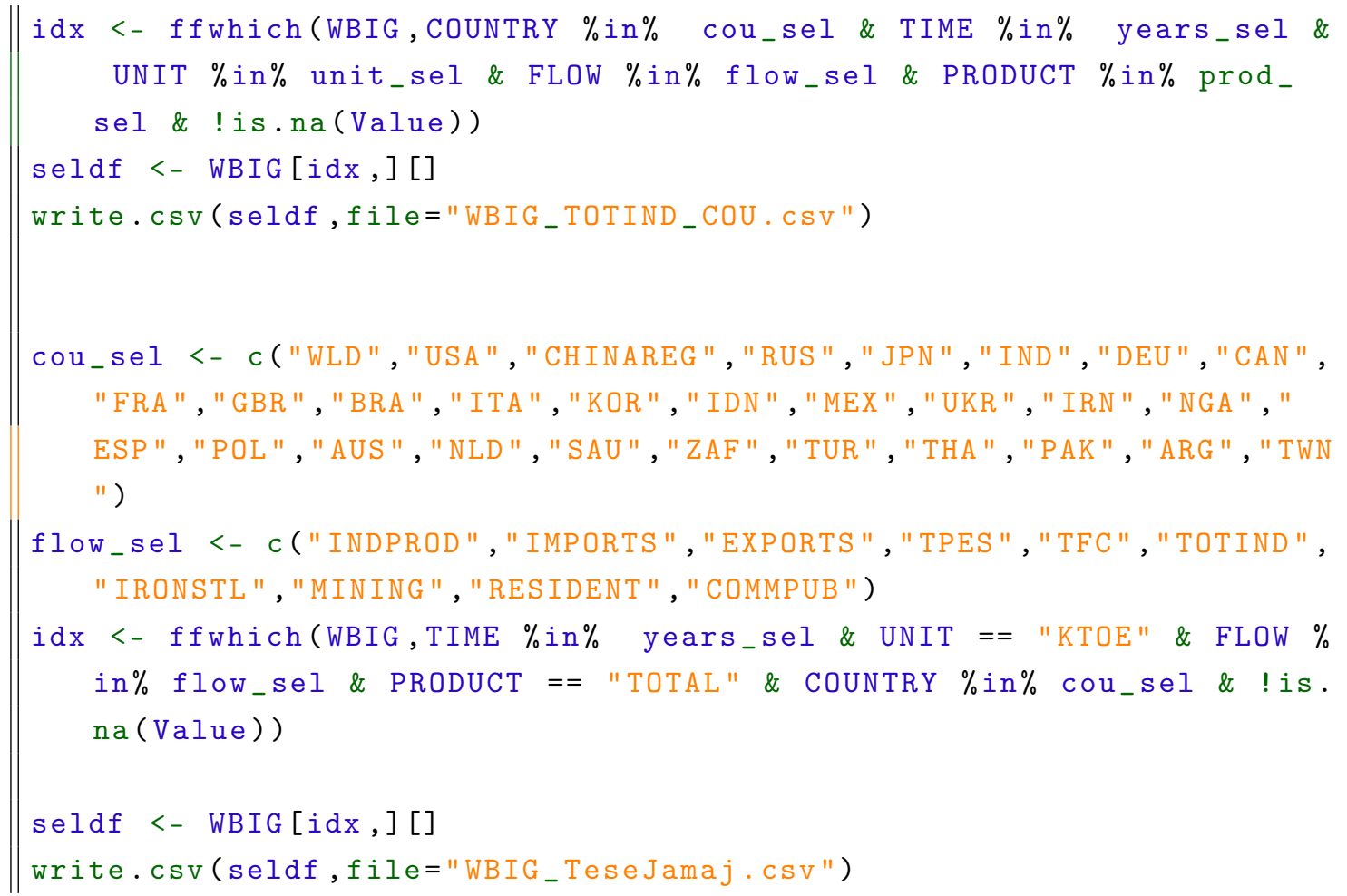

\section{B.2.1.4 Pivoteamento}

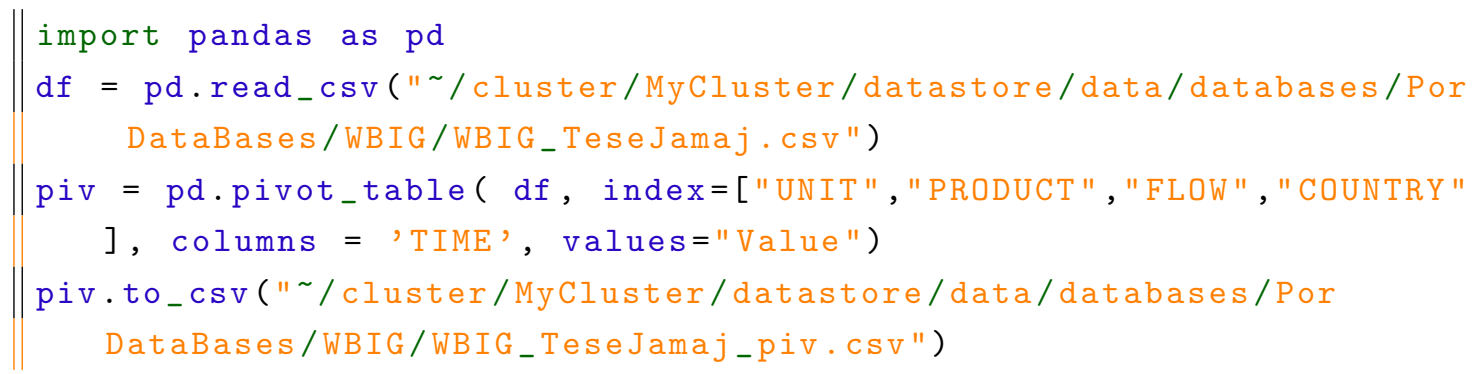

\section{B.2.1.5 Exportação para o servidor sql}

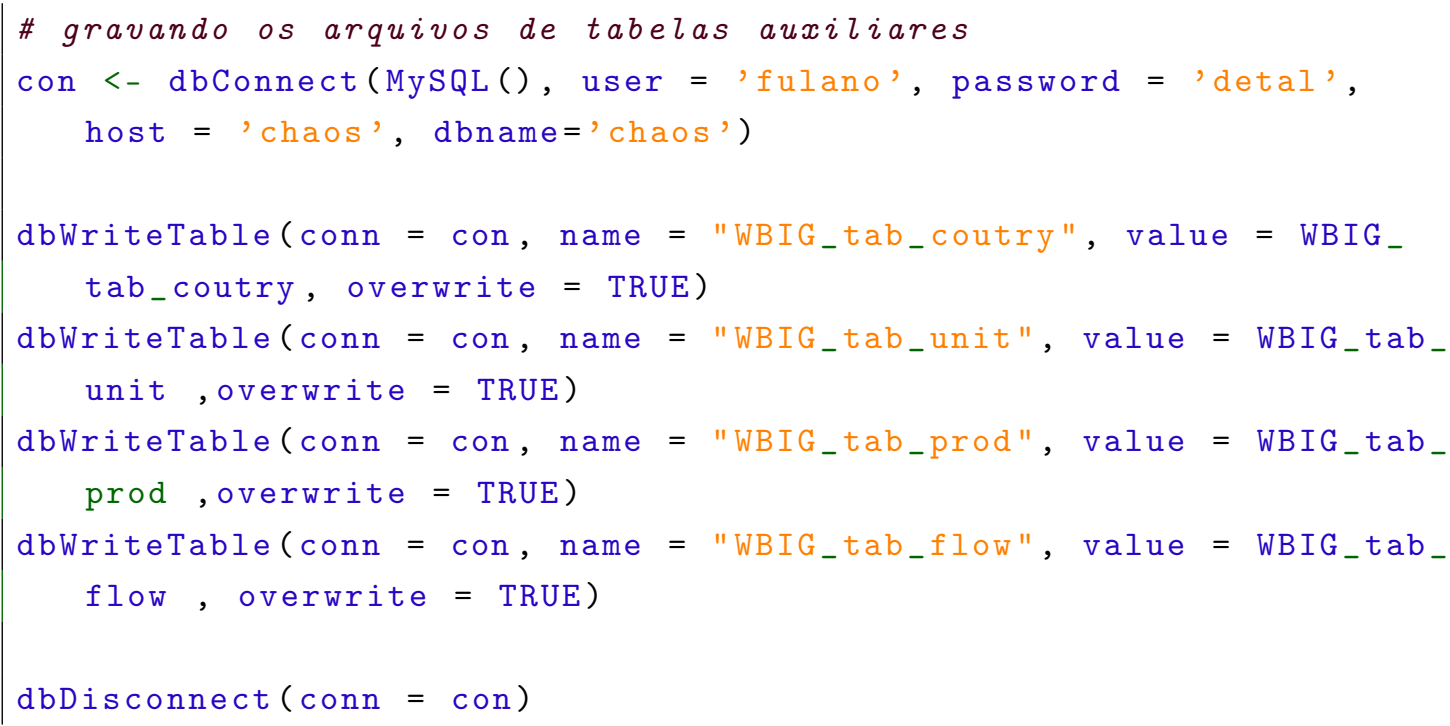


B.2.2 Tabelas auxiliares obtidas

As tabelas auxiliares da base de dados WBIG estão detalhadas na seção A.3.

\section{B.3 Base de dados BTDIXE}

$\mathrm{O}$ arquivo bruto da base de dados BTDIXE foi baixado pela internet e tem um tamanho de 10,1 GB contendo 160.271.899 registros.

Seguindo o procedimento detalhado na metodologia (seção XXX), esse arquivo foi importado e tratado utilizando diversos scripts (em R, SQL e Python), a partir dos quais foi possível obter tabelas auxiliares de normalização.

\section{B.3.1 Scripts}

B.3.1.1 Importação do arquivo bruto em $\mathrm{R}$

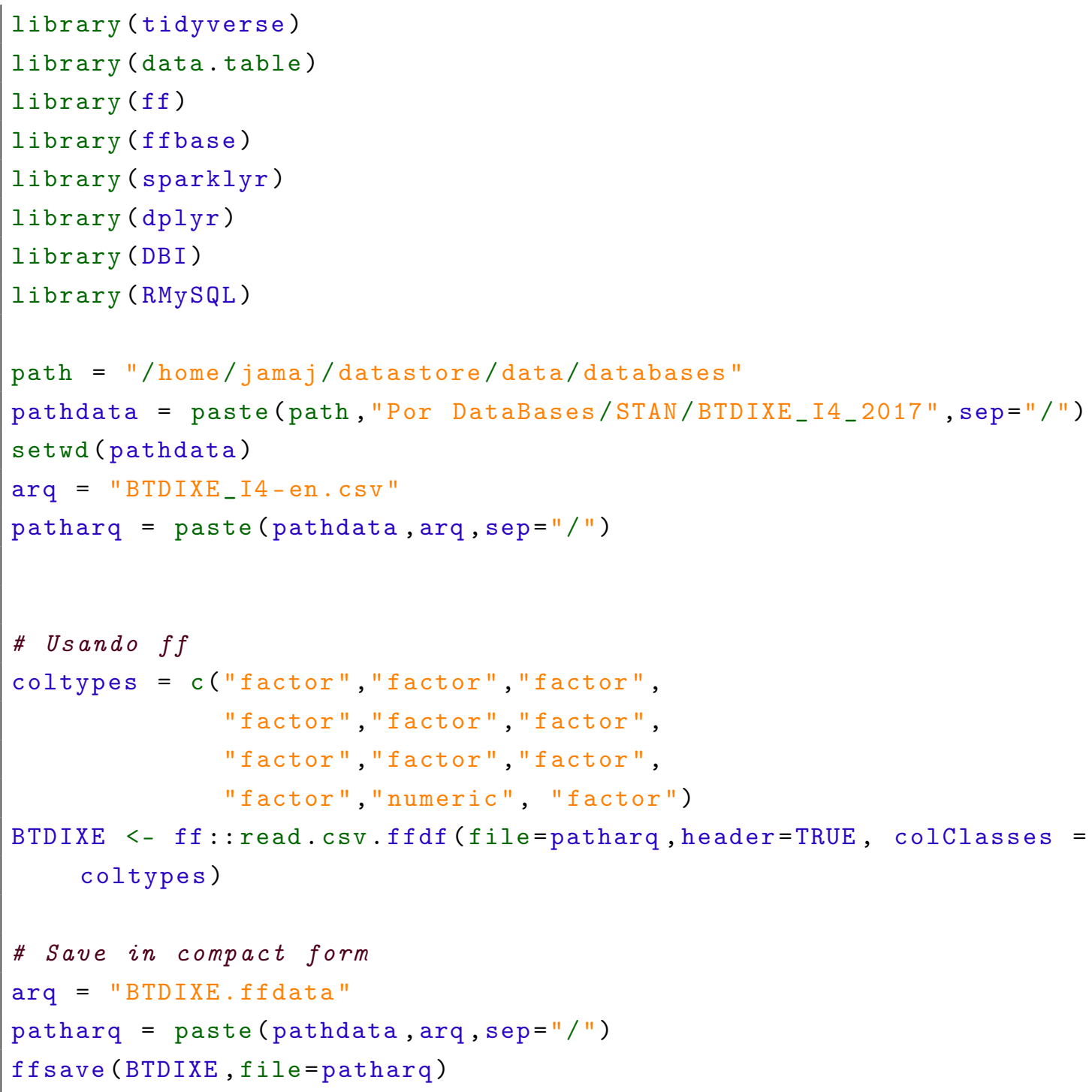




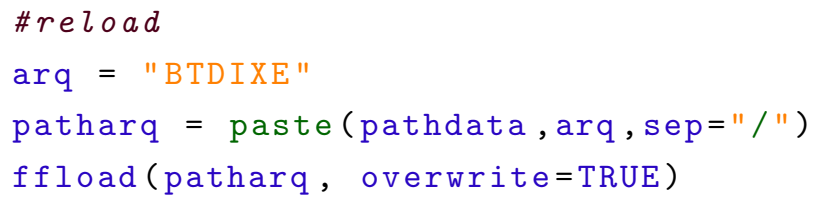

B.3.2 Tabelas auxiliares obtidas

Tabela 23 - BTDIXE - Tabela de atividades industriais (ISIC)

\begin{tabular}{|c|c|c|}
\hline & IND & Indústria (ISIC) \\
\hline 1 & DTOTAL & TOTAL \\
\hline 2 & D01T03 & Agriculture, forestry and fishing $[\mathrm{A}]$ \\
\hline 3 & D01 & $\begin{array}{l}\text { Crop and animal production, hunting and related service } \\
\text { activities }\end{array}$ \\
\hline 4 & D02 & Forestry and logging \\
\hline 5 & D03 & Fishing and aquaculture \\
\hline 6 & D05T08 & Mining and quarrying $[\mathrm{B}]$ \\
\hline 7 & D05 & Mining of coal and lignite \\
\hline 8 & D06 & Extraction of crude petroleum and natural gas \\
\hline 9 & D07 & Mining of metal ores \\
\hline 10 & D08 & Other mining and quarrying \\
\hline 11 & D10T32 & Manufacturing $[\mathrm{C}]$ \\
\hline 12 & D10T12 & Food products, beverages and tobacco \\
\hline 13 & D10 & Food products \\
\hline 14 & D11 & Beverages \\
\hline 15 & D12 & Tobacco products \\
\hline 16 & D13T15 & Textiles, wearing apparel, leather and related prodcuts \\
\hline 17 & D13 & Textiles \\
\hline 18 & D14 & Wearing apparel \\
\hline 19 & D15 & Leather and related products \\
\hline 20 & D16 & Wood and products of wood and cork, except furniture \\
\hline 21 & D17T18 & Paper and printing \\
\hline 22 & D17 & Paper and paper products \\
\hline 23 & D18 & Printing and reproduction of recorded media \\
\hline 24 & D19T22 & Chemicals, rubber, plastics and fuel products \\
\hline 25 & D19 & Coke and refined petroleum products \\
\hline 26 & D20T21 & Chemical and pharmaceutical products \\
\hline 27 & $\mathrm{D} 20$ & Chemicals and chemical products \\
\hline
\end{tabular}


Tabela 23 - BTDIXE - Tabela de atividades industriais (ISIC)

\begin{tabular}{|c|c|c|}
\hline & IND & Indústria (ISIC) \\
\hline 28 & D21 & $\begin{array}{l}\text { Basic pharmaceutical products and pharmaceutical prepa- } \\
\text { rations }\end{array}$ \\
\hline 29 & D22 & Rubber and plastics products \\
\hline 30 & D23 & Other non-metallic mineral products \\
\hline 31 & $\mathrm{D} 24 \mathrm{~T} 25$ & $\begin{array}{l}\text { Basic metals and fabricated metal products, except machi- } \\
\text { nery and equipment }\end{array}$ \\
\hline 32 & D24 & Basic metals \\
\hline 33 & D241T31 & Iron and steel \\
\hline 34 & D242T32 & Non-ferrous metals \\
\hline 35 & D25 & $\begin{array}{l}\text { Fabricated metal products, except machinery and equip- } \\
\text { ment }\end{array}$ \\
\hline 36 & D26T28 & Machinery and equipment \\
\hline 37 & D26 & Computer, electronic and optical products \\
\hline 38 & D262 & Computers and peripheral equipment \\
\hline 39 & D26X & Electronic and optical products; scientific instruments \\
\hline 40 & D27 & Electrical equipment \\
\hline 41 & D28 & Machinery and equipment n.e.c. \\
\hline 42 & D29T30 & Transport equipment \\
\hline 43 & D29 & Motor vehicles, trailers and semi-trailers \\
\hline 44 & D30 & Other transport equipment \\
\hline 45 & D301 & Building of ships and boats \\
\hline 46 & D303 & Air and spacecraft and related machinery \\
\hline 47 & D304 & Military fighting vehicles \\
\hline 48 & D302A9 & Railroad equipment and transport equipment n.e.c. \\
\hline 49 & D31T32 & Furniture, other manufacturing \\
\hline 50 & D35 & Electricity, gas, steam and air conditioning supply [D] \\
\hline 51 & D36T99 & Other activities \\
\hline 52 & DWASTE & Total Waste \\
\hline 53 & D15-USED & Waste textiles \\
\hline 54 & D17-USED & Waste paper \\
\hline 55 & D20-USED & Chemical waste \\
\hline 56 & D22-USED & Waste rubber and plastics \\
\hline 57 & D241T31-USED & Ferrous scrap metals \\
\hline 58 & D242T32-USED & Non-ferrous scrap metals \\
\hline 59 & WASTE & Other waste not elsewhere specified \\
\hline 60 & UNALLOCATED & Confidential and unallocated \\
\hline
\end{tabular}


Tabela 23 - BTDIXE - Tabela de atividades industriais (ISIC)

\begin{tabular}{lll}
\hline & IND & Indústria (ISIC) \\
\hline 61 & HITECH & High R\&D intensive industries \\
62 & MHTECH & Medium-high R\&D intensive industries \\
63 & MLTECH & Medium-low technology industries \\
64 & ICTMAN & Information Communication Technology (ICT) manufac- \\
& & turing \\
65 & D01T32 & Primary and manufactured goods \\
66 & D252 & Manufacture of weapons and ammunition \\
67 & D25X & Manufacture of other fabricated metal products; metalwor- \\
& & king service activities \\
68 & D071A241 & Mining and manufacturing of iron and steel \\
69 & D072A242 & Mining and manufacturing of non-ferrous metals \\
70 & MDTECH & Medium technology industries \\
\hline
\end{tabular}

Fonte: XXXXX.

Conclusão

Tabela 24 - BTDIXE - Tabela de tipos de fluxo

\begin{tabular}{lll}
\hline & FLW & Flow \\
\hline 1 & EXPO & Exports \\
2 & IMPO & Imports \\
3 & REEX & Re-exports \\
4 & REIM & Re-imports \\
\hline
\end{tabular}

Tabela 25 - BTDIXE - Tabela de tipos de variáveis

\begin{tabular}{lll}
\hline & VAL & Variable \\
\hline 1 & SHARE & Shares of end-use by industry in \% \\
2 & VALUE & Values in thousand USD \\
\hline
\end{tabular}

\section{B.4 Base de dados COMTRADE}

$\mathrm{O}$ arquivo bruto da base de dados COMTRADE foi baixado pela internet e tem um tamanho de 3,8 MB e XXX registros.

Seguindo o procedimento detalhado na metodologia (seção XXX), esse arquivo foi importado e tratado utilizando diversos scripts (em R, SQL e Python), a partir dos quais foi possível obter tabelas auxiliares de normalização. 
Tabela 26 - BTDIXE - Tabela de categorias de uso

\begin{tabular}{rll}
\hline & CAT & End-Use \\
\hline 1 & TOTAL & Total trade in goods \\
2 & INT & Intermediate goods \\
3 & CONS & Household consumption \\
4 & CAP & Capital goods \\
5 & XMIXED & Mixed end-use \\
6 & XPC & Personal computers \\
7 & XCARS & Passenger cars \\
8 & XPHONE & Personal phones \\
9 & XPRCS & Precious goods \\
10 & XMEDIC & Packed medicines \\
11 & XMISC & Miscellaneous \\
\hline
\end{tabular}

\section{B.4.1 Scripts}

\section{B.4.2 Tabelas auxiliares obtidas}

\section{B.5 Base de dados INDSTAT}

$\mathrm{O}$ arquivo bruto da base de dados INDSTAT foi baixado pela internet e tem um tamanho de 3,8 MB e XXX registros.

Seguindo o procedimento detalhado na metodologia (seção XXX), esse arquivo foi importado e tratado utilizando diversos scripts (em R, SQL e Python), a partir dos quais foi possível obter tabelas auxiliares de normalização.

\section{B.5.1 Scripts}

B.5.2 Tabelas auxiliares obtidas 
ÍNDICE

Análise de entrada-saída, 20

Análise de insumo-produto, 20

big data, 118

Capital, 33

Competitividade, 29

Custeio-em-sequência, 34

Data science, 43

Energia, 30

Fatores de produção, 29

Impostos, 33

insumos, 33

IPEA, 19

Justificativa da pesquisa, 18

Modelagem estrutural, 20

Multiprocessamento, 43

Produtividade, 29

Renda do trabalho, 33 